UNIVERSIDADE DE SÃO PAULO

FACULDADE DE MEDICINA DE RIBEIRÃO PRETO

PÓS-GRADUAÇÃO EM IMUNOLOGIA BÁSICA E APLICADA

\begin{abstract}
IMPORTÂNCIA DO METABOLISMO GLICOLÍTICO NA REGULAÇÃO DA PRODUÇÃO DE ADENOSINA E IL-10 EM MACRÓFAGOS: PAPEL DO METABÓLITO FRUTOSE-1,6BISFOSFATO E DA ENZIMA PKM2
\end{abstract}

Paula Ramos Viacava

Ribeirão Preto - SP 


\title{
IMPORTÂNCIA DO METABOLISMO GLICOLÍTICO NA REGULAÇÃO DA PRODUÇÃO DE ADENOSINA E IL-10 EM MACRÓFAGOS: PAPEL DO METABÓLITO FRUTOSE-1,6- BISFOSFATO E DA ENZIMA PKM2
}

\begin{abstract}
Tese apresentada ao Programa de Pósgraduação em Imunologia Básica e Aplicada da Faculdade de Medicina de Ribeirão Preto da Universidade São Paulo como parte das exigências para obtenção do título de Doutor em Ciência.
\end{abstract}

Área de concentração: Imunologia

Orientador: Prof. Dr. José Carlos Farias Alves Filho

Ribeirão Preto - SP 


\begin{abstract}
AUTORIZO A REPRODUÇÃO E DIVULGAÇÃO TOTAL OU PARCIAL DESTE TRABALHO, POR QUALQUER MEIO CONVENCIONAL OU ELETRÔNICO, PARA FINS DE ESTUDO E PESQUISA, DESDE QUE CITADA A FONTE.
\end{abstract}

Viacava, Paula Ramos

Importância do metabolismo glicolítico na regulação da produção de adenosina e IL-10 em macrófagos: papel do metabólito frutose1,6-bisfosfato e da enzima PKM2.

Ribeirão Preto, 2021. 134 p; il.:30cm

Tese de doutorado, apresentada à Faculdade de Medicina de Ribeirão Preto/USP.

Área de concentração: Imunologia Básica e Aplicada. Orientador: Alves-Filho, José Carlos Farias.

1. Frutose 1,6- Bifosfato; 2. PKM2; 3. IL-10; 4. Adenosina; 5. ATP; 6. Via Glicolítica. 
FOLHA DE APROVAÇÃO

PAULA RAMOS VIACAVA

\title{
IMPORTÂNCIA DO METABOLISMO GLICOLÍTICO NA REGULAÇÃO DA PRODUÇÃO DE ADENOSINA E IL-10 EM MACRÓFAGOS: PAPEL DO METABÓLITO FRUTOSE-1,6- BISFOSFATO E DA ENZIMA PKM2
}

\begin{abstract}
Tese apresentada ao Programa de Pósgraduação em Imunologia Básica e Aplicada da Faculdade de Medicina de Ribeirão Preto da Universidade São Paulo como parte das exigências para obtenção do título de Doutor em Ciência.
\end{abstract}

Área de concentração: Imunologia

\section{Banca examinadora}

Prof. Dr. José Carlos Farias Alves Filho

FMRP - USP 
Trabalho realizado no Laboratório de Inflamação e dor do Departamento de Farmacologia e associado à área de Imunologia Básica e Aplicada da Faculdade de Medicina de Ribeirão Preto - Universidade de São Paulo, com auxílio financeiro da FAPESP, CAPES e CNPq. 
"Acima de tudo sê fiel a ti mesmo,

Disso se segue, como a noite ao dia, Que não podes ser falso com ninguém”. W. Shakespeare em Hamlet 


\section{DEDICATÓRIA}


Dedico este trabalho à minha Mãe, Zoraide Conceição Maciel Ramos, por ser não só a melhor mamis poderosa de todo mundo, mas por nunca se ter feito ausente e ter me dado todo apoio e carinho em tantos momentos importantes. 
AGRADECIMENTOS 


\section{AGRADECIMENTOS}

Gostaria de agradecer a todos que contribuíram para execução deste trabalho.

Um agradecimento especial:

Ao Prof. Dr. José Carlos Farias Alves Filho não só pela orientação, mas também pela paciência, entusiasmo com o projeto, conselhos, paciência, tempo e atenção.

Aos Profs. Dr. Fernando de Queiróz Cunha, Dr. Thiago Cunha e Prof. Dr. Pedro Moraes Vieira pelo auxilio, disponibilidade e contribuição para a realização deste trabalho.

Ao Porf. Membros da Banca por disponibilizar parte do seu tempo para se dedicar como membro avaliador da banca de doutorado.

À Profa. Dra. Vanessa Carregaro por gentilmente ter cedido os camundongos $\mathrm{A} 2{ }_{\mathrm{A}} \mathrm{R}$ KO.

À minha família que sempre acreditou e torceu por mim (TODOS). Especialmente minha mãe, Zoraide Maciel, meu pai, Vitor Viacava (in memoria) que nos deixou tão de repente e já está fazendo muita falta, aos meus irmãos Keitiline, Vinicius e Fernando, pelo valioso apoio e companheirismo, em todos os momentos, nossa amizade será para sempre.

Ao Roberto Ferreira, por me mostrar que laços de sangue nem sempre são os que unem, sempre um prazer indescritível estar na sua companhia.

Ao Wilson Oliveira, por ser o "mori” da minha mãe e não deixar ela morrendo de saudade de mim, assim ganhei um grande amigo.

Ao Alexandre Ribeiro, por existir desse jeito que me encanta tanto, disposto a construir uma família comigo.

Aos colaboradores desse trabalho e também amigos João Paulo Mesquita, Flavio Protásio, Daniele Nascimento, Juliana Escher Toller Kawahisa, Marcos Rosa, Caio Abner Leite, Cesar Speck, Raphael Ferreira, Carlos Wagner Wanderley, Camila Meirelles, Bruno Marcel, Eduardo Damasceno, Pedro Forti, Gabriel Públio, Priscila Tartari, Paulo Henrique Melo, Douglas Prado, Annie Piñeros, Vanessa Borges, Tatiana Cecílio e Alexandre Kanashiro pela ajuda na execução do projeto, correções na escrita dessa tese e momentos de amizade inesquecíveis.

Aos amigos do Laboratório de Inflamação e Dor, com quem pude compartilhar momentos únicos de aprendizado, alegrias, medos, insegurança, conquistas e incentivo no 
desenvolvimento deste trabalho e pelas horas de lazer, não irei citar nomes para não cometer injustiças.

À Ana Kátia dos Santos, Diva Amabile Montanha de Sousa, Marcos, Sérgio Roberto Rosa, Ieda Regina dos Santos Schivo pela amizade, convívio e auxilio técnico. Especialmente à Giuliana Bertozi Francisco, por ter me passado valiosos ensinamentos de como trabalhar com cultura de células, e por carinhosamente me adotar como filha. E um agradecimento mais que especial à Juliana Abumansur e Marcella Grando que foram muito mais que suporte técnico e sim minhas grandes amigas.

Aos funcionários do biotério do Departamento de Genética, Júlio Siqueira, Dener e; e do Departamento de Farmacologia Eliana Barros e Ronaldo pela atenção e cuidado com os animais, que foi fundamental para a qualidade deste trabalho.

Aos amigos do programa de pós-graduação em Imunologia Básica e Aplicada, e do Departamento de Farmacologia da FMRP-USP.

Aos professores do programa de pós-graduação em Imunologia Básica e Aplicada pelo empenho constante para manter o nível de excelência de nosso curso.

À Ana Cristina S. Ferreira secretária da pós-graduação, pela amizade e ajuda incondicional.

Eu um agradecimento mais que especial ao apoio financeiro concedido pela Coordenação de Aperfeiçoamento de Pessoal de Nível Superior (CAPES), Conselho Nacional de Desenvolvimento Científico e Tecnológico (CNPq), Fundação de Amparo à Pesquisa do Estado de São Paulo (FAPESP), Fundação de poio ao Ensino, Pesquisa e Assistência (FAEPA) para a realização deste trabalho. 
RESUMO 


\section{RESUMO}

VIACAVA, P. R. Importância do metabolismo glicolítico na regulação da produção de adenosina e IL-10 em macrófagos: papel do metabólito frutose-1,6-bisfosfato e da enzima PKM2. Ribeirão Preto, 2021. 134p. Tese (Doutorado) - Faculdade de Medicina de Ribeirão Preto, Universidade de São Paulo.

Evidências crescentes de que os processos metabólicos desempenham um papel no controle das funções efetoras imunes, nos fazem compreender melhor os papéis e funções das vias metabólicas nas respostas imunes, assim possibilitar o surgimento de uma oportunidade terapêutica baseada no imunometabolismo. De forma interessante, a frutose 1,6-bifosfato (FBP) é um intermediário endógeno da via glicolítica que tem efeitos anti-inflamatórios quando administrado em modelo de isquemia ou artrite. Embora o mecanismo não seja totalmente claro, esse efeito protetor já foi descrito por aumentar os níveis de adenosina (ADO) como resultado de uma produção elevada de ATP proveniente da glicólise. Além disso, o aumento da glicólise é um mecanismo chave nas células ativadas por LPS, pode ocorrer pela indução da isoenzima piruvato quinase M2 (PKM2), regulando o fluxo glicolítico. Entretanto, não foi demonstrado como o PKM2 participa dessa reprogramação metabólica e modula a resposta inflamatória de macrófagos. Nossa hipótese é que a reprogramação metabólica por FBP ou ativação alostérica da PKM2 pode modular a resposta inflamatória de macrófagos. Demonstramos em várias condições experimentais que a FBP induziu uma resposta anti-inflamatória mediada por IL-10, através do aumento do metabolismo glicolítico em macrófagos. Confirmamos por metaboloma e outros ensaios que o tratamento com FBP aumenta o metabolismo celular, aumentando a produção e liberação de ATP que será transformado em adenosina pela via de CD39/CD73. Usando macrófagos deficientes para o receptor de adenosina $\left(\mathrm{A} 2_{\mathrm{A}} \mathrm{KO}\right)$, confirmamos que a produção de IL-10 induzida por $\mathrm{FBP}$ ocorre via sinalização de adenosina/A2 $\mathrm{A}$. Além disso, o efeito antiinflamatório gerado pela FBP foi confirmado em modelos experimentais de peritonite e colite. 
No entanto, ao conhecer os efeitos da FBP e sabendo que ela é o ativador alostérico natural da PKM2, avaliamos se o aumento da produção de IL-10 pela FBP ocorre de forma dependente de PKM2. Porém, demonstramos que os efeitos da FBP não eram dependentes da presença de PKM2. Mesmo assim, avaliamos se a ativação alostérica de PKM2 por TEPP-46 geraria uma resposta anti-inflamatória. Observamos em BMDM que o tratamento com TEPP-46 também foi capaz de aumentar a produção de IL-10, e essa resposta foi gerada por aumentar o metabolismo celular, elevando a produção de ATP glicolítico e assim, os níveis de adenosina pela ação de CD39/CD73 na via adenosinérgica. Em modelo experimental de peritonite, observamos que o tratamento com o TEPP-46 reduz parâmetros inflamatório dependentes da sinalização de adenosina pelo $\mathrm{A} 2 \mathrm{~A}_{\mathrm{A}}$. Juntos, esses dados demostraram que a via glicolítica é essencial para o efeito anti-inflamatório da FBP e do TEPP-46, levando ao surgimento de novas estratégias terapêuticas baseadas na modulação do imunometabolismo.

Palavras-chave: Frutose 1,6-bifosfato, PKM2, Adenosina, Via Glicolítica, Imunometabolismo e IL-10. 
ABSTRACT 


\section{ABSTRACT}

VIACAVA, P. R. Importance of glycolytic metabolism in regulating the production od adenosine and IL-10 in macrophages: role of the metabolite fructose-1,6-bisphosphate and the enzyme PKM2. Ribeirão Preto, 2021. 134p. PhD. Degree - Faculdade de Medicina de Ribeirão Preto, Universidade de São Paulo.

Growing evidence that metabolic processes play a role in control of immune effector functions leads to emergence of a therapeutic opportunity based on immunometabolism, when understand roles and functions of metabolic pathways in immune responses. Of interest, fructose 1,6-bisphosphate (FBP) is an endogenous intermediate of glycolytic pathway that has anti-inflammatory effects when administrated in ischemic or arthritis model. Although the mechanism is not fully understood, this protective effect is attributed to increased adenosine (ADO) levels as a result of enhance in ATP production by glycolysis. Besides that, increased glycolysis is key mechanism in LPS-activated cells, which may occur by inducing isoenzyme pyruvate kinase M2 (PKM2), regulating the glycolytic flux. How ever, has not been demonstrated how PKM2 can participate that metabolic reprogramming modulate the macrophage inflammatory response. We hypothesized that metabolic reprogramming by FBP or PKM2 allosteric activation could modulate the macrophage inflammatory response. Here we demonstrated in several experimental conditions that FBP induces an anti-inflammatory response mediated by IL-10 via increase of the glycolytic metabolism in macrophages. We confirmed by metabolomics and others assays that FBP treatment enhances the cellular metabolism, increasing the production and release of ATP that will be turned into adenosine by $\mathrm{CD} 39 / \mathrm{CD} 73$ pathway. Using macrophages knockout to adenosine receptor $\left(\mathrm{A} 2_{\mathrm{A}} \mathrm{KO}\right)$ we confirmed that the IL-10 production induced by FBP occur via adenosine/A2 $2_{\mathrm{A}}$ signaling. Furthermore, the regulatory immunometabolic effect of FBP was confirmed in the peritonitis and colitis model. Knowing the FBP effects and that it is the natural allosteric activator of PKM2, we evaluated if increased of IL-10 production by FBP occurs by PKM2-depend. 
Nonetheless, we demonstrated that FBP effects were not dependent the PKM2 presence. Even so, we evaluated whether the allosteric activation of PKM2 by TEPP-46 generated an antiinflammatory response. We observed in BMDM that TEPP-46 was also able to increase the production of IL-10, and this response was generated by increased cellular metabolism, enhance glycolytic ATP production and adenosine level by CD39/CD73 action in adenosinergic pathway, reducing the inflammatory response in peritonitis level. Together, these data showed that the IL-10-dependent glycolytic pathway is essential for the antiinflammatory effect of FBP and allosteric activation of PKM2 by TEPP-46, leading to the emergence of new therapeutic strategies based on immunometabolism modulation.

Key words: Fructose 1,6-bisphosphate, PKM2, Adenosine, Glycolytic pathway, Immunometabolism and IL-10. 


\section{LISTA DE ABREVIAÇÕES}

2-DG $\rightarrow$ 2-Deoxy-D-glicose

$\mathrm{A} 1 \mathrm{R} \rightarrow$ receptor de adenosina 1

$\mathrm{A} 2{ }_{\mathrm{A}} \mathrm{R} \rightarrow$ receptor de adenosina $2 \mathrm{~A}_{\mathrm{A}}$

$\mathrm{A} 2{ }_{\mathrm{B}} \mathrm{R} \rightarrow$ receptor de adenosina $2 \mathrm{~B}$

$\mathrm{A} 3 \mathrm{R} \rightarrow$ receptor de adenosina 3

ADA $\rightarrow$ Adenosina deaminase

ADO $\rightarrow$ Adenosina

ADP $\rightarrow$ Adenosina difosfato

AHR $\rightarrow$ receptor de hidrocarboneto de arilo

AMP $\rightarrow$ Adenosina monofosfato

$\mathrm{AMPc} \rightarrow$ adenosina 3',5'-monofosfato cíclico

APC $\rightarrow$ Células apresentadoras de antígenos

$\mathrm{APCP} \rightarrow$ adenosine 5'-( $\alpha, \beta$-methylene $)$ diphosphate inibidor de CD73

ARL $\rightarrow$ ARL 67156 inibidor de cd39

ATP $\rightarrow$ Adenosina trifosfato

BMDM $\rightarrow$ Macrófagos derivados da medulla óssea

$\mathrm{CBX} \rightarrow$ Carbenoxolone

$\mathrm{CD} \rightarrow$ Cluster of differentiation

Con-A $\rightarrow$ Concavalina A

$\mathrm{CREB} \rightarrow \mathrm{cAMP}$ response element-binding protein

$\mathrm{CSC} \rightarrow$ 8-(3-Chlorostyryl)caffeine, antagonista de $\mathrm{A} 2{ }_{\mathrm{A}} \mathrm{R}$

CSF-1 $\rightarrow$ colony stimulating factor 1

DAMP $\rightarrow$ Damage-associated molecular pattern molecules

DHAP $\rightarrow$ fosfato de dihidroxiacetona

DPCPX $\rightarrow$ 8-Ciclopentil-1,3-dipropilxantina, antagonista de A1R 
DSS $\rightarrow$ Dextran sulfate sodium

ERK $\rightarrow$ Extracellular signal-regulated kinases

FAS $\rightarrow$ Sítese de ácidos graxos

FBP $\rightarrow$ Frutose 1,6 - bifosfato

FIZZ1 $\rightarrow$ Found in inflammatory zone protein

IAA $\rightarrow$ Iodoacetamide

IFN- $\gamma \rightarrow$ Interferon gama

$\mathrm{IL} \rightarrow$ Interleucina

iNOS $\rightarrow$ Óxido nítrico sintase induzível

IRF4 $\rightarrow$ interferon-regulatory fator

G-CSF $\rightarrow$ Fator Estimulador de Colônias de Granulócitos

GM-CSF $\rightarrow$ Fator de estimulação de colónias de granulócitos-macrófagos

G3P $\rightarrow$ D-gliceraldeído-3-fosfato

HIF-1 $\alpha \rightarrow$ Fator induzível por hipóxia

$\mathrm{HK} \rightarrow$ Hexoquinase

LPS $\rightarrow$ Lipopolissacarídeo

MAP quinase $\rightarrow$ Mitogen Activated Protein

MHC $\rightarrow$ Complexo principal de histo-compatibilidade

MRC $1 \rightarrow$ Mannose receptor C type 1

mTOR $\rightarrow$ Mammalian Target of Rapamycin

MTX $\rightarrow$ Metotrexato

MyD88 $\rightarrow$ Myeloid differentiation primary response gene 88

$\mathrm{NADPH} \rightarrow$ Nicotinamida adenina dinucleotido fosfato

$\mathrm{NF}-\kappa \mathrm{B} \rightarrow$ Fator nuclear kappa B

MRS $\rightarrow$ MRS 1334, antagonista de A3R

MRS $\rightarrow$ MRS 1754, antagonista de $\mathrm{A} 2{ }_{\mathrm{B}} \mathrm{R}$ 
$\mathrm{NO} \rightarrow$ Óxido nítrico

OXPHOS $\rightarrow$ Mitochondrial oxidative phosphorylation system

PCA $\rightarrow$ Análise de componentes principais

PBS $\rightarrow$ Tampão salina-fosfato

PEP $\rightarrow$ Fosfoenol piruvato

PFK $1 \rightarrow$ Fosfofrutoquinase 1

PKA $\rightarrow$ Proteína quinase A

$\mathrm{PK} \rightarrow$ Piruvato quinase

PKM1 $\rightarrow$ Piruvato quinase isoforma 1

PKM2 $\rightarrow$ Piruvato quinase isoforma 2

PLC $\rightarrow$ Fosfolipase C

PMNs $\rightarrow$ Leucócitos polimorfonucleares

PRRs $\rightarrow$ Receptores de reconhecimento de padrões

PPP $\rightarrow$ Vias das pentoses

SOCS $3 \rightarrow$ Suppressor of cytokine signaling 3

STAT $\rightarrow$ Signal transducer and activator of transcription

Syk $\rightarrow$ Spleen tyrosine kinase

TAM $\rightarrow$ Macrófagos associados a tumores

TCA $\rightarrow$ Ciclo do Ácido Tricarboxílico

TCR $\rightarrow$ Receptores de células T

TGF- $\beta \rightarrow$ Transforming Growth Factor beta

TLR $\rightarrow$ Receptores de tipo Toll

TNF- $\alpha \rightarrow$ Fator de necrose tumoral alfa

TR1 $\rightarrow$ células reguladoras do tipo 1

Treg $\rightarrow$ Células $\mathrm{T}$ reguladoras 


\section{ÍNDICE DE FIGURAS}

FIGURA 1: DESENHO ESQUEMÁTICO DAS DIFERENÇAS IMUNOMETABÓLICAS EM MACRÓFAGOS M1 E M2

FIGURA 2: DESENHO ESQUEMÁTICO DA VIA GLICOLÍTICA .32

FIGURA 3: REPRESENTAÇÃO ESQUEMÁTICA DE ALGUMAS FUNÇÕES NUCLEARES E GLICOLÍTICAS REGULADA PKM2. .35

FIGURA 4: ESQUEMA DA VIA ADENOSINÉRGICA 39

FIGURA 5: FBP REDUZ A EXPRESSÃO E A PRODUÇÃO DE CITOCINAS PRÓINFLAMATÓRIAS EM MACRÓFAGOS ATIVADOS COM LPS 60

FIGURA 6: FBP AUMENTA A EXPRESSÃO E A PRODUÇÃO DE IL-10 EM MACRÓFAGOS ESTIMULADOS COM LPS 61

FIGURA 7: O AUMENTO DO METABOLISMO GLICOLÍTICO INDUZIDO PELA FBP 63

FIGURA 8: ANÁLISE DE COMPONENTES PRINCIPAIS .66

FIGURA 9: FBP MODIFICA O PADRÃO METABÓLICO DE MACRÓFAGOS .67

FIGURA 10: AUMENTO DE IL-10 PELA FBP EM MACRÓFAGOS ATIVADOS É DEPENDENTE DO METABOLISMO .69

FIGURA 11: FBP AUMENTA A PRODUÇÃO DE ATP EM MACRÓFAGOS ATIVADOS DE FORMA DEPENDENTE DO METABOLISMO .70

FIGURA 12: AUMENTO DE IL-10 PELA FBP EM MACRÓFAGOS ATIVAdOS É DEPENDENTE DO METABOLISMO GLICOLÍTICO .72

FIGURA 13: FBP AUMENTA DE IL-10 EM MACRÓFAGOS DE FORMA DEPENDENTE DA PRODUÇÃO DE ATP .74

FIGURA 14: FBP AUMENTA OS NÍVEIS DE ADENOSINA DEPENDENTE DA VIA GLICOLÍTICA .75

FIGURA 15: O AUMENTO DE IL-10 EM MACRÓFAGOS PELA FBP OCORRE PELA VIA ADENOSINÉRGICA .77

FIGURA 16: TRATAMENTO COM FBP AUMENTA OS NÍVEIS DE IL-10 EM CAMUNDONGOS COM PERITONITE .79 
FIGURA 17: O TRATAMENTO COM FBP REDUZ OS PARÂMETROS INFLAMATÓRIOS EM MODELO EXPERIMENTAL DE COLITE .82

FIGURA 18: O AUMENTO DE IL-10 EM MACRÓFAGOS PELA FBP NÃO É DEPENDENTE DA PKM2 .85

FIGURA 19: TEPP-46 AUMENTA A EXPRESSÃO E A PRODUÇÃO DE IL-10 EM MACRÓFAGOS ATIVADOS COM LPS. .88

FIGURA 20:TEPP-46 AUMENTA A EXPRESSÃO E A PRODUÇÃO DE IL-10 EM MACRÓFAGOS ATIVADOS COM LPS. .90

FIGURA 21: TEPP-46 AUMENTA A EXPRESSÃO E A PRODUÇÃO DE IL-10 EM MACRÓFAGOS ATIVADOS COM LPS. 91

FIGURA 22: TEPP-46 AUMENTA O METABOLISMO GLICOLÍTICO PELA ATIVIDADE DA PIRUVATO QUINASE .93

FIGURA 23: TEPP-46 AUMENTA A PRODUÇÃO DE ATP EM MACRÓFAGOS ATIVADOS DE FORMA SEMELHANTE AO AUMENTO DE IL-10. .95

FIGURA 24: TEPP-46 AUMENTA A PRODUÇÃO DE ATP EM MACRÓFAGOS ATIVADOS DE FORMA DEPENDENTE DA PKM2 .96

FIGURA 25: TEPP-46 AUMENTA OS NÍVEIS DE LACTATO, ATP E IL-10 DEPENDENTE DA DISPONIBILIDADE DE GLICOSE .97

FIGURA 26: TEPP-46 AUMENTA OS NÍVEIS DE LACTATO E IL-10 DEPENDENTE DA PKM2 .98

FIGURA 27: AUMENTO DE IL-10 PELO TEPP-46 EM MACRÓFAGOS ATIVADOS É DEPENDENTE DO METABOLISMO GLICOLÍTICO 100 FIGURA 28: AUMENTO DE IL-10 PELO TEPP-46 EM MACRÓFAGOS ATIVADOS É DEPENDENTE DO METABOLISMO GLICOLÍTICO E DA PRESENÇA DA PKM2. 101 FIGURA 29: TEPP-46 AUMENTA DE IL-10 EM MACRÓFAGOS DE FORMA DEPENDENTE DA PRODUÇÃO DE ATP 103 FIGURA 30: TEPP-46 AUMENTA OS NÍVEIS DE ADENOSINA. 105 
FIGURA 31: O AUMENTO DE IL-10 EM MACRÓFAGOS PELO TEPP-46 DEPENDE DA AÇÃO DE CD39 E CD73 106

FIGURA 32: O AUMENTO DE IL-10 EM MACRÓFAGOS PELO TEPP-46 OCORRE PELA VIA ADENOSINÉRGICA. 108

FIGURA 33: TRATAMENTO COM TEPP-46 AUMENTA OS NÍVEIS DE IL-10 EM CAMUNDONGOS COM PERITONITE .110

FIGURA 34: MECANISMO IMUNOMODULADOR DA FBP OU TEPP-46, ATRAVÉS DO AUMENTO DA PRODUÇÃO DE IL-10, DE FORMA DEPENDENTE DA VIA GLICOLÍTICA E ADENOSINÉRGICA 118 


\section{SUMÁRIO}

INTRODUÇÃ

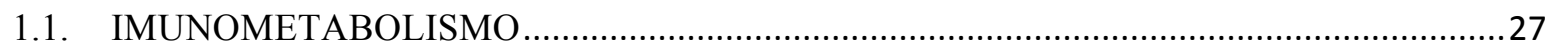

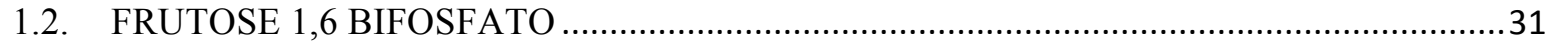

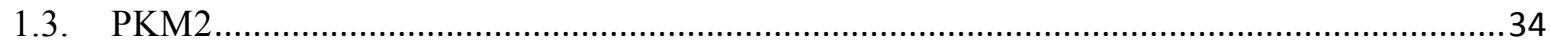

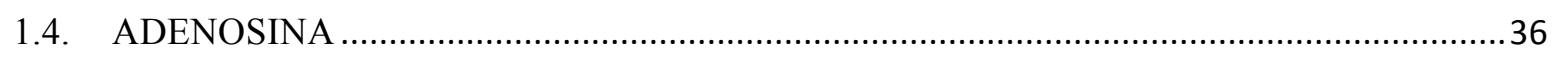

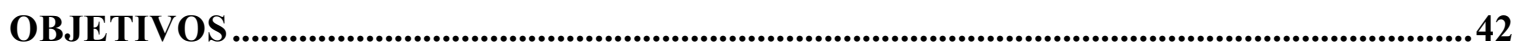

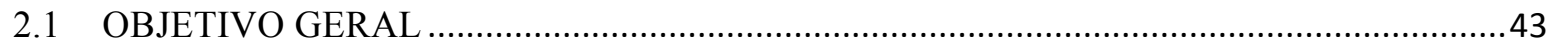

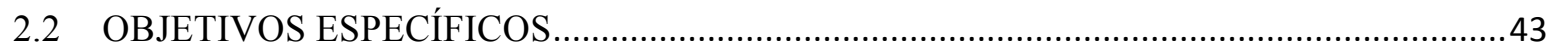

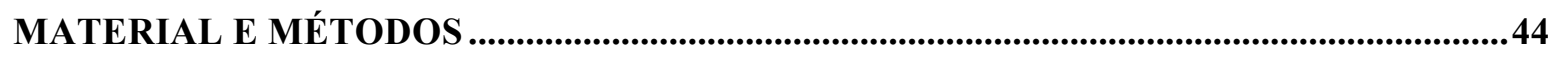

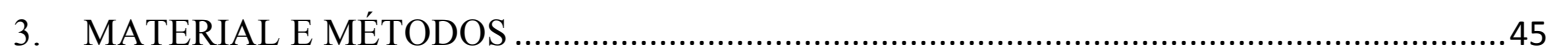

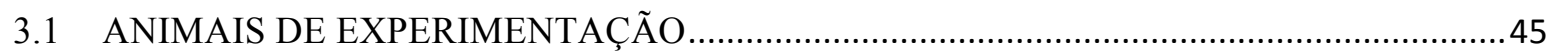

3.2 DIFERENCIAÇÃO DE MACRÓFAGOS PROVENIENTES DA MEDULA ÓSSEA...........45

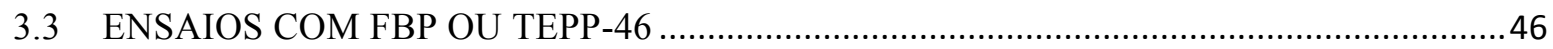

3.4 DETECÇÃO DE CITOCINAS PELO ENSAIO IMUNOENZIMÁTICO (ELISA) ................47

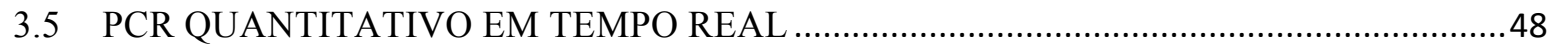

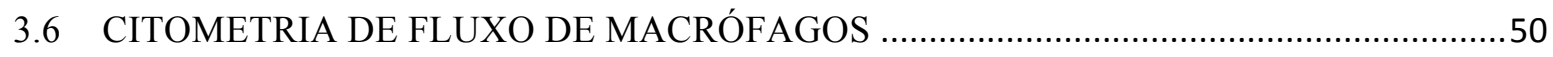

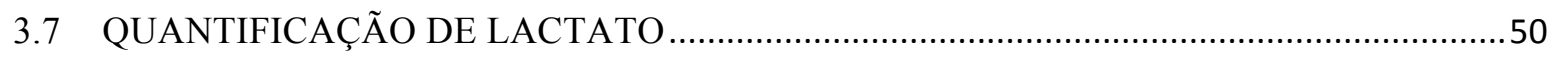

3.8 QUANTIFICAÇÃO DA ATIVIDADE DA PIRUVATO QUINASE ....................................50

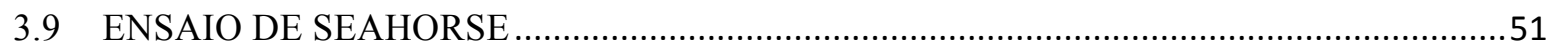

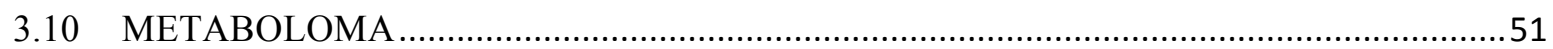

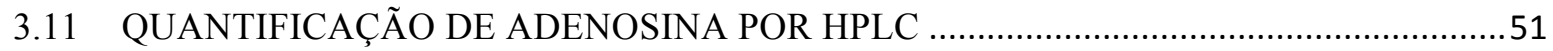

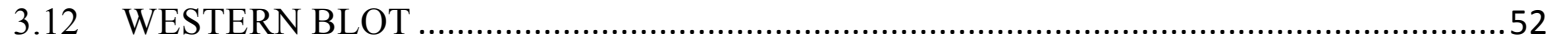

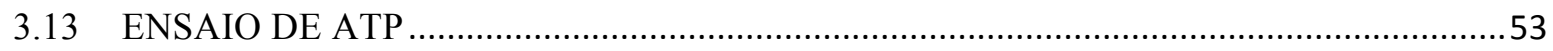

3.14 IMUNOFLUORESCÊNCIA E MICROSCOPIA COM FOCAL ..........................................53

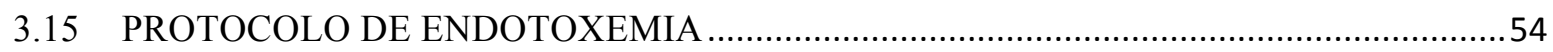

3.16 PROTOCOLO DE COLITE INDUZIDA POR COLITE …...................................................54 


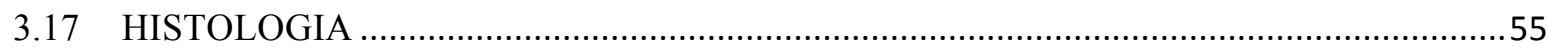

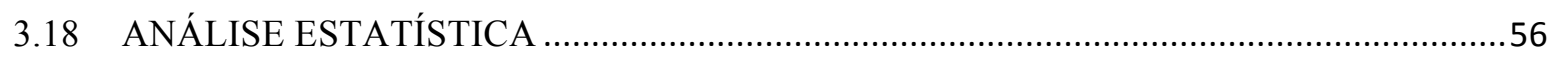

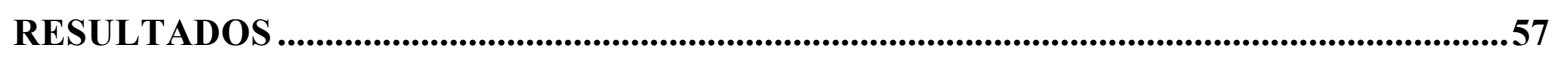

4.1 FBP IMPORTANTE PARA REDUZIR A EXPRESSÃO E A PRODUÇÃO DE CITOCINAS PRÓ-INFLAMATÓRIAS E AUMENTAR A PRODUÇÃO DE IL-10 EM MACRÓFAGOS ATIVADOS

4.2 O TRATAMENTO COM FBP AUMENTA O METABOLISMO GLICOLÍTICO DE MACRÓFAGOS

4.3 FBP AUMENTA A PRODUÇÃO DE IL-10 EM MACRÓFAGOS ATIVADOS COM LPS DE FORMA DEPENDENTE DA VIA ADENOSINÉRGIA.

4.4 TRATAMENTO PRÉVIO DE FBP AUMENTA A PRODUÇÃO DE IL-10 EM MODELO DE ENOTOXEMIA DE FORMA DEPENDENTE DA PRODUÇÃO DE ATP E VIA

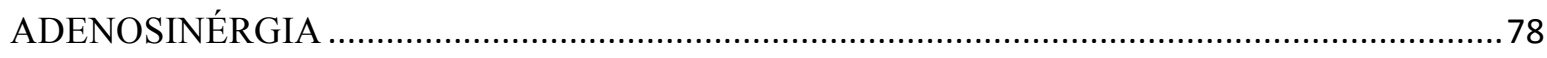

4.5 O TRATAMENTO COM FBP REDUZ A COLITE INDUZIDA POR DSS ...............................80

4.6 TRATAMENTO COM FBP NÃO É DEPENDENTE DA PKM2 .........................................84

4.7 ATIVAÇÃO ALOSTÉRICA DA PKM2 AUMENTA A PRODUÇÃO DE IL-10 .....................87

4.8 TEPP-46 É CAPAZ DE ATIVAR ALOSTERICAMENTE A PKM2 EM MACRÓFAGOS. ...89

4.9 ATIVAÇÃO ALOSTÉRIA DA PKM2 PELO TEPP-46 AUMENTA O METABOLISMO

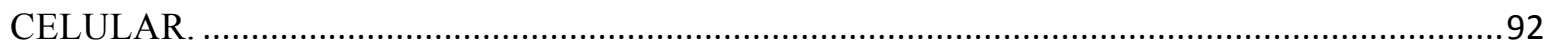

4.10 ATIVAÇÃO ALOSTÉRIA DA PKM2 PELO TEPP-46 AUMENTA A PRODUÇÃO DE ATP

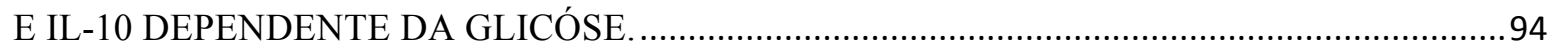

4.11 TEPP-46 AUMENTA A PRODUÇÃO DE IL-10 DEPENDENTE DA VIA

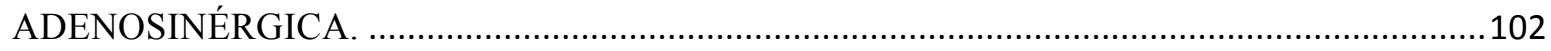

4.12 O TRATAMENTO COM TEPP-46 AUMENTA A PRODUÇÃO DE IL-10 EM MODELO

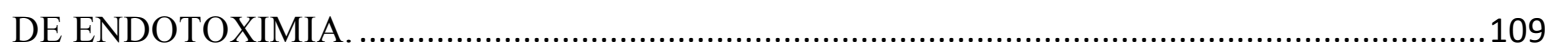

DISCUSSÃO

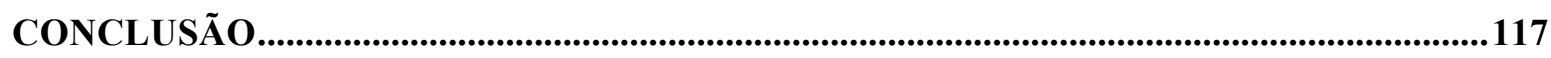

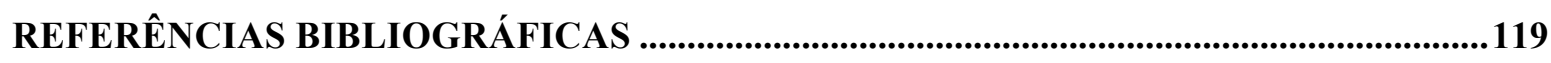

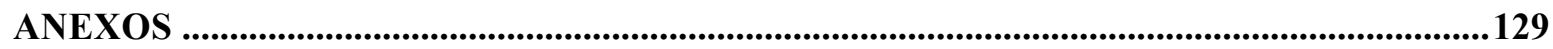


INTRODUÇÃO 


\section{INTRODUÇÃO}

\subsection{IMUNOMETABOLISMO}

O sistema imunológico abrange uma população distintas de células, geralmente inativas quando se encontram em homeostase, no entanto apresentam a capacidade de responder rapidamente a processos infecciosos ou inflamatórios. Essas respostas são controladas por diversos receptores, ativadores ou inibidores dependentes dos sinais intrínsecos aos patógenos ou do sistema imunológico (BESEDOVSKY; LANGE; HAACK, 2019). As rápidas respostas contra processos inflamatórios ou infecciosos pelas células imunes envolve mudanças nas expressões de diversos genes e aquisições de novas funções como produção de citocinas, enzimas, migração entre tecidos ou proliferação celular. Por tanto a transição entre o estado quiescente e ativo necessita um maior aporte de nutrientes e ativação de algumas vias metabólicas (BUCK et al., 2017), fazendo-se interessante o estudo dos processos metabólicos em células do sistema imune.

Os processos metabólicos regulam as respostas das células imunes em indivíduos saudáveis, bem como durante a infecções, câncer, autoimunidade e obesidade (PEARCE; PEARCE, 2013). Os primeiros estudos sobre imunometabolismo foram publicados na década de 60, descrevendo a necessidade de certos metabólitos para funções efetoras de macrófagos, neutrófilos e células $\mathrm{T}$, focaram principalmente na produção de energia visto que células ativadas ou em divisão celular tem uma enorme demanda metabólica (OREN et al., 1963; NEWSHOLME et al., 1986). Em termos de mecanismos, já foi bastante descrito a participação da proteína quinase ativada por AMP, do inglês AMP-activated protein kinase (AMPK), ao promover o catabolismo de ácido graxos e inibir a atividade do alvo da rapamicina para mamíferos, do inglês mammalian Target of Rapamycin (mTOR), um complexo que detecta aminoácidos, fatores de crescimento, além de também promover a 
síntese lipídica que é importante para a proliferação celular (LIU; ZHANG; LIU, 2015; WEICHHART; HENGSTSCHLAGER; LINKE, 2015).

Durante a última década o imunometabolismo se tornou uma das áreas mais estudada em pesquisas translacionais. Visto que, alterações metabólicas refletem no processo ativação de células efetoras, e as respostas imunes podem ser reguladas por alterações metabólicas ou derivados da microbiota e agentes infecciosos (KIM, 2018). Essas descobertas abriram caminho para novas terapias de doenças inflamatórias e autoimunes crônicas (BETTENCOURT; POWELL, 2017; PÅLSSON-MCDERMOTT; O’NEILL, 2020), além de representar uma nova classe de imunoterapia para o câncer (MARTINEZ-OUTSCHOORN et al., 2017).

Quando falamos de metabolismo, sabemos a importância da via glicolítica, pois ela representa uma das principais rotas de geração de adenosina tri fosfato (ATP) e piruvato, e o cérebro utiliza quase que exclusivamente a glicose como fonte de combustível energético (NELSON; COX, 2013). A glicólise está envolvida em vários processos imunológicos de células ativadas, tanto em macrófagos quanto em células T (PEARCE; PEARCE, 2013). Com a inibição da via glicolítica através do 2-deoxyglicose (2-DG) a ativação de macrófagos fica comprometida e suprime a inflamação em vários contextos, o que sugere uma participação importante dessa via na resposta inflamatória (ZHAO et al., 2017). Apesar da glicólise não ser a via metabólica mais eficiente em geração de ATP, ela pode ser ativada rapidamente através da indução de enzimas por fatores de transcrição. Por outro lado, uma via muito eficiente em geração de ATP, a fosforilação oxidativa, para aumentar seu potencial energético, requer a biogênese mitocondrial que é um processo lento. Uma consequência importante da via glicolítica é a capacidade de aumentar a produção de intermediários biossintéticos para favorecer a proliferação celular. Sinais de ativação, como fatores de crescimento, aumentam a 
captação de glicose que fornecem ATP, suportam o ciclo do ácido cítrico (TCA) e doam intermediários para via das pentoses (PPP), reações de glicosilação e síntese de constituintes importantes para a síntese lipídica incluindo serina, glicina, alanina e acetil-CoA (O’NEILL; KISHTON; RATHMELL, 2016).

Macrófagos são células importantes que desempenham muitas funções envolvidas em processos de eliminação de patógenos e reparo de lesões (MURRAY; WYNN, 2011), mas para que isso ocorra precisam estar ativados. Quando a ativação é feita por lipopolissacarídeo (LPS), ou por receptores de reconhecimento padrão (PRRs) ocorre a transcrição do fator induzível por hipóxia-1 $\alpha$ (HIF-1 $\alpha$ ), o que é crucial para indução de várias enzimas envolvidas na glicólise, aumentando o metabolismo celular, a fagocitose e a produção de citocinas (TANNAHILL et al., 2013). Durante anos, pensou-se que havia dois subconjuntos principais de macrófagos ativados: macrófagos M1 que promovem a inflamação e macrófagos M2 que suprimem a resposta inflamatória. Na realidade, a distinção entre os subconjuntos de ativação clássica e alternativa é mais complexo que pró-inflamatório e resolutivo, embora já se tenham elucidados os mecanismos moleculares intrínsecos na polarização, os processos de regulação desses diferentes perfis e fenótipos metabólicos ainda não foram completamente descritos (O’NEILL; PEARCE, 2016), ainda é mal compreendido como o metabolismo contribui para o controle da expressão gênica durante a ativação de células imunes, e também como o metabolismo promove o fenótipo M2, em particular os macrófagos associados a tumores (TAMs), um tipo celular que possui um papel importante na progressão, proliferação, angiogênese tumoral e evasão imunológica (RUFFELL; AFFARA; COUSSENS, 2012).

É importante ressaltar que as vias metabólicas não apenas fornecem energia, mas também regulam o fenótipo e a função dos macrófagos, onde o metabolismo alterado de aminoácidos foi uma das primeiras características empregadas para definir subconjuntos de 
macrófagos (MUNDER; EICHMANN; MODOLELL, 1998). Os macrófagos inflamatórios M1, ativados com LPS + interferon- $\gamma($ IFN- $\gamma)$ convertem a arginina em óxido nítrico (NO) por meio da atividade da NO sintetase induzida (iNOS). Por outro lado, em macrófagos resolutivos M2, ativados alternativamente pela IL-4 a arginina é metabolizada pela arginase-1 (LIU et al., 2014). Paralelamente ao metabolismo distinto da arginina, os macrófagos M1 têm um metabolismo glicolítico aumentado e uma fosforilação oxidativa mitocondrial prejudicada (OXPHOS). Um nítido contraste com as características metabólicas dos macrófagos M1, é que macrófagos M2 apresentam um ciclo de TCA intacto e OXPHOS mitocondrial aumentando.

Macrófagos M1 apresentam um metabolismo glicolítico elevado, produzindo ATP como energia para sustentar suas funções secretoras e fagocíticas, esse metabolismo aumentado também alimenta a PPP. Juntas, estas vias suportam respostas inflamatórias, gerando aminoácidos para a síntese de proteínas, ribose para nucleotídeos, e nicotinamida adenina dinucleótido fosfato $(\mathrm{NADPH})$ para a produção de espécies reativas de oxigênio (ROS). Durante a glicólise também é gerado piruvato que é substrato para o TCA, onde em M1 esse ciclo é interrompido em dois locais: após o citrato e ao succinato (VAN DEN BOSSCHE; O’NEILL; MENON, 2017).

Recentemente, foi reconhecido que a glicose também pode alimentar OXPHOS em macrófagos ativados alternativamente, e que genes associados com o perfil M2 de macrófagos são suprimidos com a inibição da glicólise ou da OXPHOS. Um modelo complexo foi proposto em que a glicose alimenta síntese de ácidos graxos (FAS) para aumentar a oxidação desses ácidos em M2, ligando assim as três vias metabólicas. Ambos os macrófagos M1 e M2 mostram glicólise aumentada, mas isso é acompanhado pela ativação do PPP apenas no primeiro (O’NEILL; PEARCE, 2016). Isto demonstra que a glicose alimenta o ciclo de TCA 
para respiração mitocondrial em M2, onde interferir com esta via em vários níveis prejudica a ativação alternativa de macrófagos. Por conseguinte, a deleção de componentes da via glicólica ou TCA podem influenciar no crescimento tumoral e na imunidade a infecções parasitárias (O’NEILL, 2016). Em conjunto, a literatura atual destaca a necessidade crucial da via glicolítica nas respostas inflamatórias e anti-inflamatórias dos macrófagos.

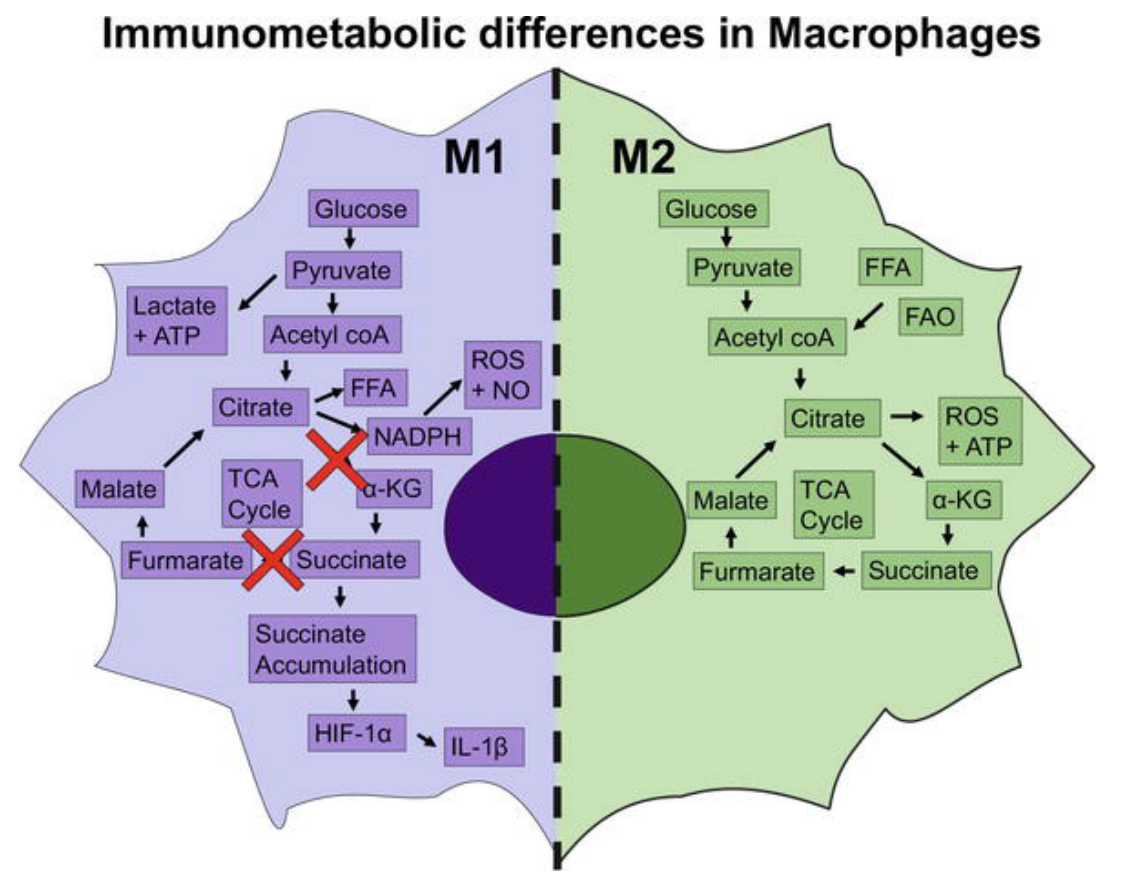

Figura 1: Desenho esquemático das diferenças imunometabólicas em macrófagos M1 e M2. Os macrófagos M1 aumentam a glicólise para a produção de energia acumulando citrato e succicinato, em contraste, os M2 usam OXPHOS e o ciclo TCA para esse fim. Adaptado de (AMICI; DONG; GUERAU-DE-ARELLANO, 2017)

\subsection{FRUTOSE 1,6 BIFOSFATO}

A Frutose 1,6 bifosfato (FBP) trata-se de uma molécula polar facilmente diluída em água, formada por um monossacarídeo de frutose fosforilada em dois carbonos, C-1 e C-6, por ser um dos carboidratos intermediários da via glicolítica é altamente energética. A FBP atua na rota metabólica da glicose e é produzida pela fosforilação da frutose-6-fosfato com a adição de um fosfato pela enzima fosfofrutoquinase 1 (PFK1) no carbono 1. Podendo ser 
clivada pela enzima aldolase em D-gliceraldeído-3-fosfato (G3P) e fosfato de dihidroxiacetona (DHAP), a participação da FBP na glicólise auxilia na produção de adenosina tri fosfato (ATP) e intermediários glicolíticos. (NELSON; COX, 2013). A via glicolítica apresenta etapas com gasto de energia que consomem duas moléculas de ATP nas reações das enzimas hexoquinase (HK) e PFK, pontos importantes para formação de FBP a partir da glicose. Em seguida a clivagem da FBP, começa etapa de produção de energia, a geração de ATP acontece na redução do 1,3 bifosfoglicerato em G3Pe também na redução do fosfoenolpiruvato em piruvato, gerando 4 moléculas de ATP. Os produtos finais da glicólise são duas moléculas de piruvato e duas moléculas de ATP (Figura 1).

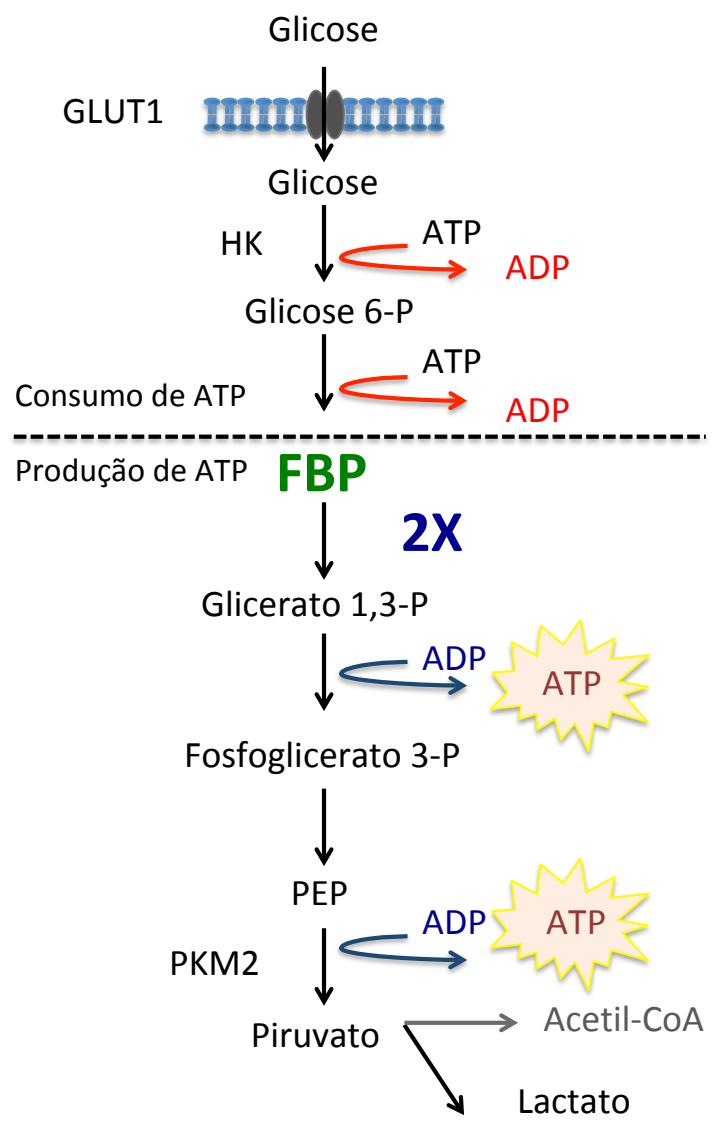

Figura 2: Desenho esquemático da via glicolítica.

Não se sabe ao certo como acontece a entrada de FBP no interior da célula, no entanto, sabe-se que a FBP é capaz de aumentar o fluxo glicolítico pela sua presença no 
citosol (Hassinen et al. 1991, Lazzarino et al. 1984, Nuutinen et al. 1991). Ainda não identificaram um transportador de membrana específico para o transporte de FBP do meio extracelular para o interior da célula. O provável mecanismo de entrada da FBP no meio intracelular, ocorre através difusão pela membrana de forma dose dependente, mesmo que a FBP seja considerada uma molécula grande, ela é altamente polar e carregada de forma negativa em pH fisiológico (HARDIN; ROBERTS, 1994; EHRINGER et al., 2000).

Os primeiros tratamentos utilizando FBP foram na preservação de órgãos para transplantes, o que acontece até nos dias de hoje e ainda gera novos estudos e patentes nessa área (COSTRINI; CANDIANI; CIFRA, 1980; YANG et al., 2016). Na década de 80, Marckov e colaboradores estudaram a FBP de forma exaustiva, demonstrando que esse monossacarídeo pode proteger dos danos causados pela hipóxia isquêmica, através da manutenção dos níveis de ATP no tecido lesionado (MARKOV et al., 1980, 1985; MARKOV, 1986). De forma interessante, o tratamento com FBP em humanos apresenta baixos efeitos tóxicos ou colaterais, mesmo na presença de altas quantidades de FBP por via intravenosa (MARKOV et al., 2000).

Além da FBP ser utilizada na clínica para tratamentos em danos isquêmicos e na preservação de órgão que serão utilizados em transplantes, a FBP apresenta propriedades antiinflamatórias como redução do edema de pata induzida por injeção de carragenina na região plantar (PLANAS et al., 1993), capacidade de reduzir a migração de leucócitos polimorfo nucleares (PMNs) para a cavidade pleural (ALVES FILHO et al., 2004), FBP também apresenta redução de citocinas pró-inflamatórias induzida em infecções por Escherichia coli, porém esse efeito não foi dependente de atividade microbicida (NUNES et al., 2003). O efeito em redução de citocinas pela FBP também foi associado com atividade antitumoral (KRAUSE et al., 2017; WANG; WU; QIU, 2019) 
Sobre o mecanismo de ação terapêutico da FBP até o início dos anos 2000 pouco se sabia, mesmo a FBP já ser descrita como um fármaco promissor em vários modelos experimentais distintos (HARDIN et al., 2001), foi então que Sola e colaboradores demonstrar que os efeitos anti-inflamatórios da FBP eram dependentes da presença de adenosina (ADO) (SOLA, 2003). Nosso grupo de pesquisa, já demonstrou que os efeitos antiinflamatórios da FBP estão relacionados com a produção de ADO e dependentes da sinalização via receptor de adenosina tipo $2 \mathrm{~A}\left(\mathrm{~A} 2_{\mathrm{A}}\right)$ em modelo experimental de artrite (VERAS et al., 2015). No entanto, ainda não está claro como a FBP é capaz de aumentar os níveis de ADO para gerar uma resposta protetora em quadros inflamatórios, e para isso vamos avaliar a participação da via glicolítica visto que a FBP é um intermediário glicolítico.

\subsection{PKM2}

Visto a importância do metabolismo na ativação de macrófagos, uma enzima chave que regula a glicólise é a piruvato quinase (PK), em homeostase as células apresentam de forma constitutiva a isoenzima da PK M1 (PKM1), uma isoforma que não pode ser regulada alostericamente e tem muita afinidade com fosfoenolpiruvato (PEP) por isso é altamente expressa em tecidos com uma demanda energética elevada (IMAMURA; TANAKA, 1972). No entanto, frente a estímulos proliferativos, em células tumorais ou em células ativadas do sistema imune, ocorre a expressão da isoenzima M2 (PKM2), onde alguns estudos já demonstraram uma participação importante dessa isoforma na glicólise aeróbica, reduzindo fluxo glicolítico e aumentando o metabolismo oxidativo (CHRISTOFK et al., 2008).

A PKM2 gera piruvato e ATP a partir do PEP e ADP durante a glicólise, essa enzima é derivada de um splincing alternativo do gene $P k m$ e regulada para retardar o fluxo glicolítico permitindo o desvio de intermediários glicolíticos para outras vias (IMAMURA; 
TANAKA, 1972). Ela pode ser ativada alostericamente e assim permanecendo na conformação tetramérica por vários reguladores endógenos que aumentam sua afinidade de ligação ao PEP, como a FBP, metabólitos não glicolíticos, intermediários da síntese de purinas, aminoácidos e pequenas moléculas (como TEPP 46 e DASA 58). Na ausência de ativadores alostéricos, a PKM2 assume uma forma dimérica ou monomérica, reduzindo a glicólise e acumulando os intermediários glicolíticos (Figura 2) (ALVES-FILHO; PÅLSSONMCDERMOTT, 2016).

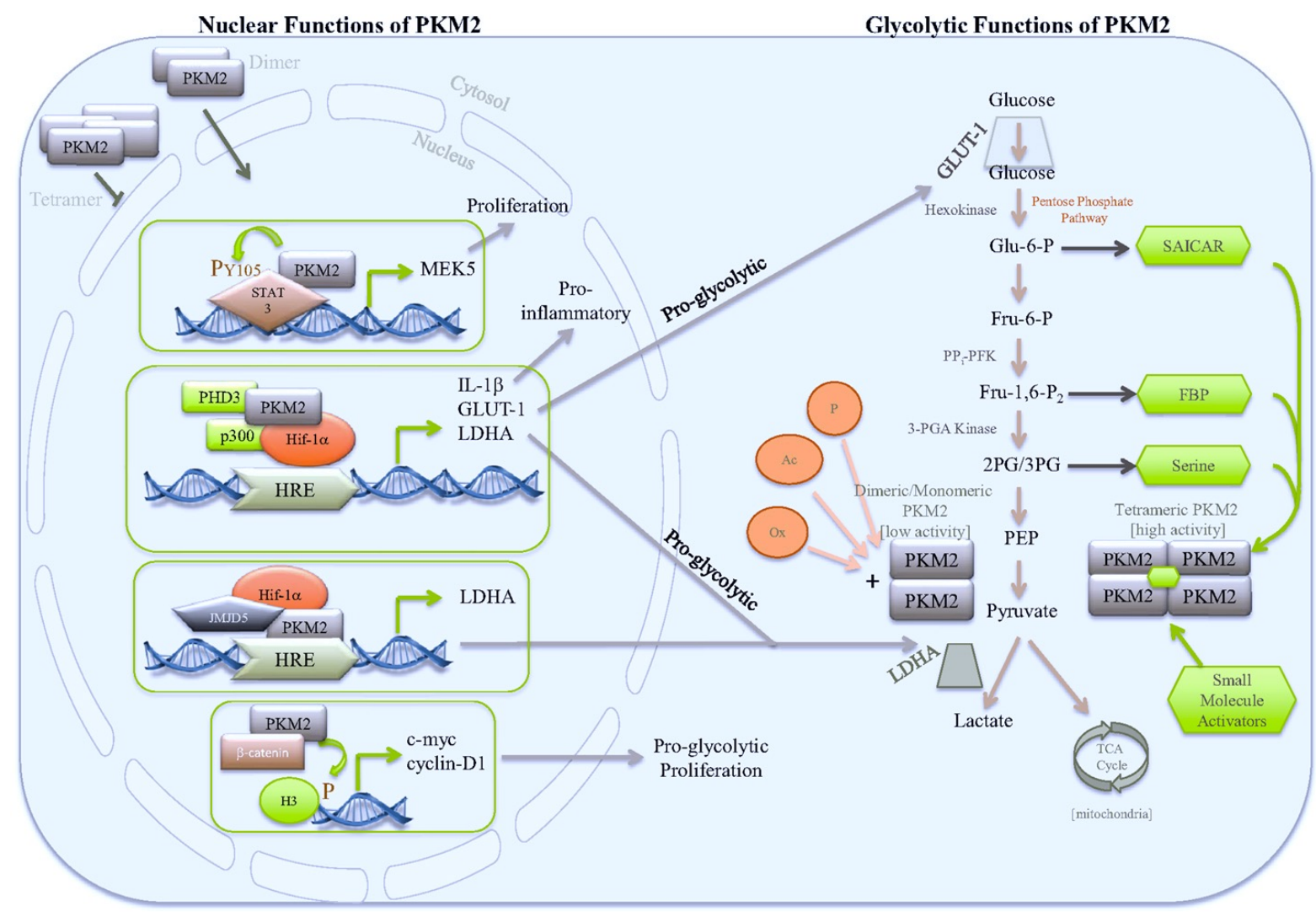

Figura 3: Representação esquemática de algumas funções nucleares e glicolíticas regulada PKM2. Adaptado de (ALVES-FILHO e PÅLSSON-MCDERMOTT, 2016).

Quando não ativada alostericamente a PKM2 é encontrada na forma dimérica e tem uma função fora do seu papel na glicólise, se transloca para o núcleo onde interage com o HIF-1 $\alpha$ e promove a expressão de genes pró-inflamatórios (LUO et al., 2011; PALSSONMCDERMOTT et al., 2015a). Recentemente, nosso grupo demonstrou em linfócitos, que a 
PKM2 na forma dimérica transloucou para o núcleo interagindo com a proteína (do inglês signal transducers and activators of transcription 3) (STAT3) o que favoreceu o aumento da diferenciação de células Th17, onde a ação não metabólica da PKM2 regula a neuroinflamação da autoimunidade causada pela (EAE) (DAMASCENO et al., 2020).

A inibição farmacológica da translocação nuclear de PKM2 ou seu silenciamento é capaz de diminuir a glicólise aeróbia e a proliferação de células tumorais (CHRISTOFK et al., 2008; ANASTASIOU et al., 2012). Além disso, estudos recentes demostraram que PKM2 pode regular a produção de citocinas inflamatórias em macrófagos ativados por LPS (YANG et al., 2012). No entanto, a ativação alostérica da PKM2 em macrófagos ativados com LPS pode gerar um aumento na produção da citocina anti-inflamatória IL-10, porém os autores não souberam explicar esse resultado e acabaram relacionando esse efeito a inibição de HIF-1 $\alpha$ pelo fato da PKM2 não ter translocado para o núcleo, sem demonstrar a possível participação da via adenosinérgica, já que a PKM2 é um ponto gerador de ATP na glicólise (PALSSONMCDERMOTT et al., 2015b).

Sabendo disso, se torna muito interessante compreender o metabolismo celular de macrófagos, controlando a expressão e funções da PKM2, visando entender se os efeitos antiinflamatórios dessa enzima estão relacionados com a via-glicolítica e assim surgir um possível alvo terapêutico e/ou para criar novas terapias de doenças inflamatórias.

\subsection{ADENOSINA}

A adenosina (ADO) é um nucleosídeo de purina, formado pela ligação de um açúcar a D-ribose a uma adenina, essa molécula pode ser encontrada em todos os tecidos do corpo humano e suas primeiras funções descritas foram na modulação do sistema cardiovascular 
(DRURY; SZENT-GYÖRGYI, 1929) e exaustivamente estudada no sistema nervoso central (SNC) (LATINI; PEDATA, 2001).

A ADO pode ser formada em processo intra ou extra celulares, por diversos tipos células, como macrófagos, fibroblastos, musculares ou ainda proveniente do catabolismo da adenosina tri fosfato (ATP), para adenosina difosfato (ADP) e adenosina mono fosfato (AMP) (NELSON; COX, 2005; JACOBSON; GAO, 2016). Nesse contexto, sabemos que altos níveis de ATP não são encontrados nos organismos vivos quando em homeostase, pois elevadas concentrações de ATP extracelular são deletérias e capazes de induzir a ativação do complexo do inflamassoma através da sinalização de receptores $\mathrm{P} 2 \mathrm{X} 7$, gerando um processo inflamatório que leva a apoptose e geração de citocinas pró-inflamatórias como IL-18 e IL-1 $\beta$ (HE; HARA; NÚÑEZ, 2016).

Geralmente, organismos em homeostase não apresentam a inflamação causada pelo complexo do inflamassoma, pois ocorre a hidrólise do ATP extracelular por ectoenzimas que retiram os fosfatos do ATP para formação de ADP e AMP, essa enzima é a NTPDase-1 (ectoapirase) também conhecida como CD39. Por fim, ocorre a formação de adenosina com a retirada do fosfato do AMP pela ação da ecto-5'-nucleotidase ou CD73. A ADO apresenta uma meia vida curta e rapidamente é convertida a inosina, uma forma inerte da ADO, pela enzima adenosina deaminase (ANTONIOLI et al., 2013).

No meio intracelular também ocorre a formação de ADO de forma dependente da hidrólise do AMP, porém agora difere pela enzima 5'-nucleotidase, ou Sadenosilhomocisteína pela ação da S-adenosilhomocisteína hidrolase (PALMER; ABELES, 1979). Os transportadores bidirecionais obviamente fazem o trabalho de transportar ADO formada no interior da célula para o ambiente extracelular ou vice-versa, o transporte de 
adenosina ocorre de forma favorável ao gradiente de concentração pelos transportadores ENTs (equilibrative nucleoside transporter). Alterações no gradiente de concentração de ADO ocorrem em situações de hipóxia e inflamação, nesses quadros o consumo de ATP aumenta e assim a ADO fica acumulada no interior da célula, por meio dos ENTs a ADO pode ser transportada para o meio extracelular em favor do gradiente de concentração, sem que ocorra o consumo de energia. No entanto, quando o transporte de ADO ocorre pelos concentrative nucleoside tranporter (CNT), que são transportadores dependentes da concentração de $\mathrm{Na}^{+}$, esse transporte acaba consumindo energia (MOLINA-ARCAS; CASADO; PASTOR-ANGLADA, 2009).

A $\mathrm{ADO}$ atua em um conjunto de receptores purinérgicos $\left(\mathrm{A} 1, \mathrm{~A} 2_{\mathrm{A}}, \mathrm{A} 2_{\mathrm{B}}\right.$ e $\left.\mathrm{A} 3\right)$, esses receptores contêm sete domínios transmembrana acoplados a proteínas G (ligantes de GTP intracelular) estimulatória (Gs) ou inibitória (Gi) da adenilato ciclase, enzima responsável pelos níveis de cAMP (AMP cíclico) intracelular. Quando a ADO sinaliza via receptores Gi como o A1R ou A3R a atividade da adenilil ciclase é inibida e assim reduz os níveis de cAMP, como consequência não ocorre a ativação da proteína quinase A (PKA) e aumento da atividade da fosfolipase C (PLC) (HAUSER et al., 2018). Os receptores de ADO com mecanismo de sinalização intracelular via proteína Gs são os $\mathrm{A} 2_{\mathrm{A}}$ e $\mathrm{A} 2_{\mathrm{B}}$, o que promove a ativação da adenilil ciclase, e com isso o aumento dos níveis intracelulares do cAMP, podendo assim ativar a PKA e consequentemente o fator de transcrição CREB (cAMP response element-binding protein), afetando diretamente a expressão ou a produção de citocinas pró-inflamatórias, devido a ligação na região promotora desses genes, ou indiretamente por competir com NF-кB (NÉMETH et al., 2003; DARASHCHONAK et al., 2014). 

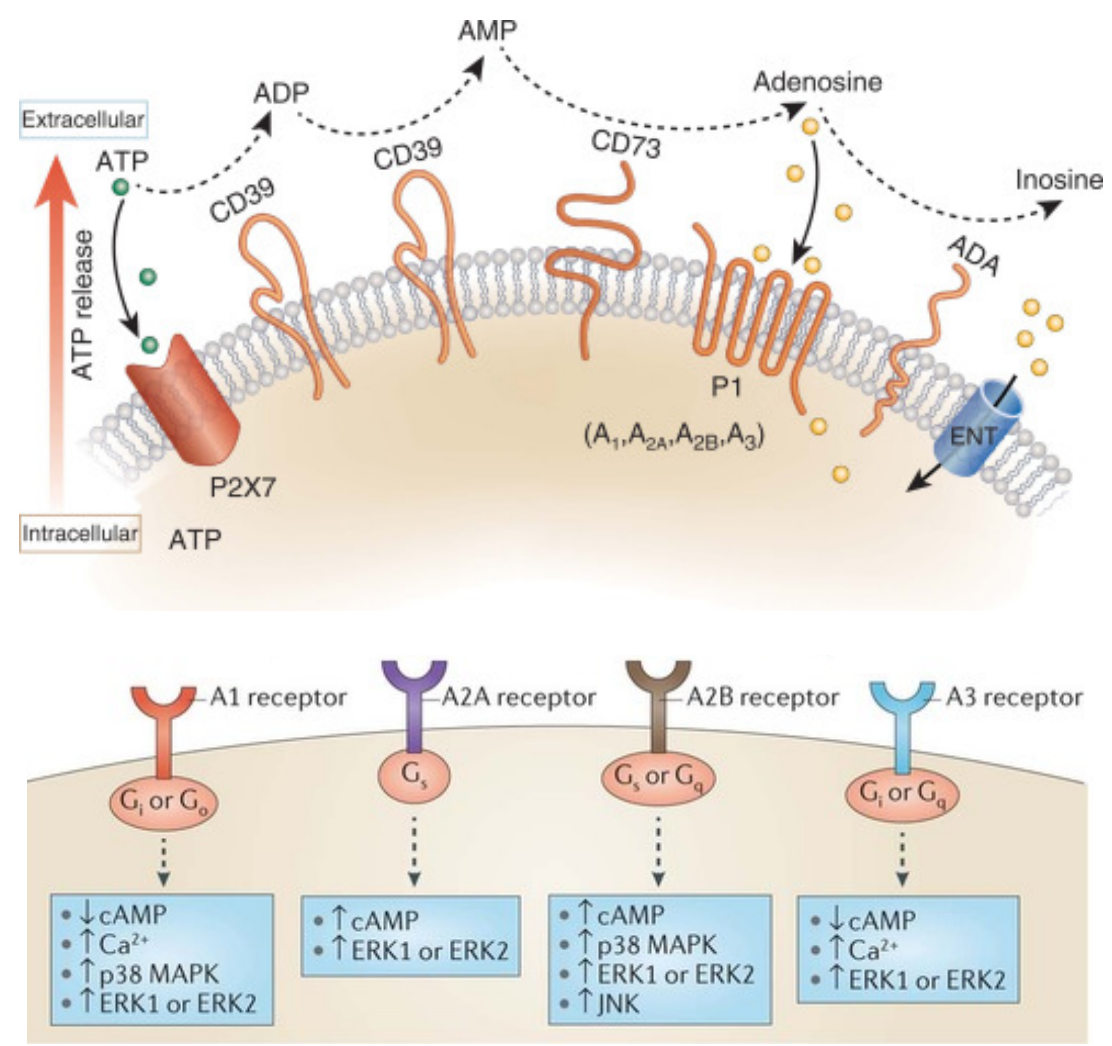

Figura 4: Esquema da via adenosinérgica. Adaptado de (ANTONIOLI et al., 2013; ROBERTS et al., 2014).

Os primeiros relatos descrevendo a modulação da resposta inflamatória dependente da sinalização do $\mathrm{A} 2{ }_{\mathrm{A}} \mathrm{R}$ foi em modelos de lesão hepática, demonstrando que a sinalização via esse receptor é capaz de reduzir a produção de citocinas pró-inflamatórias como TNF- $\alpha$, IL12 e IFN- $\gamma$ (OHTA; SITKOVSKY, 2001). Além disso, a deleção gênica do $A 2{ }_{A} R$ promove um aumento na severidade de processos inflamatórios, relacionado com a diminuição da citocina IL-10 (DA ROCHA LAPA et al., 2012; MILLS et al., 2012; CRONSTEIN; SITKOVSKY, 2017).

A citocina imunomoduladora IL-10, tem seus genes induzidos pelo fator de transcrição CREB, regulado pelos níveis do cAMP (SANIN; PRENDERGAST; MOUNTFORD, 2015). A IL-10 é uma proteína homodimérica, constituída por uma cadeia polipleptídica em quatro $\alpha$-hélices (STROUD; WELLS, 2004). Tem um importante papel na 
regulando a proliferação e sobrevivência celular, pois downregulação da secreção de IL-12 TNF- $\alpha$, IL-1 $\beta$, IL-6, entre outras (FIORENTINO et al., 1991). A produção de IL-10 ocorre por diversos tipos celulares como alguns linfócitos Th1, células T reguladoras, células B, macrófagos, queratinócitos, células dendríticas, entre outras células (SARAIVA; O'GARRA, 2010).

Sabe-se que em macrófagos, a IL-10 consegue suprimir a produção de óxido nítrico e outros mediadores inflamatórios como TNF- $\alpha$, IL-1 $\beta$, IL-6, IL-8 e GM-CSF (OUYANG et al., 2011). Além disso, esse tipo celular quando ativado com bactérias a produção de IL-10 ocorre de forma dependente da sinalização de $\mathrm{A} 2{ }_{\mathrm{A}} \mathrm{R}$ e pelo fator de transcrição $\mathrm{C} / \mathrm{EBP} \beta$ (CCAAT/enhancer-binding protein beta) (CSÓKA et al., 2007). Percebemos a importância da ADO na produção de IL-10, sendo assim, em macrófagos, a ADO é capaz de bloquear a ativação clássica desse tipo celular, inibindo seus mecanismos microbicidas (CSÓKA et al., 2012), redução da produção de espécies reativas de oxigênio (ROS) (CRONSTEIN et al., 1990), favorecer a diferenciação para o perfil M2 (HASKÓ et al., 2000).

A forma mais conhecida de produção de ADO em macrófagos ocorre através da hidrólise do ATP, demonstrado em macrófagos ativados com LPS liberando ATP no meio extracelular, e por ter uma alta expressão das ectonucleotidases CD39 e CD73, essas células são capazes de converter o ATP liberado em ADO aumentando a produção de IL-10 (COHEN et al., 2013). Uma das principais vias de geração de ATP nas células ocorre através do metabolismo glicolítico, no entanto, ainda não está claro como a FBP e a via glicolítica podem aumentar a produção de ADO. Nesse sentido, torna-se interessante investigar se a administração exógena de FBP pode apresentar um papel no aumento da produção de ADO através da via glicolítica, assim como a participação alostérica da PKM2 nesse efeito antiinflamatório. 
Nossa hipótese de trabalho foi que a FBP, assim como a ativação alostérica da PKM2, promovem o aumento dos níveis de ATP extracelular em macrófagos ativados, que sofre ação das ectonucleotidases e seria hidrolisado para ADO, promovendo um efeito anti-inflamatório dependente das vias adenosinérgica e glicolítica. 


\section{OBJETIVOS}




\section{OBJETIVOS}

\subsection{OBJETIVO GERAL}

Investigar os mecanismos que frutose 1,6 bifosfato (FBP) ou a ativação alostérica da PKM2 pelo TEPP-46 em regula na resposta inflamatória de macrófagos ativados.

\subsection{OBJETIVOS ESPECÍFICOS}

2.2.1 Avaliar o efeito da FBP na produção e expressão de citocinas pro- e antiinflamatórias;

2.2.2 Avaliar as alterações metabólicas de macrófagos ativados na presença de FBP;

2.2.3 Verificar o papel da FBP na produção de ATP em macrófagos ativados com LPS;

2.2.4 Verificar participação da via adenosinérgica nos efeitos imunomoduladores da FBP em modular a produção de IL-10;

2.2.5 Verificar os efeitos anti-inflamatórios da FBP in vivo em modelo de endotoxemia.

2.2.6 Avaliar os efeitos do tratamento com FBP em colite induzida por DSS e a participação da via adenosinérgica nesse modelo.

2.2.7 Avaliar o efeito da ativação alostérica da PKM2 na produção e expressão de citocinas pro- e anti-inflamatórias;

2.2.8 Verificar se TEPP-46 é capaz de ativar alostericamente a PKM2;

2.2.9 Avaliar a participação da PKM2 na produção de IL-10

2.2.10 Avaliar a participação do metabolismo glicolítico na produção de IL-10 de forma de pendente de PKM2;

2.2.11 Avaliar a participação de via adenosinérgica na produção de IL-10 aumentada pela ativação alostérica de PKM2. 


\section{MATERIAL E MÉTODOS}




\section{MATERIAL E MÉTODOS}

\subsection{ANIMAIS DE EXPERIMENTAÇÃO}

Para esse projeto, utilizamos camundongos machos isogênicos da linhagem BALB/c e C57BL/6, com 6 semanas de idade. Os animais foram adquiridos no Serviço de Biotério da Prefeitura do Campus da USP-Ribeirão Preto. Além desses, também utilizamos camundongos modificados geneticamente, como os deficientes para o receptor de adenosina $A 2{ }_{A} R\left(A 22_{A}\right.$ KO) (background BALB/c), deficientes para o canal de panexina-1 (PAN KO), e camundongos deficientes para PKM2 apenas nas células mieloides $\mathrm{LysM}^{\text {cre }} / \mathrm{PKM}^{\mathrm{fl} / \mathrm{fl}}$ com seu respectivo controle $\mathrm{LysM}^{\text {cre }}$ os quais foram criados no Centro de Criação de Camundongos Especiais da FMRP USP, ambos (background C57BL/6). Mantemos todos os animais em experimentação no biotério do Departamento de Farmacologia da FMRP-USP em microisoladores de $30 \mathrm{~cm} \times 20 \mathrm{~cm} \times 12 \mathrm{~cm}$, forrados com maravalha, em temperatura de $(23-25$ $\left.{ }^{\circ} \mathrm{C}\right)$ e ciclo claro/escuro controlados, com livre acesso à ração e água, com no máximo 5 animais por microisolador. Os protocolos experimentais 113/2015 e 0145/2019 realizados neste trabalho estão de acordo com os Princípios Éticos de Experimentação Animal, adotado pelo Colégio Brasileiro de Experimentação Animal (lei 11794/2008) e aprovados pelo Conselho Nacional de Controle de Experimentação Animal (CONCEA).

\subsection{DIFERENCIAÇÃO DE MACRÓFAGOS PROVENIENTES DA MEDULA ÓSSEA}

A diferenciação de macrófagos derivados da medula óssea (BMDM) foi realizada como descrito previamente (KUROWSKA-STOLARSKA et al., 2009). Resumidamente, utilizamos células da medula óssea para obtenção dos progenitores mieoloídes, para isso coletamos os fêmur de camundongos que foram sacrificados por dose excessiva de anestésico com injeção subcutânea de cloridrato de xilazina $(10 \mathrm{mg} / \mathrm{kg})$ e cloridrato de cetamina 
(80mg/kg) seguido de deslocamento cervical, nos fêmures cortamos as epífises e assim ocorreu a exposição do canal medular. A medula óssea foi removida por flush com uma agulha de 26-gauge acoplada a uma seringa plástica de $3 \mathrm{ml}$ que foi inserida na cavidade medular com meio de cultura RPMI-C. A suspensão de medula óssea foi homogeneizada e centrifugada à $400 \mathrm{~g}$ por 10 minutos à $4^{\circ} \mathrm{C}$, o sobrenadante foi desprezado, e mantemos apenas o pelet celular, para ressuspender as células utilizamos meio RPMI-C enriquecido com $20 \%$ de SFB-I e $20 \%$ do sobrenadante de cultura de L929, essas células foram colocadas em 4 placas de Petri sem tratamento para manter baixa aderência (Corning 430591) contendo 10mL do meio para macrófagos e ficaram por 3 dias numa estufa de $\mathrm{CO}_{2}$ à $37^{\circ} \mathrm{C}$, no terceiro dia adicionamos mais $10 \mathrm{~mL}$ do meio de diferenciação para macrófagos essas células ficaram mais 4 dias para completar a diferenciação celular.

Após a diferenciação dos progenitores mieloídes da medula óssea para macrófagos, essas células foram destacadas com tampão fosfato salina (PBS) gelado e com o auxílio de um suporte plástico (Cell Scraper, Corning NY) para a raspagem das células aderentes, a solução contendo os macrófagos foi centrifugada a $400 \mathrm{~g}$ por 10 minutos a $4^{\circ} \mathrm{C}$, após o sobrenadante desprezado as células foram ressuspendida em RPMI-C e a diferenciação de macrófagos foi confirmada por citometria de fluxo, onde demonstramos que essas células foram positivas para $\mathrm{F} 4 / 80$.

\subsection{ENSAIOS COM FBP OU TEPP-46}

Nos ensaios, utilizamos macrófagos em placas Costar (Sigma) de 96 poços contendo $\left(2 \times 10^{5}\right.$ células/poço) ou em placas Constar (Sigma) de 12 poços contendo $\left(1 \times 10^{6}\right.$ células/poço) e incubados por 1 hora na estufa de $\mathrm{CO}_{2}$ a $37^{\circ} \mathrm{C}$ para a aderência das células na placa. Após a aderência celular adicionamos o tratamento de D-Fructose 1,6-bisphosphate 


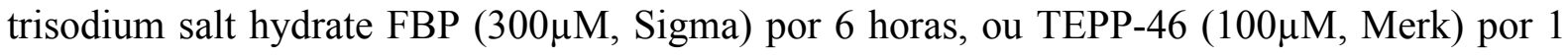
hora, ainda utilizamos alguns controles positivos como Adenosine 5'-triphosphate disodium salt hydrate ATP $(100 \mu \mathrm{M}$, Sigma), Adenosine 5'-diphosphate sodium salt ADP $(100 \mu \mathrm{M}$, Tocris) ou NECA $\left(10 \mu \mathrm{M}\right.$, Tocris) por 1 horas na estufa de $\mathrm{CO}_{2}$ a $37^{\circ} \mathrm{C}$, juntamente com o tratamento, também utilizamos alguns inibidores, agonistas ou antagonistas como Adenosina deaminase ADA (1U/ml, Sigma), 8-Ciclopentil-1,3-dipropilxantina DPCPX (10 $\mu \mathrm{M}$, Sigma),

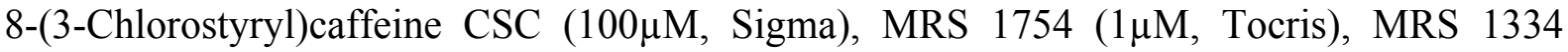
$(10 \mu \mathrm{M}$, Tocris), ARL 67156 trisodium salt ARL $(200 \mu \mathrm{M}$, Tocris $)$, adenosine 5'-( $\alpha, \beta-$

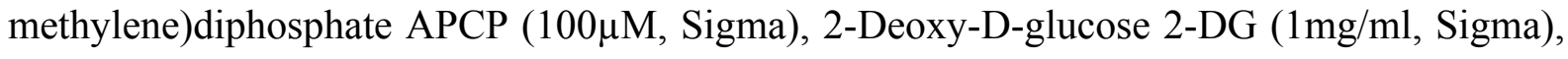
STF-31 (10 $\mu \mathrm{M}$, Sigma), Iodoacetamide IAA ( $3 \mu \mathrm{M}$, Sigma), Carbenoxolone disodium salt

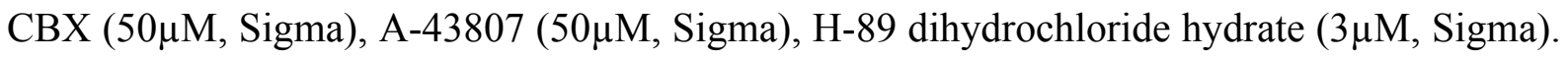
Após o tratamento de 6 horas no caso de usado FBP ou 1 hora se utilizamos o TEPP-46, estimulamos as células com LPS (100ng/ml, Sigma) por até 24 horas, então coletamos o sobrenadante da cultura celular para dosagem de citocinas por ELISA, ensaios enzimáticos, bioquímicos, cromatografia, quantificação de ATP, ou a células para ensaios de PCR, Western-blot, metaboloma ou citometria de fluxo.

\subsection{DETECÇÃO DE CITOCINAS PELO ENSAIO IMUNOENZIMÁTICO (ELISA)}

A determinação dos níveis das citocinas IL-10, IL-6, IL-1 $\beta$ e TNF murinos foram realizadas pelo método imunoenzimático (ELISA) utilizando kits DuoSet ELISA Development Systems (R\&D Systems) de acordo com as informações do fabricante. Brevemente, as placas de microtitulação de 96 poços (Thermo Fisher) foram recobertas com $50 \mu 1 /$ poço do anticorpo primário específico para a citocina de interesse, no caso anti-IL-10, anti-IL6, anti-IL-1 $\beta$ e anti-TNF- $\alpha$, nas concentrações descritas pelo fabricante diluídos em PBS e incubados overnight a $4^{\circ} \mathrm{C}$. As placas foram lavadas por quatro vezes com PBS/Tween- 
20 (0,05\% Sigma), e em seguida bloqueadas com $100 \mu \mathrm{L}$ de PBS contendo BSA 1\% durante 1 hora em temperatura ambiente para que não houvesse ligações inespecíficas. Seguindo as orientações do fabricante lavamos novamente as placas com PBS/T e então adicionamos as 50 $50 \mu \mathrm{L}$ de amostras e do padrão (curva-padrão) contendo as concentrações conhecidas de IL-10 (2000pg/ml), IL-6 (2000pg/ml), IL-1 $\beta \quad(2000 \mathrm{pg} / \mathrm{ml})$ e TNF- $\alpha \quad(2000 \mathrm{pg} / \mathrm{ml}) \quad$ incubados overnight a $4{ }^{\circ} \mathrm{C}$. Após esse período, as placas foram lavadas novamente e em seguida adicionados $50 \mu \mathrm{L}$ dos anticorpos secundários biotinilados que são específicos para cada citocina. Após duas horas, as placas foram novamente lavadas e adicionamos o conjugado estreptavidina-peroxidase, na diluição de 1:40 e incubadas por 1 hora em temperatura ambiente, por fim as placas foram lavadas e então adicionamos $100 \mu \mathrm{L}$ do substrato TMB, aguardamos 10 minutos para adicionar a solução de parada (Ácido sulfúrico $\mathrm{H}_{2} \mathrm{SO}_{4}$ na diluição 1:20). A densidade ótica foi mensurada no comprimento de onda de 450nm no espectrofotômetro SpectraMAX 190 Microplate Reader (Molecular Devices). Os dados foram analisados usando o software SoftMax Pro 5 e a concentração de citocinas contidas nas amostras foi calculada a partir de uma curva padrão com 12 pontos obtidos por diluição seriada com os resultados expressos em $\mathrm{pg} / \mathrm{ml}$.

\subsection{PCR QUANTITATIVO EM TEMPO REAL}

Analisar a expressão gênica de macrófagos pela técnica da reação em cadeia da polimerase em tempo real (RT-PCR ), o RNA total de $1 \times 10^{6}$ de macrófagos derivados da medula óssea de murinos, esse RNA foi extraído usando o Kiti da (Quiagem) RNeasy Mini Kit 250, seguindo as orientações do fabricante. Com o $1 \mu \mathrm{g}$ de RNA total realizamos as reações de transcrição reversa através do kit High-CapacitycDNA Reverse Transcription (AppliedBiosystems) sempre seguindo as instruções fornecidas pelo fabricante. 
A expressão do RNA mensageiro (RNAm) por RT-PCR para os genes $I l 10, I l-6, I l-1 \beta$, Tnf- $\alpha$ e utilizamos o como controle endógeno o gene Gapdh. A reação quantitativa do PCR em tempo real foi feita no Via7 Real-Time PCR (Life Technologies) usando o sistema de fluorescência SYBR green (Applied Biosystems, Warrington, UK) ou TaqMan (AppliedBiosystems) para a quantificação das amplificações.

Os resultados foram analisados através do método comparative de cycle threshold (CT). Todos dados foram normalizados em relação aos valores de Gapdh, e a quantificação das diferenças entre os grupos foi calculada de acordo com as instruções do fabricante. A expressão gênica foi apresentada baseada na quantidade de vezes que aumentou em relação aos BMDMs não-estimulados

Tabela - Primers utilizados nas reações de RT-PCR e suas respectivas sequências sense e anti-sense:

\begin{tabular}{|l|l|l|}
\hline Primers & Sense & Anti-sense \\
\hline$I L-10$ & 5'-TGGACAACATACTGCT-3' & 5'-GGATCATTTCCGATAAGGCT-3' \\
\hline$I L-6$ & 5'-GAGGATACCACTCCCAACAGACC-3' & 5'-AAGTGCATCATCGTTGTTCATACA-3' \\
\hline IL-1 $\beta$ & 5'-CCTTCCAGGATGAGGACATGA-3' & 5'-TGAGTCACAGAGGATGGGCTC-3' \\
\hline$T N F-\alpha$ & 5'-GAGTGACAAGCCTGTAGCC-3' & 5'-CCTTCCAGGATGAGGACATGA-3' \\
\hline GAPDH & 5'-GGGTGTGAACCACGAGAAAT-3' & 5'-CCTTCCACAATGCCAAAGTT-3' \\
\hline
\end{tabular}




\subsection{CITOMETRIA DE FLUXO DE MACRÓFAGOS}

Para caracterizar a expressão de CD39 e CD73 na população de BMDM ou RAW realizamos as marcações com F4/80+ e CD39+ ou F4/80+ e CD73+.

Macrófagos pré-incubados 6 horas na presença ou ausência de $300 \mu \mathrm{M}$ de FBP e estimulados ou não com $100 \mathrm{ng} / \mathrm{ml}$ de LPS por 24 horas, coletamos os macrófagos $1 \times 10^{6}$ (células/tubo) incubadas com $1 \mu \mathrm{L}(1 \mu \mathrm{g})$ de F4/80 FITC (eBioscience) e $1 \mu \mathrm{L}$ de CD39 ou CD73 ambos PE (eBioscience) (anticorpos monoclonais extracelulares), por 30 minutos, a $4^{\circ} \mathrm{C}$. Após a incubação, lavamos as amostras 2 vezes com $2 \mathrm{ml}$ de PBS contendo $2 \%$ de soro bovino fetal, centrifugadas a $400 \mathrm{~g}$ por 10 minutos e ressuspensas em $100 \mu \mathrm{L}$ de solução de formaldeído a 1\% em PBS. Após esses procedimentos, adquirimos as amostras em FACSVerse (BD Immunocytometry System, Franklin Lakes, NJ), e as análises realizadas no programa FlowJo ${ }^{\mathrm{TM}}$ v10 (BD Biosciences).

\subsection{QUANTIFICAÇÃO DE LACTATO}

A concentração de lactato foi medida no sobrenadante da cultura celular usando um kit de ensaio colorimétrico (Quibasa-Bioclin, Belo Horizonte, MG, Brasil), seguindo as instruções do fabricante.

\subsection{QUANTIFICAÇÃO DA ATIVIDADE DA PIRUVATO QUINASE}

A atividade da PKM2 foi medida com o kit de ensaio de atividade de piruvato quinase de base colorimétrica (BioVision) de acordo com as instruções recomendadas pelo fabricante. 


\subsection{ENSAIO DE SEAHORSE}

O ECAR foi medido com um analisador de fluxo extracelular Seahorse Bioscience XF-96 (Seahorse Bioscience) de acordo com as instruções do fabricante. As macrófagos foram expostos a presença de FBP ou não por 6h e então ativadas com LPS por mais 6 h. Assim observamos a atividade glicolítica através do ECAR em tempo real, onde os dados foram expressos em $\mathrm{mpH} / \mathrm{min}$.

\subsection{METABOLOMA}

A análise metabolômica foi realizada com $1 \times 10^{6}$ macrófagos tratados com FBP $(300 \mu \mathrm{M}), 2-\mathrm{DG}(2 \mathrm{mM})$ ou IAA $(10 \mu \mathrm{M})$ por 6 horas e seguido de estímulo LPS $(100 \mathrm{ng} / \mathrm{mL})$ por 12 horas. As células foram coletadas com a adição $1 \mathrm{ml} 8: 2$ de metanol: $\mathrm{H}_{2} \mathrm{O}$ e então colocadas em gelo seco $\left(-75^{\circ} \mathrm{C}\right)$ por 30 min para reduzir o metabolismo celular adicionamos

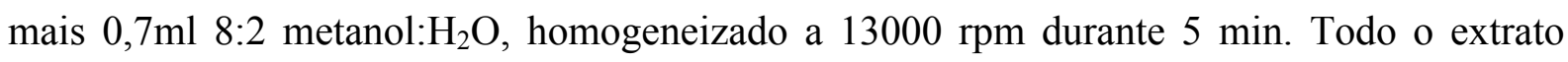
solúvel foi removido e as amostras foram secadas usando o Speedvac a $30^{\circ} \mathrm{C}$. Os pellets foram usados para medir a proteína total. A amostra foi enviada para o Northwest Metabolomics Research Center (Seatle, Washington, EUA) para análise de perfil de metabólitos por meio de espectroscopia de ressonância magnética nuclear (RMN) e espectrometria de massa (MS). A análise metabólica não direcionada de 210 metabólitos nas descrições detalhadas dos macrófagos da plataforma pode ser encontrada em (NAGANA GOWDA; GOWDA; RAFTERY, 2015) e analisada por MetaboAnalyst (XiaLab, Montreal, Canadá).

\subsection{QUANTIFICAÇÃO DE ADENOSINA POR HPLC}

A determinação dos níveis de ADO no meio foi isolada para quantificação por espectrometria de massa, sobrenadantes de cultura de celular de $2 \times 10^{5}$ BMDM foi tratada 
com FBP $(300 \mu \mathrm{M})$ por $6 \mathrm{~h}$ ou com TEPP-46 $(100 \mu \mathrm{M})$ por $1 \mathrm{~h}$, seguido de estimulação LPS (100ng/ml) por $3 \mathrm{~h}$. O sobrenadante foi precipitado com $66 \%$ de acetonitrila para extrair a adenosina estabilizando a proteína e então diluído em 33\% de água. A separação por cromatografia líquida foi realizada utilizando um sistema Xevo TQ-S Waters Acquity UPLC HSS com coluna C18 Acuity UPLC HSS com 1,0x150mm e as diferentes concentrações de adenosina (Sigma) preparadas em metanol para padrão de curva obtiveram um modelo de regressão para calibração. A temperatura da coluna foi fixada em $40^{\circ} \mathrm{C}$. O sistema de solventes consistiu em $0,1 \%$ de ácido acético em água e $0,1 \%$ de ácido acético em metanol. A taxa de fluxo foi definida para $500 \mu 1 /$ min e o volume de injeção de $5 \mu 1$ foi usado em um tempo total de execução de 4,5min. Os fragmentos de íon positivo 268 e $136 \mathrm{~m} / \mathrm{z}$ foram observados. A concentração de adenosina e as razões de área de pico foram calculadas usando o software MassLynx V4.1 SCN 843.

\subsection{WESTERN BLOT}

Os lisados celular foram preparados usando tampão de lise de ensaio de radioimunoprecipitação (Sigma-Aldrich) suplementado com protease e coquetel de inibidor de fosfatase (Cell Signaling), para observar a PKM2 na forma de monômero, dímero, ou tetrâmero utilizamos o $500 \mu \mathrm{M}$ de cross-linked disuccinimidyl suberate (cl-DSS, SigmaAldrich). As concentrações de proteína foram determinadas com um kit de reagente de ensaio de proteína de ácido bicinconínico (BAC, Sigma-Aldrich). Para a separação por eletroforese, $10 \mu \mathrm{g}$ de proteína total foram carregados em géis de SDS-poliacrilamida de acordo com os protocolos padrão (SDS-PAGE) e depois transferidos para membrana de nitrocelulose (GE Healthcare), utilizando o sistema de transferência Trans Blot Turbo ( Bio-Rad). Após a transferência, as membranas foram bloqueadas com 5\% de leite desnatado (Cell Signaling) em solução salina tamponada com Tris com 0,1\% Tween-20 (TBST) por $1 \mathrm{~h}$ em temperatura 
ambiente e, em seguida, incubadas durante a noite a $4^{\circ} \mathrm{C}$ com diluições 1:1.000 de anticorpos primários contra PKM1, PKM2, fosfo-PKM2 (Y105) ou $\beta$-actina como controle (todos anticorpos da Cell Signaling). Subsequentemente, as membranas foram lavadas repetidamente com TBST e incubadas durante $2 \mathrm{~h}$ com o anticorpo secundário conjugado com HRP apropriado (diluição 1:5.000; Sigma-Aldrich).

\subsection{ENSAIO DE ATP}

Avaliamos os níveis de ATP extracelular no sobrenadante das culturas de macrófagos incubadas na presença do inibidor de CD-39 ARL $(200 \mu \mathrm{M})$, enquanto o ATP foi medido na presença do inibidor do canal de panexina-1 CBX $(100 \mu \mathrm{M})$. Utilizamos o ensaio luminescente ATPlite PerkinElmer conforme as recomendações do fabricante. Adicionamos numa placa preta de 96 branca $100 \mu \mathrm{L}$ de amostra ou meio de cultura contendo uma diluição seriada do padrão $\left(1 \times 10^{-5} \mathrm{M}\right)$, adicionamos $500 \mu \mathrm{L}$ da solução de lise celular e aguardamos 5 minutos num shaker a 700rpm. Após adicionamos $50 \mu \mathrm{L}$ da solução substrato e novamente deixamos 5 minutos num shaker a $700 \mathrm{rpm}, 10$ minutos após medimos a luminescência (Flexstation 3, Molecular Devices), os valores expressos em nM.

\subsection{IMUNOFLUORESCÊNCIA E MICROSCOPIA COM FOCAL}

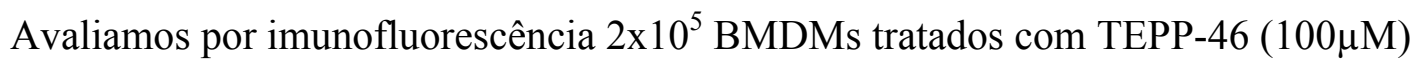
por 1 hora e então ativados com LPS (100ng/ml) por 12 horas em placa. Os macrófagos foram fixados com uma solução de 4\% de PFA, após a fixação as células foram acondicionadas numa solução de PBS com 30\% de sacarose. Após esse processo de fixação celular dos macrófagos adicionamos os anticorpos anti-PKM2 e anti-phaloidin (1:200, Abcan) e mantidos durante toda a noite em temperatura $4 \mathrm{C}$, em seguir adicionamos os anticorpos secundários IgG goat ant-rabbit AlexaFluor 488(1:400) por 1 hora em temperatura ambiente e juntamente 
com o meio de montagem adicionamos o Prolong gold anti-antifade reagent with DAPI. As imagens foram adquiridas utilizando o microscópio confocal Axio Observer combined with LSM 800 (Carl Zeiss Microscopy) e analizamos com o software Fiji by ImageJ.

\subsection{PROTOCOLO DE ENDOTOXEMIA}

Os animais submetidos à endotoxemia receberam duas injeções via intraperitoneal (i.p) de FBP ou salina, a segunda injeção foi 23 horas após a primeira, na dose de $300 \mathrm{mg} / \mathrm{kg}$ de FBP, ou uma injeção de TEPP-46 (50mg/Kg). Após uma hora da última injeção de tratamento, os animais receberam uma injeção de $25 \mathrm{mg} / \mathrm{kg}$ de LPS de bactéria Escherichia coli (Sigma-Aldrich). Transcorridas 6 horas após o protocolo de endotoxemia, os animais foram anestesiados com Ketamina $1,25 \mathrm{mg} / \mathrm{ml}$ e Xylazina $0,5 \mathrm{mg} / \mathrm{ml}$ com injeção subcutânea e então coletados o sangue pelo plexo retro-orbrital, lavado peritoneal e pulmão.

Para a coleta do pulmão realizamos uma perfusão cardíaca logo seguinte a coleta do lavado peritoneal. As amostras foram congeladas e processadas para as dosagens de citocinas por ELISA.

\subsection{PROTOCOLO DE COLITE INDUZIDA POR COLITE}

Sulfato de dextran de sódio DSS (Sigma) foi administrado ad. libitum em água na concentração de $3 \%$ por 7 dias, após trocamos por água potável normal por mais 5 dias. FBP (300mg/kg, Sigma) e ou inibidor de CD39 ARL (1 mg/kg, Tocris) foram administrados diariamente por via intraperitoneal e avaliados o peso corporal. O escore do índice de atividade da doença (DAI) que foi composto por 4 parâmetros (achados perianais, transparência da parede, sangramento intestinal e lesões focais), resultando em uma faixa de pontuação total de 0 a 12, foram avaliados através de colonoscopia por um examinador cego (Kodani et al., 2013), as pontuações dos quatro parâmetros de inflamação colorretal foi 
atribuída da seguinte forma: Achados perianais $(0=$ ausente; $1=$ diarreia ou aglomerados fecais; 2 = sangue anal; 3 = prolapso retal $)$, transparência da parede $(0=$ vasos pequenos e grandes são visíveis; 1 = não observando os vasos pequenos; $2=$ apenas os vasos muito grandes são vistos; 3 = vasos sanguíneos não podem ser observados), sangramento intestinal $(0=$ ausente; $1=$ sangramento de contato por colonoscopia; $2=$ pequenos sangramento espontâneo; 3 = sangue espontâneo grande), lesões focais $(0=$ ausente; 1 = áreas edematosas da mucosa; 2 = áreas com erosão; 3 = úlceras).

Para realizar a colonoscopia, os camundongos foram anestesiados com isoflurano (13\%, Cristalia, Brasil) e submetidos a solução salina morna e lubrificante íntimo (KY, Johnson \& Johnsons) previamente à colonoscopia. Um vídeo endoscópio de mouse de alta resolução (TELEPACK VET X, Karl Storz ${ }^{\circledR}$ ) foi usado para monitorar a colite seguindo um protocolo descrito (KODANI et al., 2013). O material consiste em câmera, fonte de luz e monitor, HOPKINS ${ }^{\circledR}$ Forward-Oblique Telescope $30^{\circ}$ (diâmetro $1,9 \mathrm{~mm}$, comprimento $10 \mathrm{~cm}$ ). Após a colonoscopia sacrificamos os animais e então coletamos o soro e cólon para análises histológicas e quantificação de citocinas.

\subsection{HISTOLOGIA}

As seções proximal e distal do cólon $(4 \mu \mathrm{m})$ foram preparadas a partir de blocos de tecido embebidos em parafina, corados com hematoxilina e eosina (H\&E), e avaliados de forma cega por um patologista experiente. O dano epitelial do cólon microscópico recebeu pontuações como a infiltração com células inflamatórias foi pontuações atribuídas separadamente para mucosa $(0=$ normal, $1=$ leve, $2=$ modesto, $3=$ grave $)$, submucosa $(0=$ normal, $1=$ leve a modesto, $2=$ grave $)$ e músculo $/$ serosa $(0=$ normal, $1=$ moderado a grave). 


\subsection{ANÁLISE ESTATÍSTICA}

Apresentamos nossos resultados com média \pm SEM de três experimentos independentes. A significância estatística foi estimada por teste $t$ de Student para amostras não pareadas para comparação entre dois grupos. Para comparação entre três ou mais grupos utilizamos ANOVA de uma via, seguido pelo pós-teste de Bonferroni. Consideramos estatisticamente diferente grupos que diferiam com $p<0,05$. Para realizar as análises estatísticas utilizamos o GraphPadPrism 5.0 (GraphPad Software). 
RESULTADOS 


\section{PARTE I}




\section{RESULTADOS}

\subsection{FBP IMPORTANTE PARA REDUZIR A EXPRESSÃO E A PRODUÇÃO DE CITOCINAS PRÓ-INFLAMATÓRIAS E AUMENTAR A PRODUÇÃO DE IL-10 EM MACRÓFAGOS ATIVADOS}

Como visto anteriormente (VIACAVA, PAULA RAMOS; ALVES FILHO, 2015), confirmamos o potencial anti-inflamatório da FBP em macrófagos, tratando BMDM com FBP $(300 \mu \mathrm{M})$ durante 6 horas, após esse período ativamos com LPS $(100 \mathrm{ng} / \mathrm{ml})$ por 24 horas. No sobrenadante da cultura celular demonstramos por ELISA que macrófagos estimulados com LPS (grupo LPS) na presença de FBP, não altera os níveis de TNF- $\alpha$ entre os grupos (Figura 5A). No entanto, o tratamento com FBP reduz significativa a produção de IL-6 (Figura 5B) e IL-1 $\beta$ (Figura 5C).

Ao avaliarmos a produção de IL-10 uma citocina anti-inflamatória, observamos que o tratamento com FBP $(300 \mu \mathrm{M})$ apresenta um aumento significativo nos níveis de IL-10 quando comparados com o grupo LPS (Figura 6). Confirmamos o aumento da expressão de IL-10 induzido por FBP, a tanto pela expressão de RNAm dessa citocina por RT-PCR (Figura 6A), quanto pela presença da proteína por ELISA (Figura 6B). Visto que, o aumento na produção de IL-10 proporcionado pela FBP foi substancial indicando uma possível participação biológica na resposta inflamatória, nos nossos próximos passos avaliamos a participação da FBP na inflamação pela produção de IL-10.

A FBP é um intermediário glicolítico com alto potencial energético, sabendo disto nos questionamos se outros monossacarídeos também aumentariam a produção de IL-10. Para esse fim, tratamos BMDM com FBP, frutose ou glicose ambas com $300 \mu \mathrm{M}$ por 6 horas e ativamos essas células com LPS por 24 horas. Porém, apenas a FBP aumentou os níveis de IL-10, enquanto que os outros açucares não alteram a produção de IL-10 (Figura 6C). 

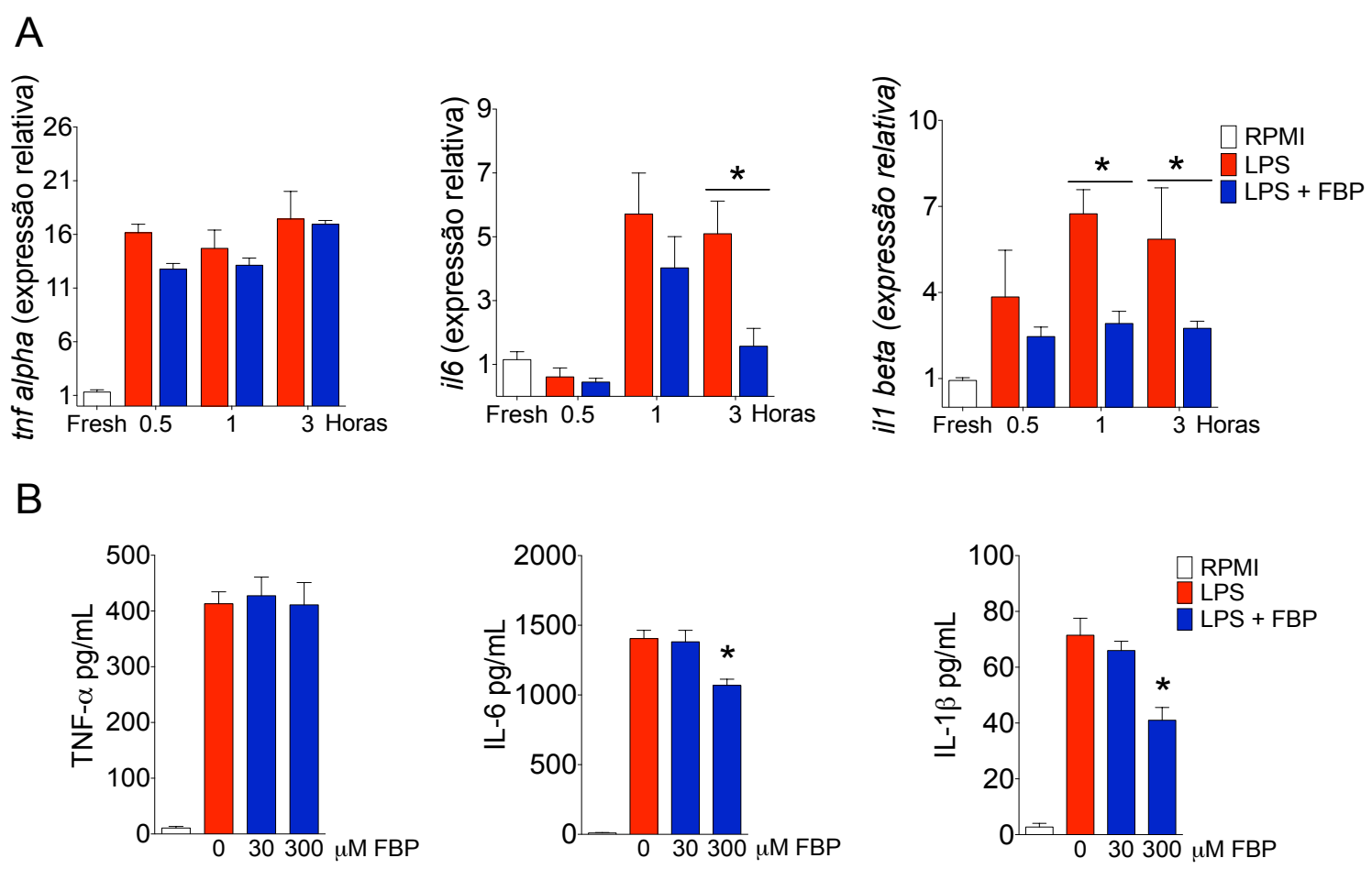

Figura 5: FBP reduz a expressão e a produção de citocinas pró-inflamatórias em macrófagos ativados com LPS. (A) BMDM foram incubados por 6 horas na presença de FBP, então ativados com LPS por 30 min, 1 e 3 horas, quantificamos a expressão relativa do gene de TNF- $\alpha$, IL-6 e IL1 $\beta$ respectivamente por RT-PCR e normalizada por GADPH. (B) BMDMs foram tratados com FBP $(0$, 30 e $300 \mu \mathrm{M}$ ) por 6 horas e então estimulados com LPS durante 24 horas. Após foi quantificado no sobrenadante da cultura celular a produção das citocinas TNF- $\alpha$ IL-6 e IL- $1 \beta$ respectivamente por ELISA. Os gráficos representam média $\pm \mathrm{SEM}, * \mathrm{p}<0,05$ indicam valores significativamente do diferentes do grupo LPS. 
A

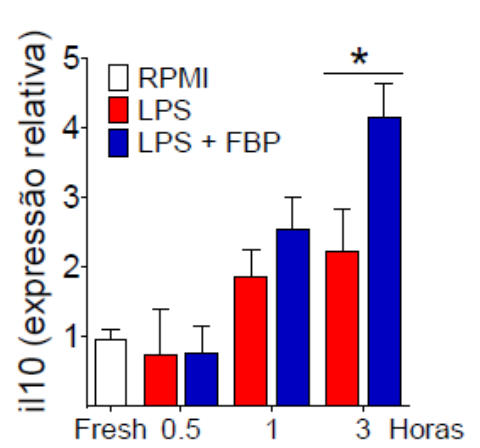

B

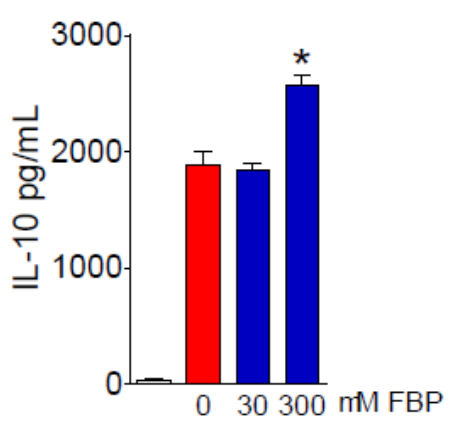

C

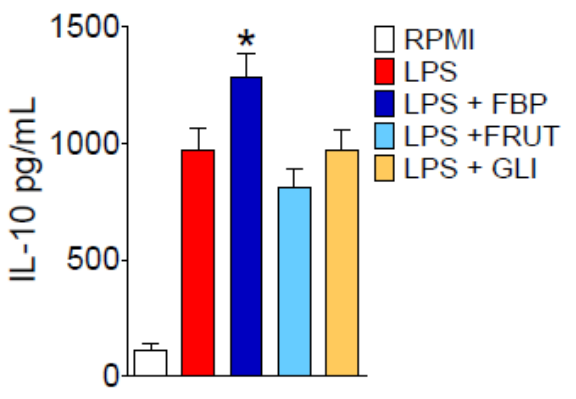

Figura 6: FBP aumenta a expressão e a produção de IL-10 em macrófagos estimulados com LPS. (A) BMDM foram incubados por 6 horas na presença de FBP, então ativados com LPS por 30 min, 1 e 3 horas, quantificamos a expressão relativa do gene da IL-10 por RT-PCR e normalizada por GADPH. (B-C) BMDM foram incubados por 6h na presença de FBP então estimulados com LPS (100ng/ml) durante $24 \mathrm{~h}$ no sobrenadante da cultura celular foi quantificado a concentração de IL-10 por ELISA; (B) concentrações crescentes de FBP (0, 30 e $300 \mu \mathrm{M})$ (B); (C) $300 \mu \mathrm{M}$ de FBP, Frutose ou Glicose. Os gráficos representam média $\pm \mathrm{SEM},{ }^{*} \mathrm{p}<0,05$ indicam valores significativamente do diferentes do grupo LPS. 


\subsection{O TRATAMENTO COM FBP AUMENTA O METABOLISMO GLICOLÍTICO DE MACRÓFAGOS}

Visto que, a participação da via glicolítica na resposta anti-inflamatória da FBP em aumentar a produção de IL-10 não estava clara, verificamos se a FBP por ser um intermediário glicolítico poderia interferir no metabolismo celular. Para isso, avaliamos a atividade glicolítica pelo ensaio de seahorse através dos níveis de ECAR dos BMDM tratados com FBP por 6 horas e ativados com LPS por mais 5 horas. Sabe-se que ativação de macrófagos por LPS aumenta os níveis de ECAR (DRESCHERS et al., 2019). Nesse contexto, observamos que o LPS foi capaz de aumentar a acidificação do meio, além disso, apenas a presença de FBP fez com que os macrófagos aumentassem os níveis de ECAR, e esse aumento foi mais evidente quando essas células foram ativadas com LPS (Figura 7A). Outro indicativo de uma alta atividade glicolítica são os níveis de lactato, que é produto final da glicólise (NELSON; COX, 2013). Observamos que os níveis de lactato aumentam no sobrenadante de cultura de macrófagos no decorrer da ativação por LPS, e que o tratamento com FBP fez com que esses níveis de lactato fossem mais elevados de forma significativa (Figura 7B), indicando que a FBP pode aumentar o metabolismo glicolítico de macrófagos. 

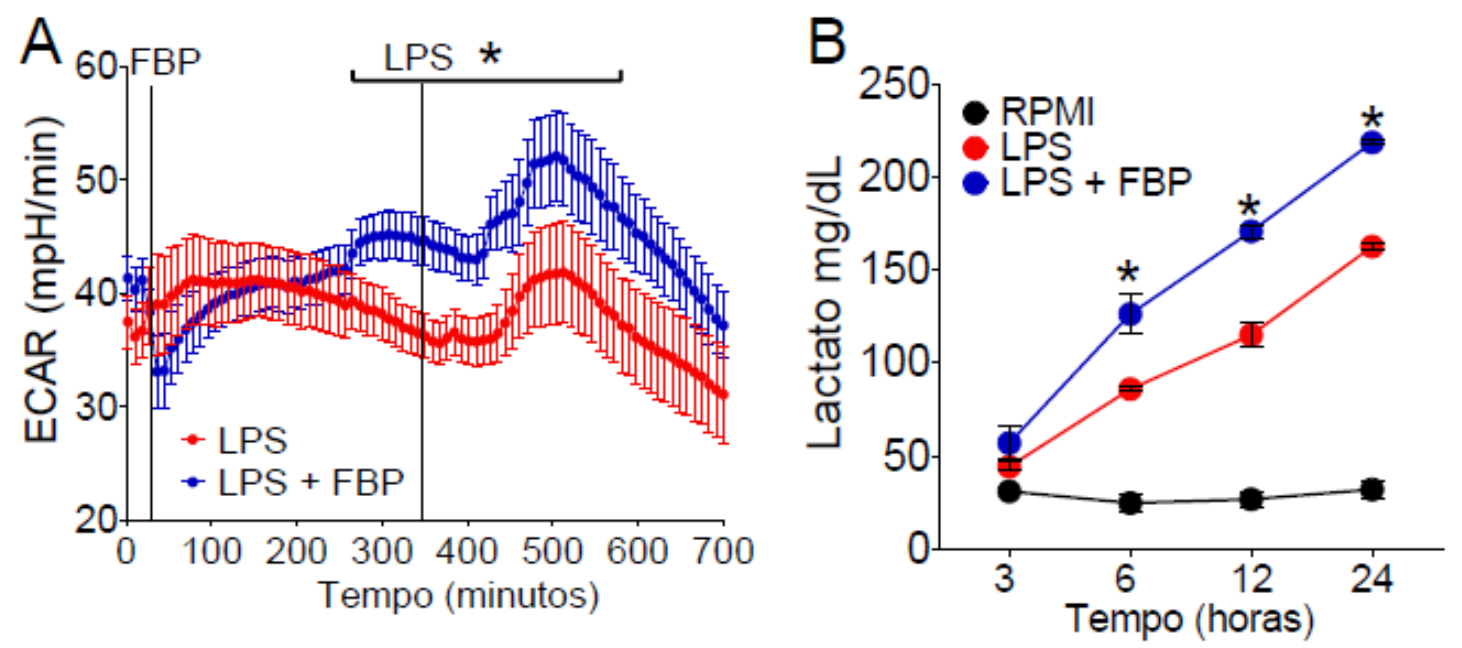

Figura 7: $O$ aumento do metabolismo glicolítico induzido pela FBP. BMDM foram incubados com FBP $(300 \mu \mathrm{M})$ por $6 \mathrm{~h}$ e posteriormente estimulados por LPS $(100 \mathrm{ng} / \mathrm{ml})$ até $24 \mathrm{~h}$. (A) Níveis ECAR durante o tratamento de FBP e estimulação com LPS por 6h pelo ensaio de Seahorse. (B) Níveis de lactato no sobrenadante de BMDM incubados por $6 \mathrm{~h}$ com FBP $(300 \mu \mathrm{M})$ e ativados com LPS (100ng/ml) durante 3, 6, 12 e 24h. Os gráficos representam média $\pm \mathrm{SEM},{ }^{*} \mathrm{p}<0,05$ indicam valores significativamente diferentes do grupo LPS. 
Com os fortes indícios de que a presença de FBP induz um aumento no metabolismo glicolítico em macrófagos, o próximo passo foi investigar quais os metabolitos estavam alterados nesses macrófagos ativados com LPS na presença de FBP por metaboloma. Com essa técnica geramos um volume de dados abundante e complexo, por isso, utilizamos o software MetaboAnalyst para o tratamento de dados metabolômicos. Através da análise de componentes principais (PCA), agrupamos as variáveis por cálculo matemático utilizando vetores convertendo as variáveis observadas possivelmente correlacionadas num conjunto de valores de variáveis linearmente não correlacionadas, e com isso conseguimos a classificação e discriminação de entidades ou metabólitos responsáveis por diferenciar os grupos de amostras, observando grande distinção nos padrões metabólicos dos grupos avaliados (Figura 8).

Para avaliar as alterações metabólicas ocasionadas pela FBP em macrófagos dependentes da via glicolítica, realizamos um protocolo de metaboloma (Figura 9) e utilizamos uma estratégia de inibir a glicólise em pontos estratégicos, com a inibição da hexoquinase através do 2-deoxiglicose (2-DG), um ponto upstream a FBP, e com o iodoacetic acid (IAA) um inibidor do Glyceraldehyde-3-Phosphate Dehydrogenase (GAPDH) uma enzima glicolítica abaixo a FBP, ficando claro na ilustração esquemática da glicólise (Figura 9A).

No ensaio de metaboloma observamos os metabólitos glicolíticos e do ciclo do ácido cítrico produzido em macrófagos ativados com LPS por $12 \mathrm{~h}$ em diferentes condições. Podemos observar que células não ativadas apresentam uma baixa produção de metabólitos, no entanto, o tratamento prévio com FBP fez com que o metabólito frutose 1,6-bifosfato aumentasse, indicando que a FBP foi capaz de entrar nas células e provavelmente ficou acumulado já que as enzimas glicolíticas estariam em níveis basais (Figura 9B). As células 
que foram ativadas com LPS apresentaram maiores níveis de metabólitos, e esse aumento foi mais proeminente no grupo tratado com FBP, indicando um aumento do metabolismo celular. Além disso, a inibição do fluxo glicolítico com 2-DG, como se era esperado, reduziu a produção de metabólitos. No entanto, a FBP conseguiu manter os altos níveis metabólicos mesmo na presença do 2-DG, indicando que ela foi capaz de preservar o metabolismo celular. Ao passo que, se inibirmos a via glicolítica num ponto downstream a FBP, como por exemplo a GAPDH com IAA, observamos uma redução dos níveis metabólicos onde observamos uma evidente redução dos níveis dos metabólitos produzidos em ambos os grupos (Figura 9B). 


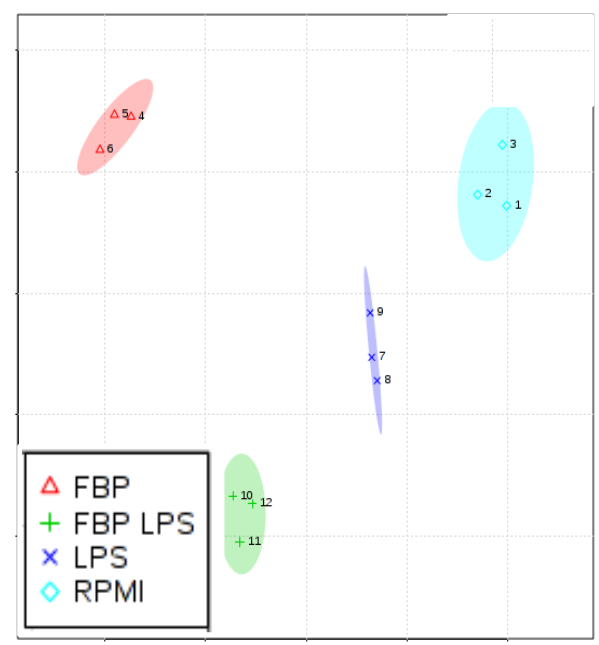

Figura 8: Análise de componentes principais. BMDM foram incubados na presença de FBP $(300 \mu \mathrm{M})$, por $6 \mathrm{~h}$ e então estimulados com LPS $(100 \mathrm{ng} / \mathrm{ml})$ durante $12 \mathrm{~h}$, no lisado celular avaliamos os níveis metabólicos por HPLC e o PCA gerado pelo software MetaboAnalyst. 
A

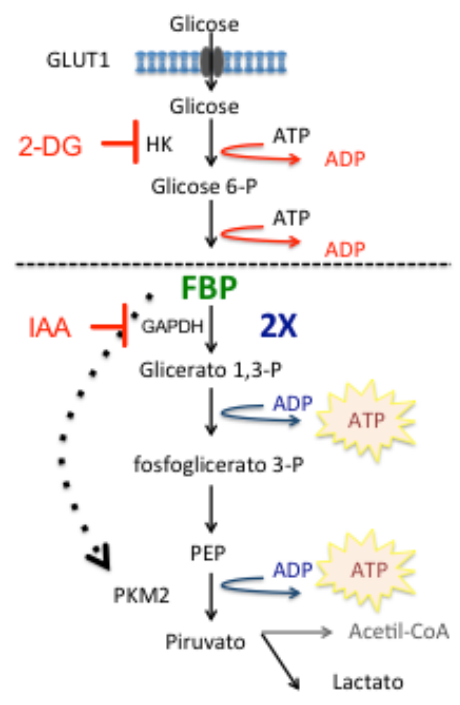

B

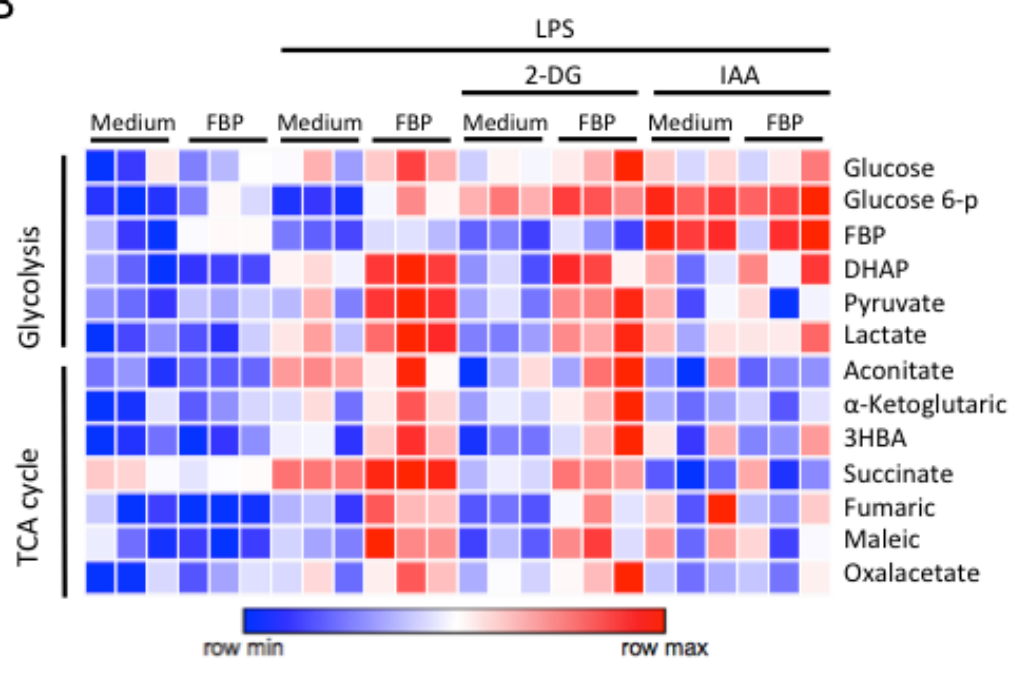

Figura 9: FBP modifica o padrão metabólico de macrófagos. (A) Desenho esquemático da via glicolítica com os pontos de inibição escolhidos. (B) BMDM incubados na presença ou não com FBP $(300 \mu \mathrm{M}), 2$-DG $(2 \mathrm{mM})$ ou IAA $(3 \mu \mathrm{M})$ por $6 \mathrm{~h}$ e então estimulados com LPS $(100 \mathrm{ng} / \mathrm{ml})$ durante $12 \mathrm{~h}$, no lisado celular foi quantificada a concentração de metabólitos glicolíticos e do ciclo do ácido cítrico por UPLC. O heatmap gerado pelo software Morpheus, indicam valores relativos quando comparados entre os grupos, azul são os valores menores e vermelho os valores maiores. 
Sugerida à participação da FBP no metabolismo celular (Figura 9), avaliamos se esse aumento metabólico refletia na produção de lactato, que é um dos produtos finais da glicólise, além de verificar se a via glicolítica tem participação na produção de IL-10 (Figura 10). Observamos que, ativação com LPS em macrófagos aumenta a produção de lactato, ademais o tratamento com FBP também foi capaz de aumentar a produção de lactato, quando utilizamos meio sem glicose. Além disso, a presença de IAA fez com que abolisse o efeito da FBP, visto que é um inibidor de um ponto abaixo a FBP na via glicolítica mesmo em meio rico de glicose (Figura 10A).

Observamos um resultado semelhante ao lactato quando avaliamos a expressão do gene para IL-10 (Figura 10B), onde a FBP aumenta a expressão dessa citocina, mesmo na ausência de glicose, e a inibição do GAPDH com o IAA aboliu a expressão de IL-10 aumentada pela FBP. De forma semelhante observamos a produção de IL-10, onde a FBP manteve altos níveis mesmo com a via glicolítica inibida por 2-DG e sem efeito com a presença do IAA (Figura 10C).

Umas das consequências da via glicolítica é a produção de ATP (CHAUDHRY; VARACALLO, 2018), por isso verificamos se a FBP aumentava a produção de ATP, já que está aumentando o metabolismo glicolítico dos macrófagos e se encontra na glicólise no ponto abaixo da fase de investimento. Como esperado, observamos que o LPS é capaz de aumentar a produção de ATP e o tratamento com FBP faz com que a célula possa produzia ainda mais ATP (Figura 11A). Esse aumento na produção de ATP pela FBP foi observado tanto no interior celular (Figura 11B) quanto no meio extracelular (Figura 11C) mesmo na ausência de glicose, corroborando com o nosso resultado anterior na presença de IAA a FBP perdeu efeito em aumentar os níveis de ATP. 
A

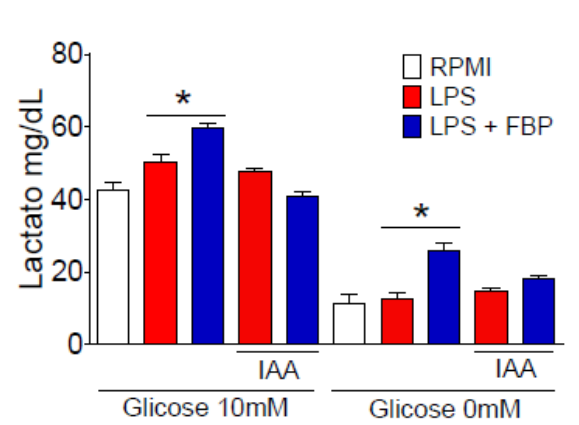

B

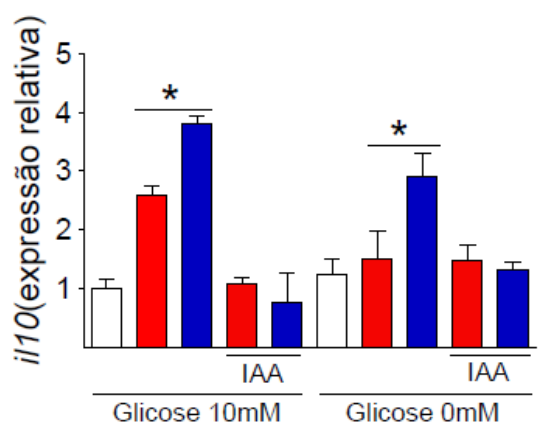

C

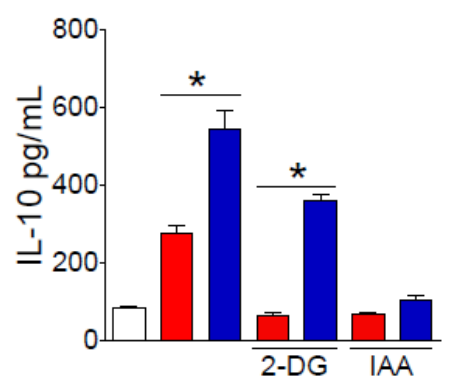

Figura 10: Aumento de IL-10 pela FBP em macrófagos ativados é dependente do metabolismo.

BMDM foram incubados com FBP $(300 \mu \mathrm{M})$ por $6 \mathrm{~h}$ e então estimulados com LPS $(100 \mathrm{ng} / \mathrm{ml})$ por 24h em meio RPMI com 10mM ou livre de glicose, na presença de IAA $(3 \mu \mathrm{M})$ ou 2-DG (2mM). (A) Quantificação de lactato no sobrenadante de cultura por ensaio colorimétrico; (B) Expressão relativa do gene de IL-10 por RT-PCR; (C) Quantificação de IL-10 em sobrenadante celular por ensaio de ELISA. Os gráficos representam média \pm SEM, $* p<0,05$ indicam valores significativamente diferentes do grupo LPS. 
A

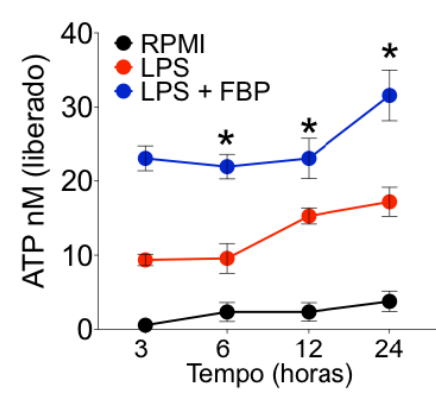

B

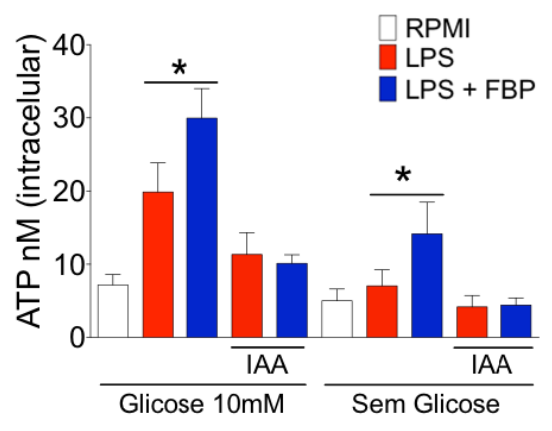

C

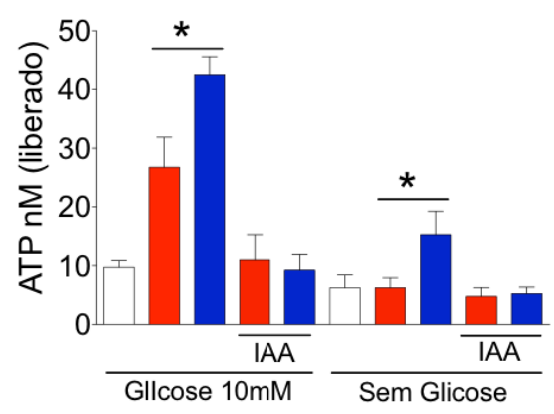

Figura 11: FBP aumenta a produção de ATP em macrófagos ativados de forma dependente do metabolismo. BMDM foram incubados com FBP $(300 \mu \mathrm{M})$ por 6h e então estimulados com LPS (100ng/ml) por até $24 \mathrm{~h}$ em meio RPMI com $10 \mathrm{mM}$ ou livre de glicose, na presença de IAA $(3 \mu \mathrm{M})$ ou 2-DG (2mM) e então quantificados os níveis de ATP por ensaio luminescente. (A) Quantificação de ATP no sobrenadante de cultura em 3, 6, 12 e 24 horas de ativação com LPS; (B) Quantificação dos níveis de ATP no meio intracelular em 3h de ativação com LPS; (C) Quantificação dos níveis de ATP no meio extracelular em $3 \mathrm{~h}$ de ativação com LPS. Os níveis de ATP no meio extracelular foram detectados na presença de iCD39 (ARL $200 \mu \mathrm{M}$ ), enquanto que o intracelular na presença do inibidor do canal de panexina-1 (CBX $50 \mu \mathrm{M})$. Os gráficos representam média $\pm \mathrm{SEM},{ }^{*} \mathrm{p}<0,05$ indicam valores significativamente diferentes do grupo LPS. 
Através do metabolismo da galactose, onde sabe-se que na ausência de glicose e apenas com galactose o ATP produzido pela célula e proveniente da mitocôndria e não da glicólise (C. et al., 2011). Pois o metabolismo da galactose para produção de piruvato, consome 4 moléculas de ATP e assim anulam a produção dos ATPs da glicólise. Observamos que na ausência da glicose e presença de galactose, a FBP foi capaz de aumentar os níveis de ATP (Figura 12A), lactato (Figura 12B) e IL-10 (Figura 12C), então podemos inferir que a FBP é capaz de aumentar o lactado, ATP e IL-10 de forma dependente da glicólise. 
A

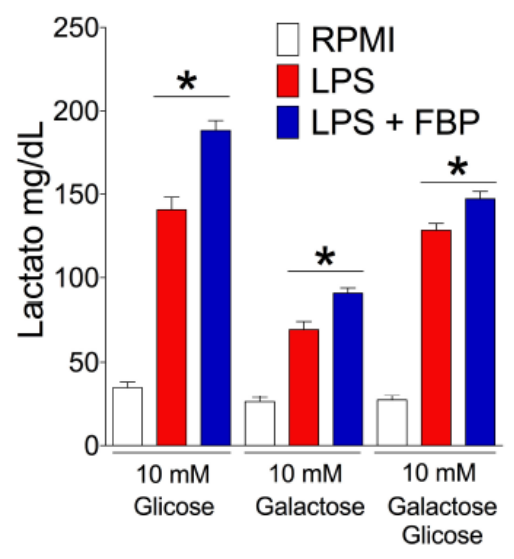

B

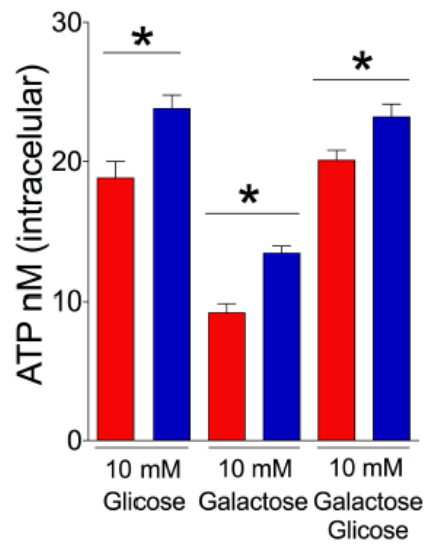

C

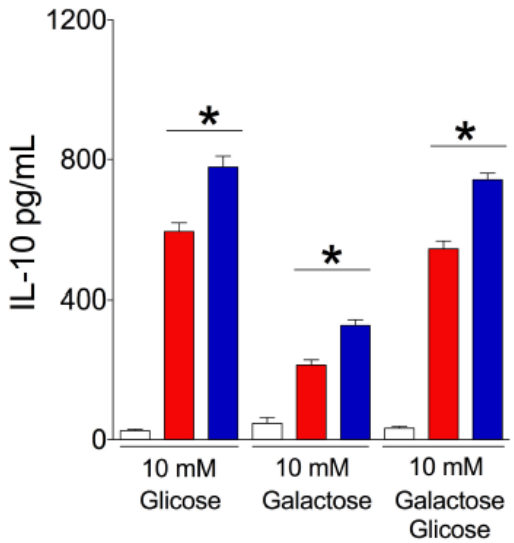

Figura 12: Aumento de IL-10 pela FBP em macrófagos ativados é dependente do metabolismo glicolítico. BMDM foram incubados com $\mathrm{FBP}(300 \mu \mathrm{M})$ por 6h e então estimulados com LPS (100ng/ml) por $24 \mathrm{~h}$ em meio RPMI com $10 \mathrm{mM}$ de glicose, $10 \mathrm{mM}$ de galactose os dois açúcares. (A) Quantificação de lactato no sobrenadante de cultura por ensaio colorimétrico; (B) Quantificação de ATP intracelular na presença de CBX $(50 \mu \mathrm{M})$; (C) Quantificação de IL-10 em sobrenadante celular por ensaio de ELISA. Os gráficos representam média $\pm \mathrm{SEM},{ }^{*} \mathrm{p}<0,05$ indicam valores significativamente diferentes do grupo LPS. 


\subsection{FBP AUMENTA A PRODUÇÃO DE IL-10 EM MACRÓFAGOS ATIVADOS COM LPS DE FORMA DEPENDENTE DA VIA ADENOSINÉRGIA}

O mecanismo de como o tratamento com a FBP gera uma resposta anti-inflamatória foi primeiramente descrito por (SOLA, 2003) e colaboradores, onde demonstraram em 2003 que a FBP age de forma dependente da ação de adenosina, e que a inibição através da adenosina deaminase abolia seus efeitos. Os nossos resultados corroboram com as descrições de SOLA, demonstramos o que a resposta da FBP em aumentar a produção de IL-10 em macrófagos depende da via adenosinérgica (Figura 13A). Macrófagos ativados com LPS na presença de FBP, aumentaram a produção de ATP intracelular em camundongos deficientes para o canal de panexina-1 (PAN KO), e por não possuir o canal para saída do ATP do interior da célula, o ATP fica acumulado dentro da célula (Figura 13C), ao passo que, quando o canal de panexina-1 está funcional, observamos a liberação desse ATP para o meio extracelular (Figura 13 B e D) e a FBP aumenta os níveis de ATP. De forma interessante, macrófagos com o canal de panexina-1 inibido, ou deficientes para ele PAN KO, a FBP não foi capaz de aumentar a produção de IL-10, no entanto reposição exógena de ATP fez com que a célula produzisse altos níveis dessa citocina (Figura 13E e F).

A presença de ATP no meio extracelular nos levou a avaliar a participação da via adenosinérgica na resposta anti-inflamatória induzida pela FBP. Sabemos que a ativação de LPS em macrófagos aumenta à produção de ADO (YANG et al., 2014), em experimento com cromatografia de alta eficiência (UPLC) demonstramos que FBP é capaz de aumentar os níveis de ADO em macrófagos ativados (Figura 3A). Corroborando com nossa hipótese de que a FBP modula a resposta inflamatória de uma maneira dependente do metabolismo glicolítico, e da via adenosinérgica a inibição de GAPDH ou de CD39 bloqueou a produção de ADO (FIG 3B). 
A

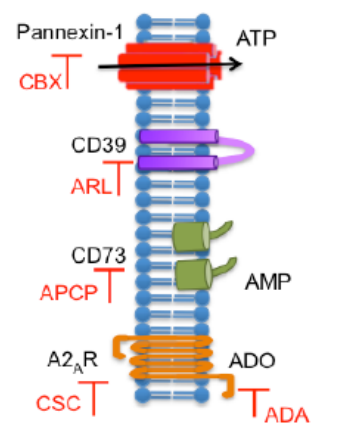

Intracellular Extracellular

$\mathrm{E}$
B

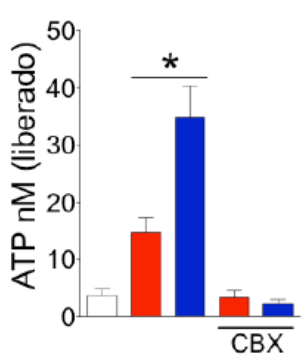

C

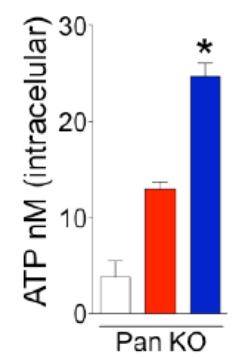

D

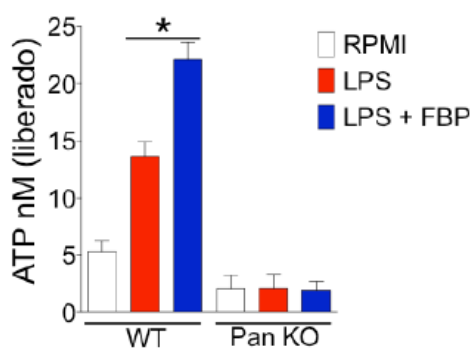

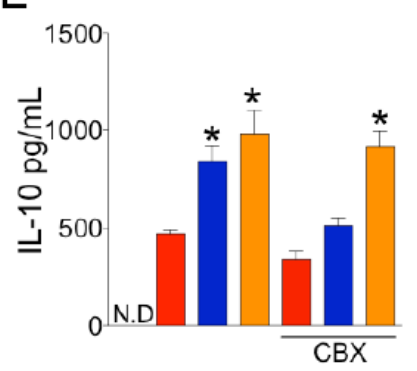

$\mathrm{F}$

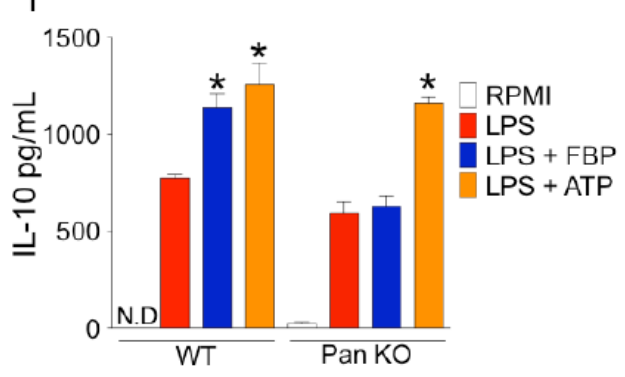

Figura 13: FBP aumenta de IL-10 em macrófagos de forma dependente da produção de ATP. BMDM foram incubados por 6 horas na presença de FBP $(300 \mu \mathrm{M})$ ou ATP $(100 \mu \mathrm{M})$ e então ativados com LPS (100ng/ml) durante 24h. (A) Desenho esquemático da via adenosinérgica com a estratégia de inibição. (B e D) Quantificação de ATP extracelular no sobrenadante celular por ensaio luminescente

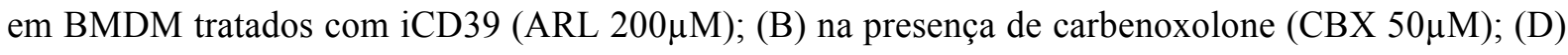
WT v.s. Pan KO; (C) Quantificação de ATP no lisado celular em BMDM deficientes para Panexina1; (E e F) Concentração de IL-10 no sobrenadante da cultura celular quantificado por ELISA, (E) na presença de CBX $(50 \mu \mathrm{M})$; (F) BMDMS WT v.s. deficientes para o canal de panexina-1 PAN KO; os gráficos representam média $\pm \mathrm{SEM},{ }^{*} \mathrm{p}<0,05$ indicam valores significativamente do diferentes do grupo LPS. 

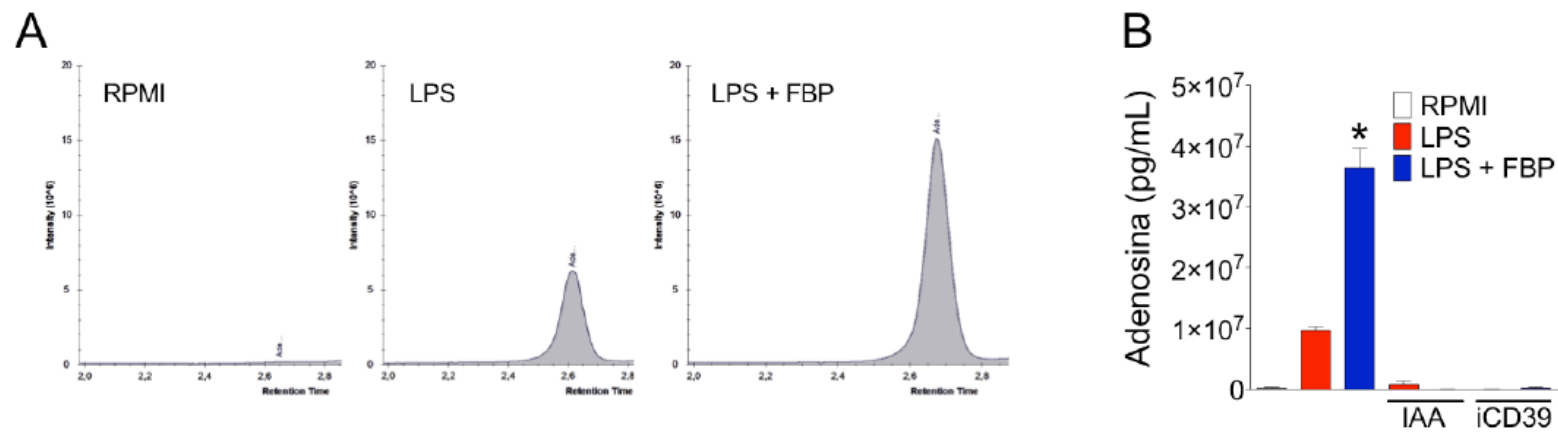

Figura 14: FBP aumenta os níveis de adenosina dependente da via glicolítica. BMDM foram incubados por 6 horas na presença de FBP $(300 \mu \mathrm{M})$ então ativados com LPS $(100 \mathrm{ng} / \mathrm{ml})$ por $3 \mathrm{~h}$. (A) Quantificação de adenosina pelo sistema UPLC-MS, Cromatograma representativo de adenosina em sobrenadante de cultura de BMDM. (B) Concentração de adenosina detectada por UPCL-MS no sobrenadante de BMDM com ou sem inibidor de GAPDH (IAA 30 $\mu \mathrm{M}$ ) ou inibidor de CD39 (iCD39 $200 \mu \mathrm{M})$. Os gráficos representam média $\pm \mathrm{SEM}, * \mathrm{p}<0,05$ indicam valores significativamente do diferentes do grupo LPS. 
Quando o ATP se encontrava no meio extracelular é capaz de sofre ação das ectonucleotidases CD39 e CD73, que são altamente expressas em BMDM mesmo que o tratamento com FBP não aumente a expressão delas em macrófagos (Figura 15A), a atividade de CD39 e CD73 retirando fosfatos da molécula de ATP e assim formando adenosina, a qual tem um papel importante no aumento da produção de IL-10 pela FBP. Visto que a inibição das ectonucleotidases CD39 (ARL) (Figura 15B) e CD73 (APCPD) (Figura 15C) reduziu a produção de IL-10, mesmo com tratamento de ATP exógeno. Confirmamos a participação da ADO no aumento de IL-10 em macrófagos pela FBP em experimentos utilizando a ADA, nesse protocolo observamos que a ADA aboliu os efeitos em aumentar os níveis de IL-10 em macrófagos tratados com FBP (Figura 15D). Por fim, demonstramos também que para a FBP aumentar a produção de IL-10, ela produz adenosina que sinaliza através do receptor de adenosina $\mathrm{A} 22_{\mathrm{A}}\left(\mathrm{A} 2_{\mathrm{A}} \mathrm{R}\right)$, a presença do antagonista para o $\mathrm{A} 2_{\mathrm{A}}(\mathrm{CSC})$ (Figura 15E) ou macrófagos deficientes para esse receptor (Figura 15F) não apresentaram aumento na produção de IL-10. 
A

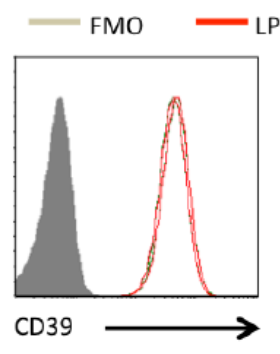

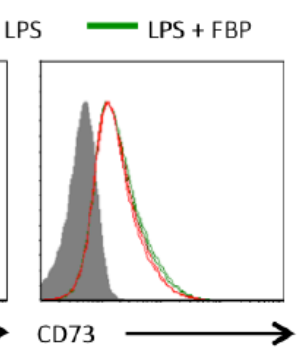

E
B

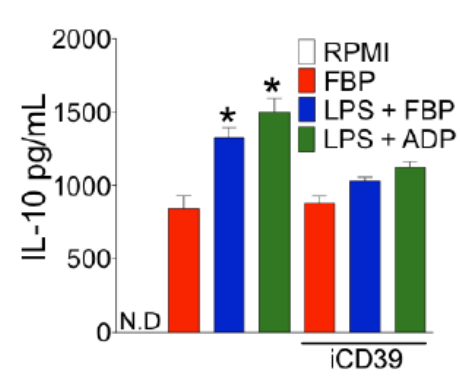

C

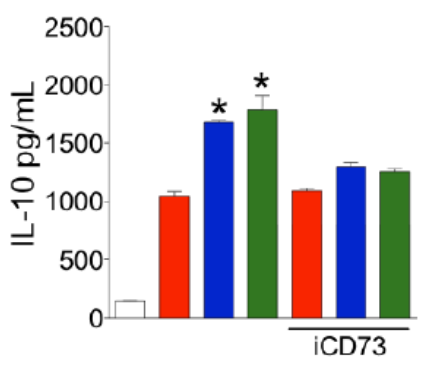

D

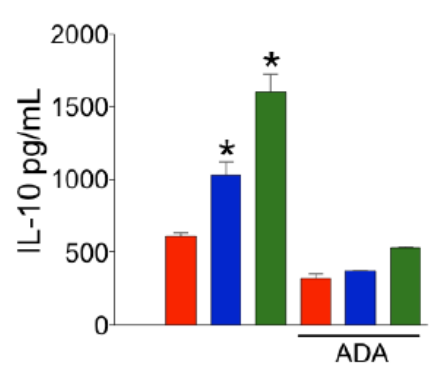

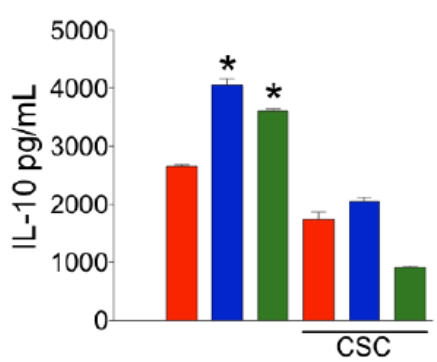

$\mathrm{F}$

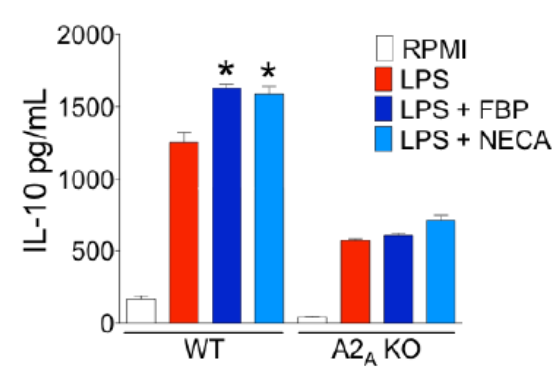

Figura 15: $O$ aumento de IL-10 em macrófagos pela FBP ocorre pela via adenosinérgica. BMDM foram incubados por 6 horas na presença de FBP $(300 \mu \mathrm{M})$, ADP $(100 \mu \mathrm{M})$ ou NECA $(10 \mu \mathrm{M})$ e então ativados com LPS (100ng/ml) durante 24h. (A) Expressão de CD39 (esquerda) e CD73 (direita) em células ativadas com LPS (vermelhas) ou na presença de FBP (verdes) por citometria de fluxo; (B-F) Concentração de IL-10 no sobrenadante da cultura celular quantificado por ELISA; (B) com inibição

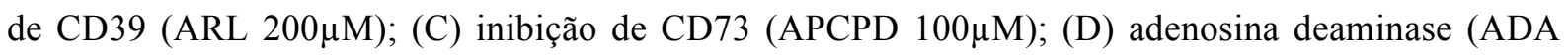
$1 \mathrm{U} / \mathrm{ml})$; (E) 8-(3-chlorostyryl) caffeine antagonista para o receptor de $\mathrm{A} 2_{\mathrm{A}}(\mathrm{CSC} 100 \mu \mathrm{M})$; (F) $\mathrm{BMDMs}$ deficientes para $\mathrm{A} 2_{\mathrm{A}}\left(\mathrm{A} 2_{\mathrm{A}} \mathrm{KO}\right)$. Os gráficos representam média $\pm \mathrm{SEM},{ }^{*} \mathrm{p}<0,05$ indicam valores significativamente do diferentes do grupo LPS. 
4.4 TRATAMENTO PRÉVIO DE FBP AUMENTA A PRODUÇÃO DE IL-10 EM MODELO DE ENOTOXEMIA DE FORMA DEPENDENTE DA PRODUÇÃO DE ATP E VIA ADENOSINÉRGIA

Confirmamos efeito anti-inflamatório da FBP, por um modelo de endotoxemia. Para isso, utilizamos camundongos $\mathrm{C} 57 / \mathrm{BL} 6, \mathrm{Balb} / \mathrm{c}$ PAN $\mathrm{KO}$ e $\mathrm{A} 2_{\mathrm{A}} \mathrm{KO}$ que foram tratados previamente com FBP $(300 \mathrm{mg} / \mathrm{kg})$ e $23 \mathrm{~h}$ após uma outra dose de FBP $1 \mathrm{~h}$ antes da injeção de LPS, o desafio com LPS ocorreu com uma injeção de $(25 \mathrm{mg} / \mathrm{kg})$ abas injeções ocorrem na cavidade peritoneal. Coletamos o soro e o lavado peritoneal 6 horas após o estímulo com LPS, para dosagem de citocinas IL-10 (Figura 16A).

Observamos que camundongos tratados previamente com FBP quando submetidos à endotoxemia apresentaram um aumento das concentrações de IL-10 séricas (Figura 16B-D), bem como no lavado peritoneal (Figura 16E-G). No entanto, camundongos tratados com o inibidor de CD39 (ARL 1mg/kg) (Figura $16 \mathrm{C}$ e F), deficientes para o canal de panexina1(Figura $16 \mathrm{~B}$ e E) ou o receptor $\mathrm{A} 2_{\mathrm{A}}$ (Figura $16 \mathrm{D}$ e $\mathrm{G}$ ), não apresentaram o aumento dos níveis de IL-10 nos grupos tratados com FBP, indicando que esse efeito anti-inflamatório em uma doença aguda é dependente do aumento do metabolismo glicolítico e da participação da via adenosinérgica. 


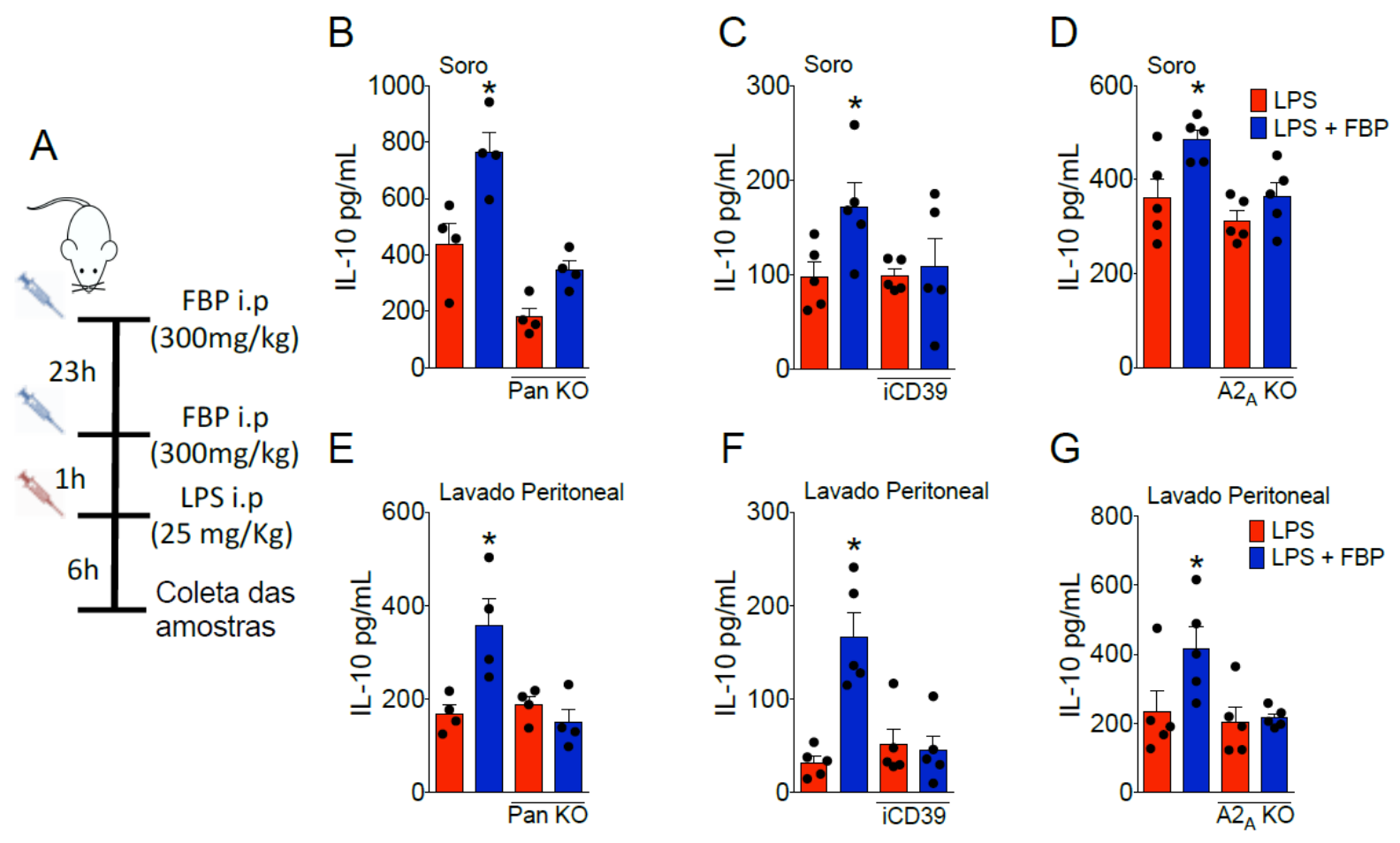

Figura 16: Tratamento com FBP aumenta os níveis de IL-10 em camundongos com peritonite.

Camundongos foram tratados com FBP $(300 \mathrm{mg} / \mathrm{kg})$ i.p, seguidos por uma segunda dose de FBP $23 \mathrm{~h}$ depois, após um período de $1 \mathrm{~h}$, induzimos endotoxemia por LPS $(25 \mathrm{mg} / \mathrm{kg})$ i.p. por $6 \mathrm{~h}$. (A) Desenho experimental. (B-G) IL-10 quantificada por ELISA no soro (B-D) ou no lavado peritoneal (E-G); WT v.s. Pan KO (B e E), tratamento com inibidor de CD39 (iCD39 1mg $/ \mathrm{kg}$ ) (C e F) ou WT v.s. A2 ${ }_{\mathrm{A}} \mathrm{KO}$ (D e G). Todos os dados significam \pm SEM $(p *<0,05)$. Representante de três experimentos independentes. 


\subsection{O TRATAMENTO COM FBP REDUZ A COLITE INDUZIDA POR DSS}

A colite é uma das doenças inflamatórias intestinais (Inflammatory Bowel Disease IBD), que afeta o cólon, reto, intestino delgado e grosso, com etiologia desconhecida, afetando aproximadamente 1,17 milhão de pessoas nos Estados Unidos, e com o índice de incidência aumentando no mundo todo (ALATAB et al., 2020). Sabe-se que a citocina IL-10 tem uma contribuição fundamental para o controle da doença, uma vez que camundongos IL$10 \mathrm{KO}$ desenvolvem espontaneamente uma doença intestinal muito similar a colite humana (KENNEDY et al., 2000). Assim, realizamos o modelo experimental de colite induzida por DSS, (dextran sulfate sodium) na água potável dos animais.

Para confirmar a nossa hipótese de que a FBP estaria aumentando a produção de IL10 de forma dependente da via adenosinérgica, tratamos com injeções intraperitoneal diárias de FBP (300 mg/kg) e ou inibidor de CD39 (iCD9 $1 \mathrm{mg} / \mathrm{kg}$ ) os animais que foram expostos a 3\% de DSS na água de beber durante 7 dias (Figura 17A). Durante todo o período experimental observamos o peso corporal dos animais, e obtivemos o resultado de que o DSS reduziu cerca de $15 \%$ da massa corpórea dos animais, enquanto o grupo controle ganhou 2 gramas de peso. Curiosamente, os animais tratados com FBP recuperam seu peso inicial após a retirada do DSS, enquanto que os tratados com FBP na presença do iCD39 não ganharam peso, provavelmente porque não incapaz de gerar grandes quantidades de ADO (Figura 17B).

A severidade da doença foi representada pelo escore do índice de atividade da doença (Disease activity index - DAI), composto por 4 parâmetros (achados perianais, transparência da parede, sangramento intestinal e lesões focais), resultando em um escore total de 0 a 12 , avaliado por colonoscopia por um examinador cego (KODANI et al., 2013). O tratamento com FBP reduziu os parâmetros da doença como sangramento e formação de úlceras (Figura 17C). Além disso, outro parâmetro da gravidade da doença é o encurtamento do cólon, e 
observamos uma evidente manutenção do tamanho do cólon no grupo dos animais tratados com FBP, o mesmo não foi observado no grupo tratado com FBP + iCD39, provavelmente pela redução dos níveis de ADO (Figura 17 D-F).

Finalmente, observamos que o tratamento com FBP aumentou os níveis de IL-10 no cólon de maneira dependente da ação da CD39 (Figura 17G), além de ter reduzido o infiltrado inflamatório e manter a arquitetura tecidual, conforme observado pela análise histológica (Figura 17H). 
A

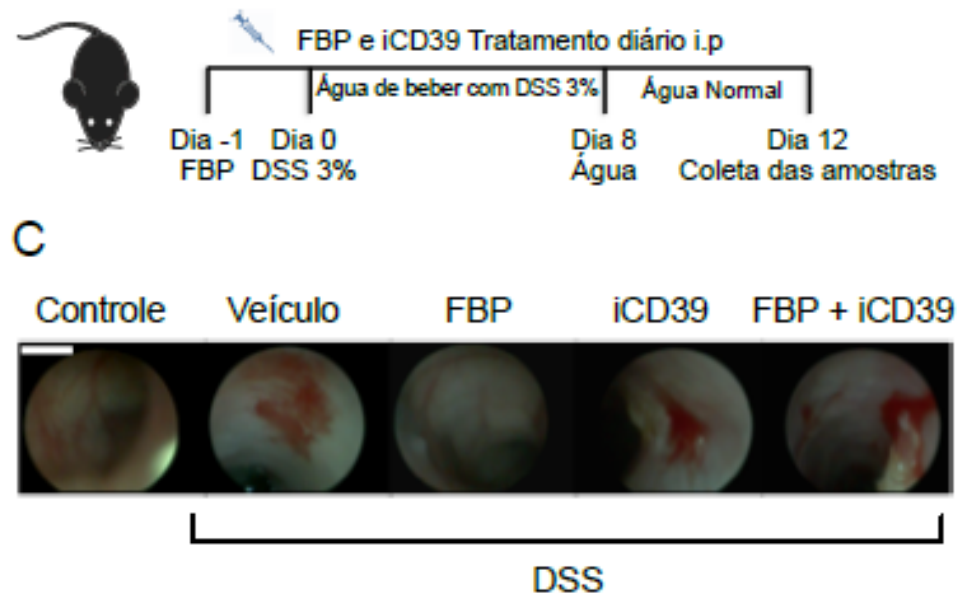

B

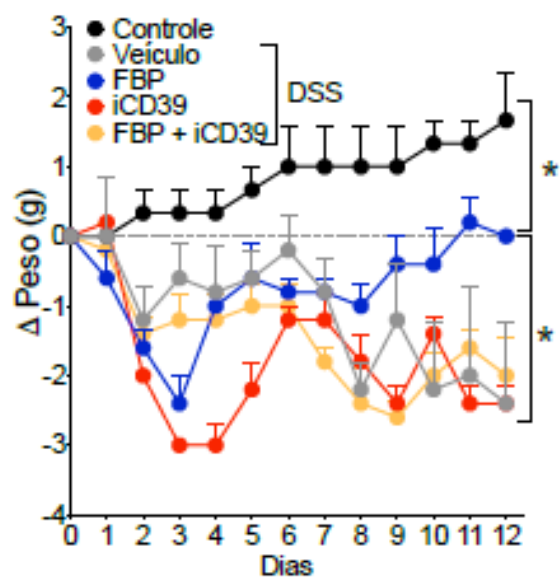

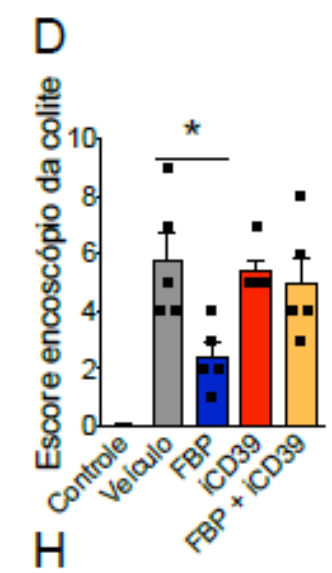

E

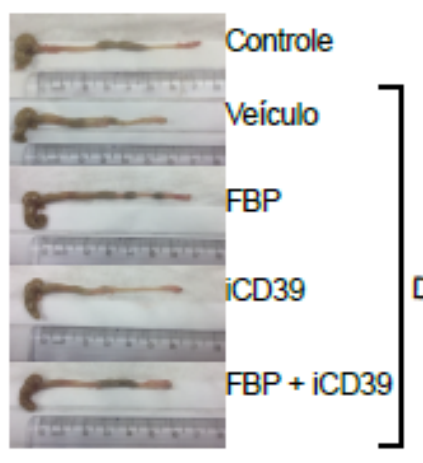

F

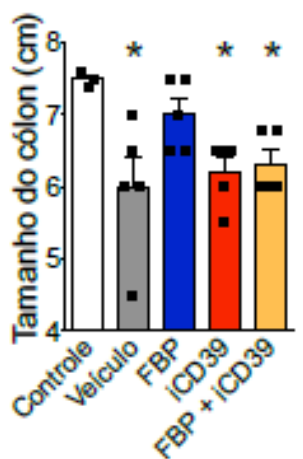

G

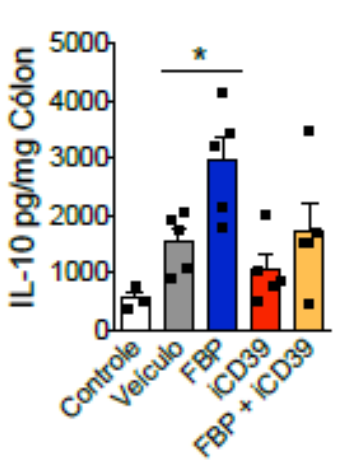

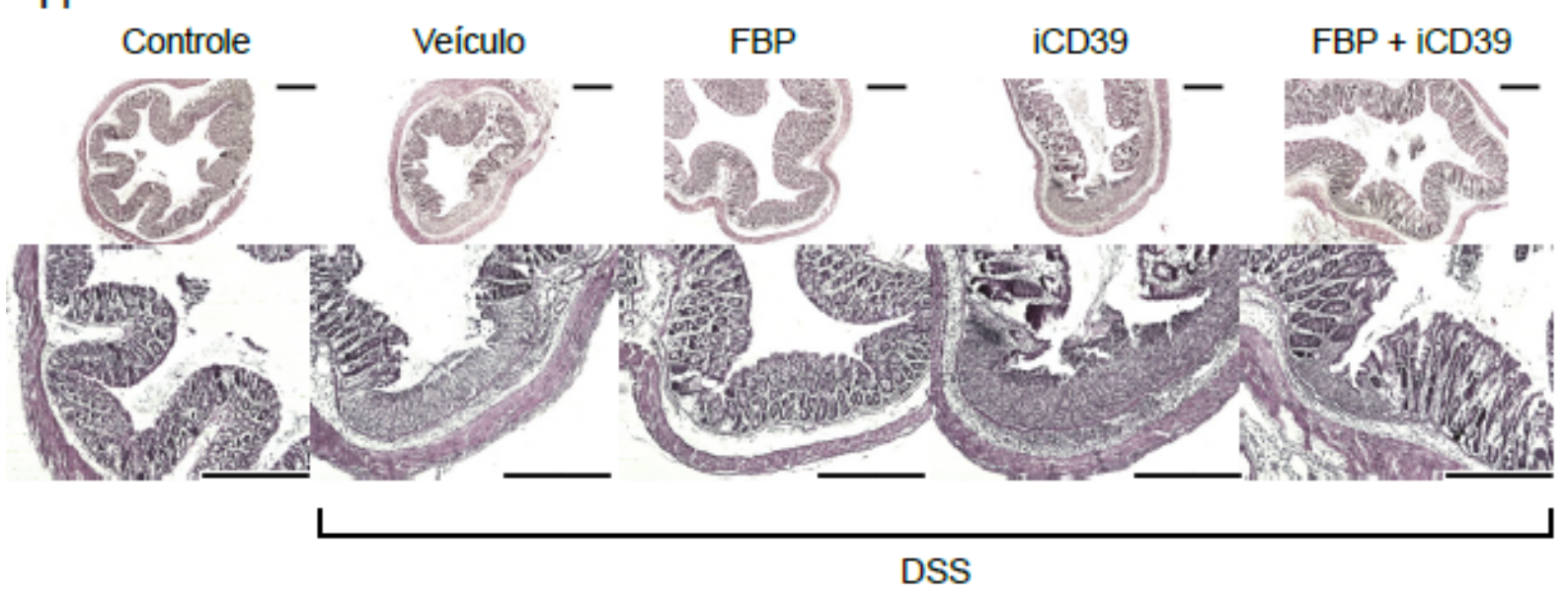

Figura 17: O tratamento com FBP reduz os parâmetros inflamatórios em modelo experimental de colite. Os animais foram tratados diariamente com FBP $(300 \mathrm{mg} / \mathrm{kg}$ ) ou iCD39 (ARL $1 \mathrm{mg} / \mathrm{Kg}$ ) por 13 dias, divididos da seguinte forma: nos primeiros 7 dias foram expostos a DSS a 3\% diluído na água potável, o restante dias eles foram autorizados a desenvolver totalmente a colite, bebendo apenas água até a coleta da amostra. (A) Cronograma esquemático da administração de FBP e iCD39 no modelo de colite; (B) Alteração do peso corporal do grupo controle (cinza) ou do grupo DSS: veículo (preto), 
FBP (azul), iCD39 (vermelho) e FBP mais iCD39 (amarelo); (C) Imagens colonoscópicas

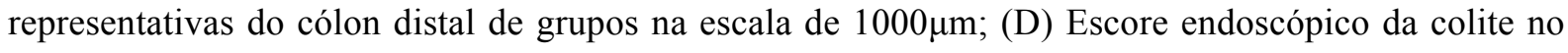
dia 12; (E-F) comprimento do cólon; Imagem representativa do comprimento do cólon (E); Comprimento médio do cólon (F); (G) Quantificação de IL-10 no cólon por ELISA; (H) Representante de imagens histológicas; controle, Veículo, FBP; iCD39; iCD39 + FBP no aumento de

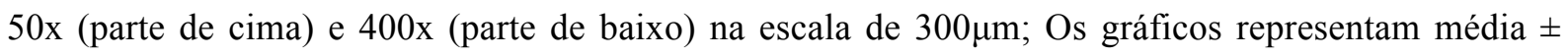
$\mathrm{SEM},{ }^{*} \mathrm{p}<0,05$ indicam valores significativamente diferentes do grupo veículo. 


\subsection{TRATAMENTO COM FBP NÃO É DEPENDENTE DA PKM2.}

A ativação alostérica da PKM2, uma enzima glicolítica uma participação na resposta inflamatória já descrita, principalmente quando for ativada alostericamente e se encontrar na forma tetramérica permanecendo na via glicolítica (ANASTASIOU et al., 2012). A FBP é o ativador alostérico natural da PKM2 (YANG et al., 2016), por isso, nos questionamos se os efeitos observados pelo tratamento com FBP foram decorrentes do aumento na produção de ATP, pois não consumir duas moléculas de ATP durante a fase de investimento, ou pela ativação alostérica da PKM2.

Observamos que, a FBP foi capaz de aumentar os níveis de ATP extracelular (Figura 18A), assim como a produção de lactato (Figura 18B) e IL-10 (Figura 18D), além de reduzir a produção da citocina pró-inflamatória IL-6 (Figura 18C). No entanto, BMDMs provenientes de animais deficientes para PKM2 nas células mielóides, a FBP continuou apresentando os mesmos efeitos dos que nos BMDMs originados de animais WT, indicando que os efeitos da FBP não foram dependentes da ativação alostérica da PKM2 (figura 18). 
A

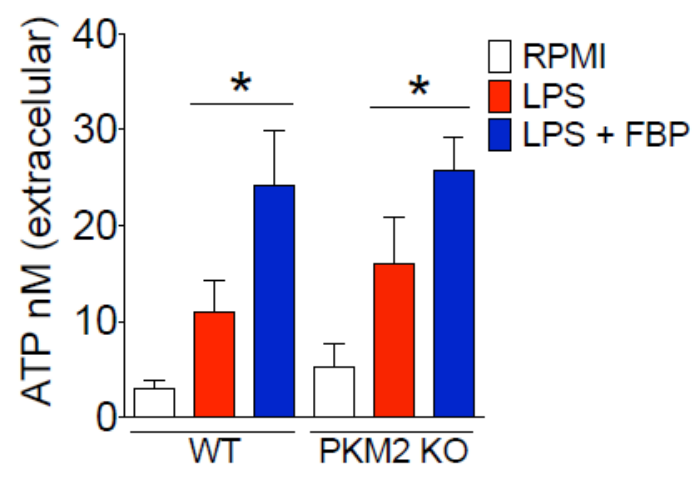

C

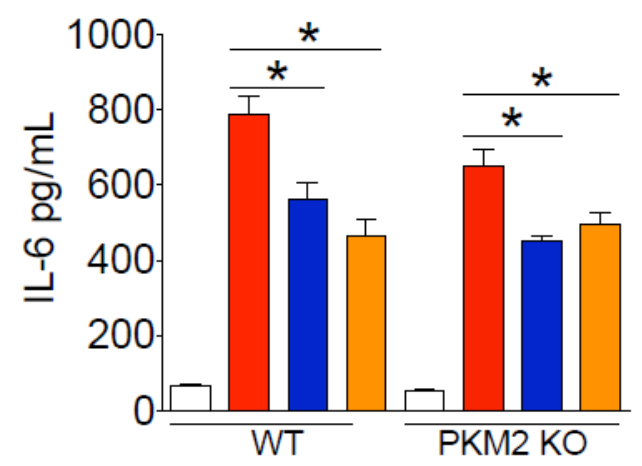

B
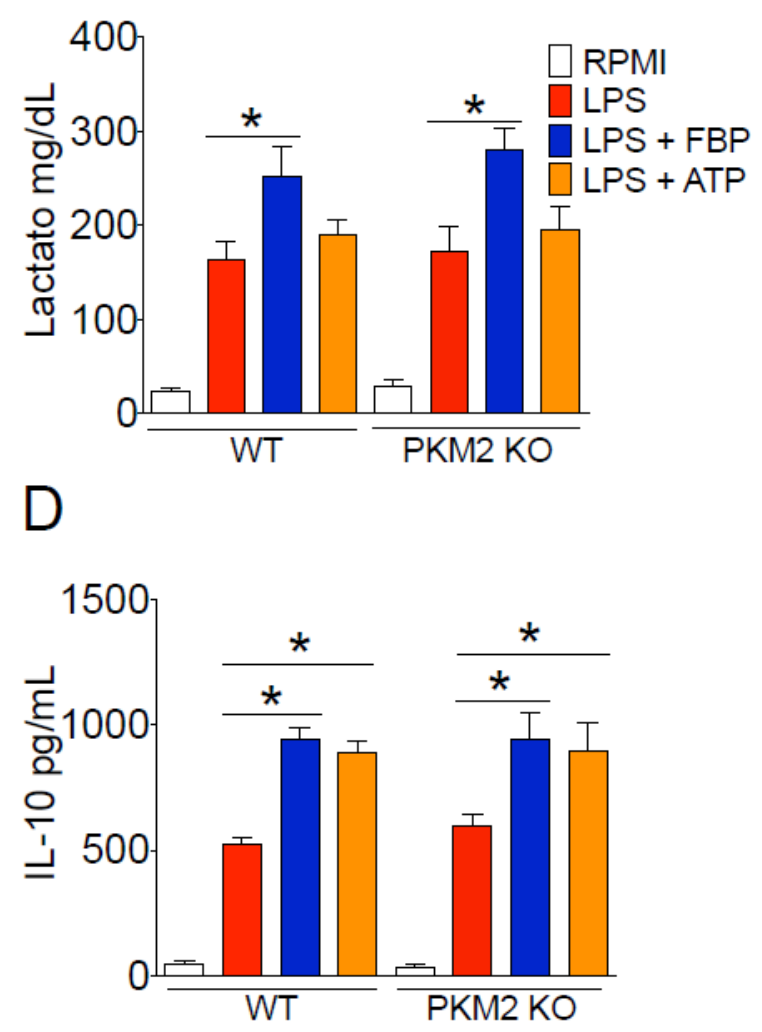

Figura 18: O aumento de IL-10 em macrófagos pela FBP não é dependente da PKM2. BMDM de animais WT ou deficientes para PKM2 (PKM2 KO) foram incubados por 6 horas na presença FBP $(300 \mu \mathrm{M})$ ou ATP $(100 \mu \mathrm{M})$ e então ativado com LPS $(100 \mathrm{ng} / \mathrm{ml})$ durante $24 \mathrm{~h}$ da IL-10. (A) Níveis de ATP extracelular por ensaio luminescente; (B) Níveis de lactato por ensaio colorimétrico; (C-D) Níveis das citocinas IL-6 (C) e IL-10 (D) por ensaio de ELISA. Os gráficos representam média \pm SEM, * $<<0,05$ indicam valores significativamente do diferentes do grupo LPS. 


\section{PARTE II}




\subsection{ATIVAÇÃO ALOSTÉRICA DA PKM2 AUMENTA A PRODUÇ̃̃O DE IL-10.}

A piruvato quinase catalisa a última etapa da glicólise, transferindo o fosfato de fosfoenolpiruvato (PEP) para o ADP e assim produzindo ATP e piruvato (Figura 19A). A maioria dos tecidos expressam a isoforma PKM1 ou PKM2, apesar de sequências primárias muito semelhantes, PKM1 e PKM2 têm diferentes propriedades catalíticas e regulatórias. PKM1 exibe alta atividade enzimática constitutiva, em contraste, PKM2 é menos ativa, mas pode ser ativada alostericamente (IKEDA; NOGUCHI, 1998).

Entre as classes de ativadores da o TEPP-46 é um mebros dos tieno [3,2-b] pirrol [3,2d] piridazinonas, e tem propriedades farmacocinéticas passíveis de experimentos em camundongos e células para avaliar as propriedades regulatórias da PKM2 que influenciam o metabolismo da glicose alterado a interação de proteínas e resposta inflamatória (ANASTASIOU et al., 2012).

Observamos em macrófagos onde a PKM2 foi ativada alostericamente com TEPP-46 $(100 \mu \mathrm{M})$ e então essas células estimuladas com LPS $(100 \mathrm{ng} / \mathrm{ml})$ por até 24 horas, que o tratamento com TEPP-46 não altera a expressão dos genes glicolíticos como PKM1 ou PKM2 (Figura 19 B e C), no entanto o estímulo com LPS é capaz de aumentar a expressão de PKM2 em 6 horas (Figura 19C). Apesar do TEPP-46 não alterar a expressão de enzimas da glicólise, foi capaz de aumentar a expressão e também a produção da citocina reguladora IL-10 (Figura $10 \mathrm{D}$ e $\mathrm{E})$. 


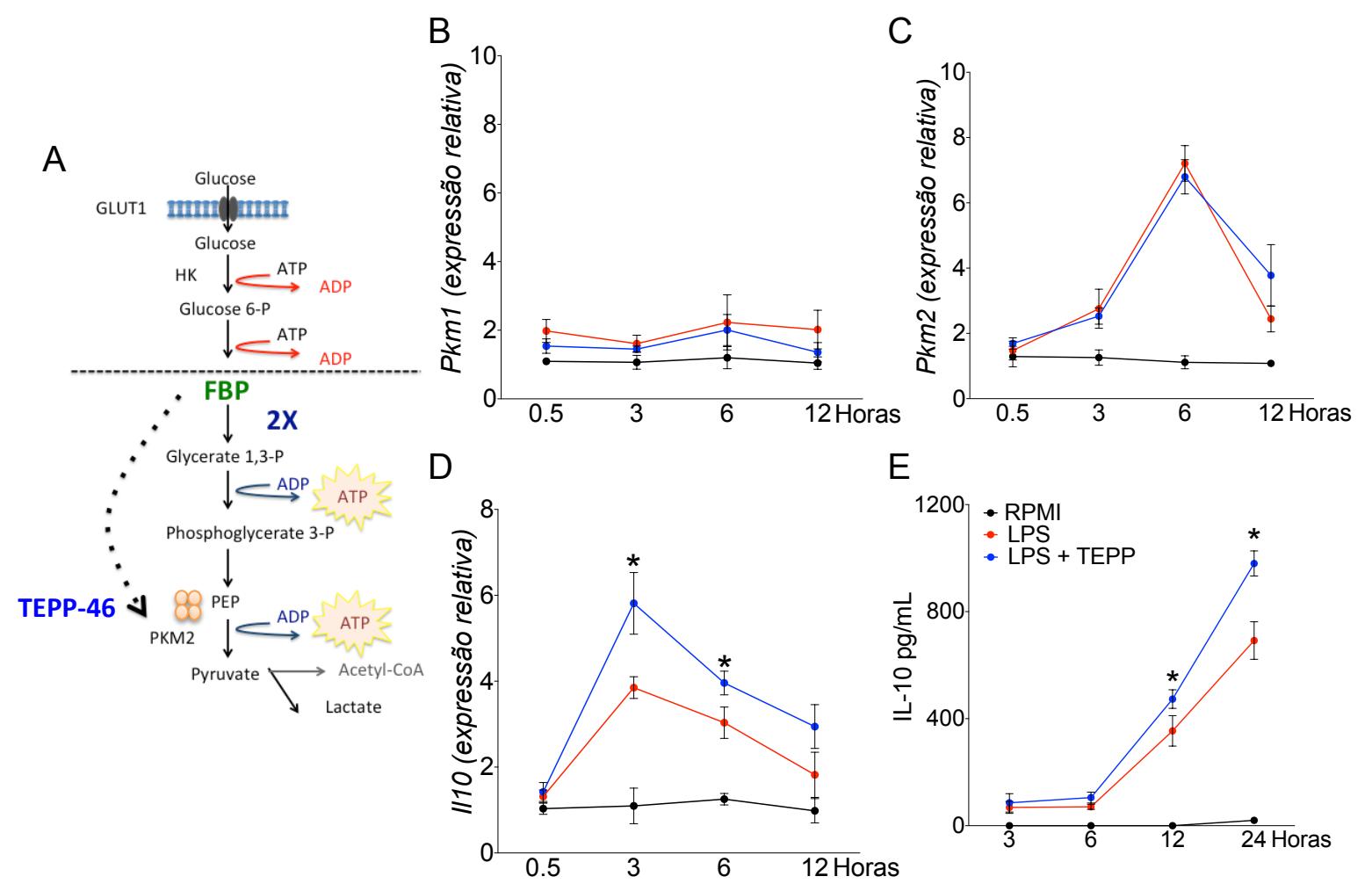

Figura 19: TEPP-46 aumenta a expressão e a produção de IL-10 em macrófagos ativados com LPS. BMDM foram incubados por 1 horas na presença de TEPP-46 $(100 \mu \mathrm{M})$, então ativados com LPS (100ng/ml) por $30 \mathrm{~min}, 3$, 6, 12 e 24 horas, (A) via glicolítica esquemática; (B-D) quantificamos a expressão relativa do gene da PKM1 (B), PKM2 (C) e da citocina IL-10 (D) por RT-PCR e normalizada por GADPH. (D) Quantificamos no sobrenadante da cultura celular a produção de IL-10 por ELISA. Os gráficos representam média $\pm \mathrm{SEM},{ }^{*} \mathrm{p}<0,05$ indicam valores significativamente do diferentes do grupo LPS. 


\subsection{TEPP-46 É CAPAZ DE ATIVAR ALOSTERICAMENTE A PKM2 EM} MACRÓFAGOS.

Análises de western-blot que revela todas as formas oligoméricas de PKM2 (Figura 20) demonstraram que a ativação com LPS aumentou a fosforilação da PKM2 em 3 e 6 horas de ativação, além disso, o tratamento com o TEPP-46 foi capaz de reduzir os níveis dessa fosforilação de PKM2 em macrófagos (Figura 20 A). Podemos observar também que o tratamento com o TEPP-46 fez com que a PKM2 se apresentasse na forma dimérica, enquanto que os macrófagos ativado com LPS a PKM2 se encontrou preferencialmente na forma tetramérica (Figura 20 B), sugerindo que o tratamento com o TEPP-46 é capaz de impedir a fosforilação da PKM2 e assim, essa enzima encontra-se na forma dimérica e passível de uma maior afinidade ao PEP.

No mesmo sentido, observamos por imunofluorescência que a ativação com LPS em macrófagos faz com que a PKM2 transloque para o núcleo (Figura 21A), se encontrando preferencialmente no núcleo celular. Por outro lado, o tratamento com TEPP-46 apresentou a presença da PKM2 no citoplasma (Figura 21B). Esse conjunto de resultados das figuras 20 e 21 indicam que o tratamento com TEPP-46 é capaz de ativar alostericamente a PKM2, fazendo com que essa enzima permaneça no citoplasma mesmo em células ativadas com LPS. 
A
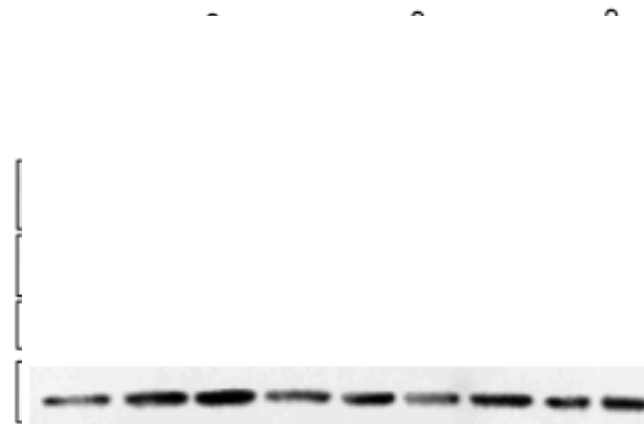

3

6
B

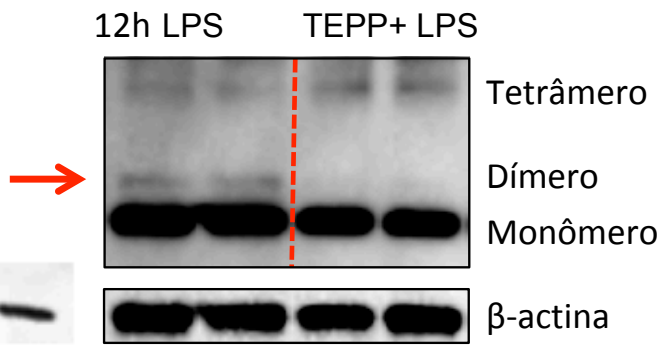

Figura 20:TEPP-46 reduz a fosforilação da PKM2 favorecendo a forma dimérica. BMDM foram incubados por 1 horas na presença TEPP-46 $(100 \mu \mathrm{M})$, então ativado com LPS $(100 \mathrm{ng} / \mathrm{ml})$ por 3, 6 e 12 horas, por Western Blot avaliarmos a expressão de pPKM2 e da PKM2. (A) Expressão de pPKM2, PKM2, PKM1 e B-actina como endógeno; (B) Expressão de dímeros, tetrâmeros e monômeros de PKM2. As imagens apresentam o representativo de três experimentos independentes. 


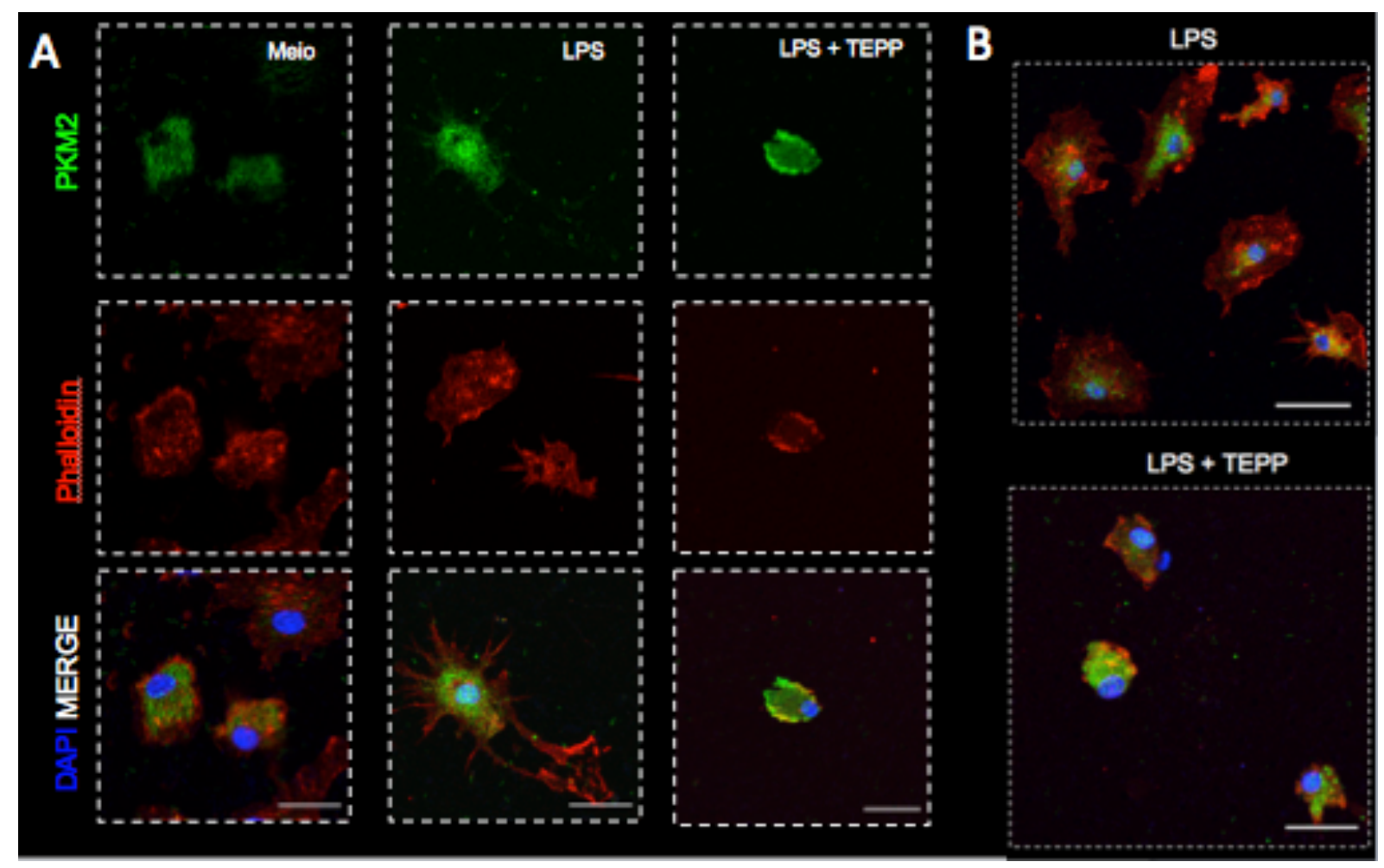

Figura 21: Expressão de PKM2 em macrófagos ativados com LPS e tratados com TEPP-46. BMDM foram incubados por 1 horas na presença TEPP-46 (100 $\mu \mathrm{M})$, então ativado com LPS (100ng/ml) por 12 horas, expressão para PKM2 (verde), Faloidina (vermelho) para o citoplasma e DAPI para núcleo celular (azul). (A) Expressão em células não ativadas (meio, coluna da esquerda), ativadas com LPS (LPS, coluna do meio) e células ativadas com LPS na presença de TEPP-46 (LPS + TEPP, coluna da direita) no aumento de 50x; (B) Expressão da PKM2 em células ativadas (cima) ou ativadas na presença de TEPP-46 (baixo) no aumento 100x. As imagens foram captadas utilizando o microscópio confocal Axio Observer acoplado ao sistema multifoton LSM 800 (Carl Zeiss Microscopy). Barra da escala representa $100 \mu \mathrm{m}$. 


\subsection{ATIVAÇÃO ALOSTÉRIA DA PKM2 PELO TEPP-46 AUMENTA O METABOLISMO}

\section{CELULAR.}

Visto que, o tratamento com TEPP-46 ativou a PKM2 alostericamente, avaliamos se esse tratamento era capaz de alterar os padrões metabólicos, pois a PKM2 na forma dimérica tem um aumento da afinidade ao PEP e assim poder aumentar a glicólise (PRAKASAM et al., 2018). Demonstramos que o TEPP-46 aumenta o consumo de glicose aumentando a produção de lactato macrófagos (Figura 22A). Corroborando com a nossa hipótese, que o tratamento com TEPP-46 aumenta o metabolismo glicolítico, observamos pelo experimento de seahorse que a presença do TEPP-46 é capaz de aumentar os níveis do ECAR em macrófagos ativados com LPS (Figura 22B).

Para comprovar se os efeitos da ativação alostérica da PKM2 pelo TEPP-46 era dependente da presença dessa enzima, avaliamos em macrófagos deficientes para PKM2 (PKM2 KO) os efeitos metabólicos promovidos pelo TEPP-46. Primeiramente vimos que, macrófagos PKM2 KO realmente não expressavam a enzima PKM2 sem ter grandes alterações em PKM1 (Figura 22C). Quando observamos os efeitos metabólicos, como o consumo de glicose e produção de lactato, podemos notar que os macrófagos PKM2 KO não demonstraram o aumento desses parâmetros (Figura 22D). Além disso, o TEPP-46 aumentou a atividade de piruvato quinase em macrófagos WT, enquanto os PKM2 KO apresentaram um resultado ao visto em células não ativadas (Figura 22E). 
A

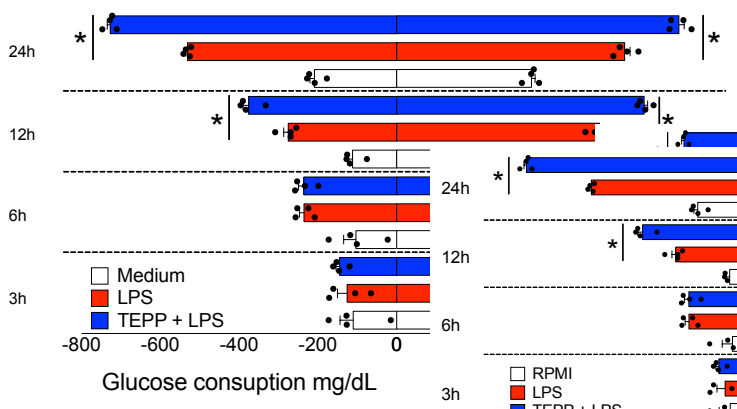

B

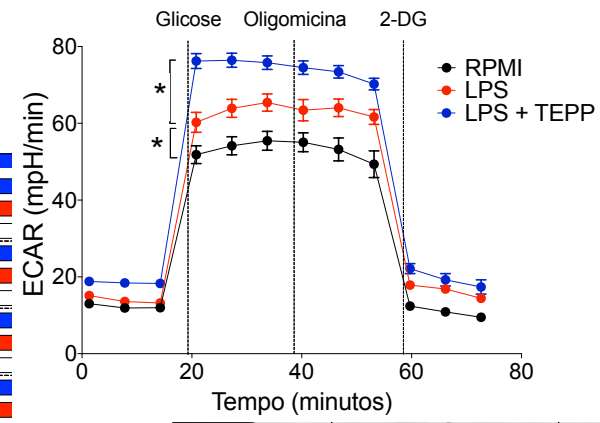

C

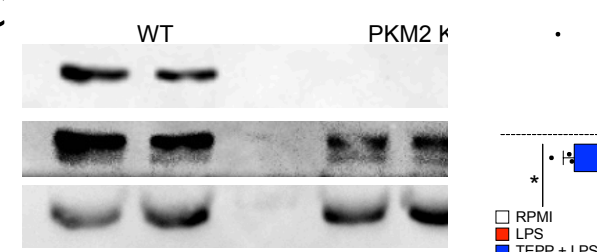

D

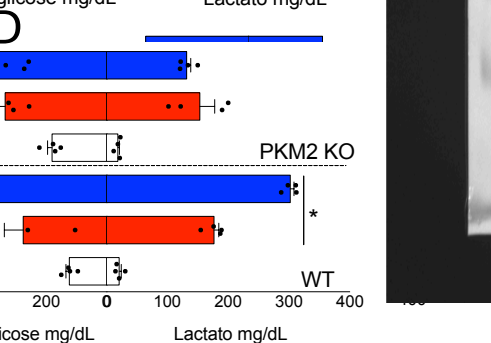

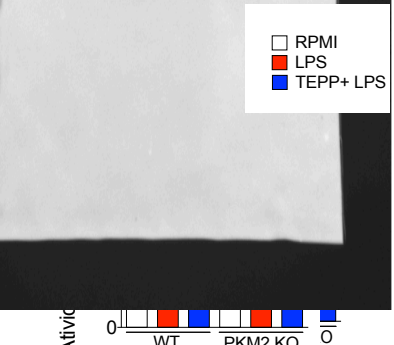

Figura 22: TEPP-46 aumenta o metabolismo glicolítico pela atividade da piruvato quinase. BMDM foram incubados por 1 horas na presença de TEPP-46 $(100 \mu \mathrm{M})$, então ativado com LPS (100ng/ml) por até 24 horas; (A) Quantificação do consumo de glicose (lado esquerdo do gráfico) vs a produção de lactado (lado direto do gráfico) em 3, 6, 12 e 24 horas de ativação com LPS por ensaio colorimátrico; (B) ECAR de BMDM ativados com LPS por 6h na presença de TEPP-46, (C) Western Blot para PKM1, PKM2 e $\beta$-actina em BMDM WT ou deficientes para PKM2 (PKM2 KO); (D) Quantificação do consumo de glicose (lado esquerdo do gráfico) vs a produção de lactado (lado direto do gráfico) em BMDM WT ou deficientes para PKM2 por ensaio colorimétrico; (E) Atividade da piruvato quinase em BMDM WT ou deficientes para PKM2 (PKM2 KO)por ensaio colorimétrico. Os gráficos representam média $\pm \mathrm{SEM},{ }^{*} \mathrm{p}<0,05$ indicam valores significativamente do diferentes do grupo LPS. 


\subsection{ATIVAÇÃO ALOSTÉRIA DA PKM2 PELO TEPP-46 AUMENTA A PRODUÇÃO DE ATP E IL-10 DEPENDENTE DA GLICÓSE.}

Sabemos que uma das consequências do metabolismo glicolítico é a produção de ATP, por isso avaliamos se o tratamento com o TEPP-46 em macrófagos era capaz de alterar os níveis de ATP. Observamos que a presença do TEPP-46 aumentou os níveis de ATP intracelular (Figura 23A), ATP liberado para o meio extracelular (Figura 23B), e assim como observado nos experimentos com a FBP, o TEPP-46 também aumentou a produção de IL-10 (Figura 23C).

Em contrapartida, o tratamento com TEPP-46 em macrófagos deficientes para PKM2, demonstrou resultado semelhante ao do grupo LPS, onde não observamos aumento nos níveis de ATP intracelular, extracelular ou na produção da citocina IL-10 (Figura 24 A-C), indicando que esses efeitos foram dependentes da ativação alostérica da PKM2.

Nesse sentido, observando uma importância da via glicolítica nos efeitos promovidos pelo TEPP-46 em macrófagos, avaliamos se concentrações distintas de glicólise alterava a resposta observada com TEPP-46. Podemos notar que, a redução da concentração de glicose para $3 \mathrm{mM}$ ou $1 \mathrm{mM}$ de aboliram os efeitos que o TEPP-46 gerava em aumentar as produções de lactato, ATP intra e extracelular e IL-10 (Figura 25 A-D). Em contraste, macrófagos deficientes para PKM2, mesmo na presença de níveis elevados de glicose (30mM) o TEPP-46 continuou não apresentando aumento na produção de lactato (Figura 26A) ou nos níveis de IL-10 (Figura 26B). 
A

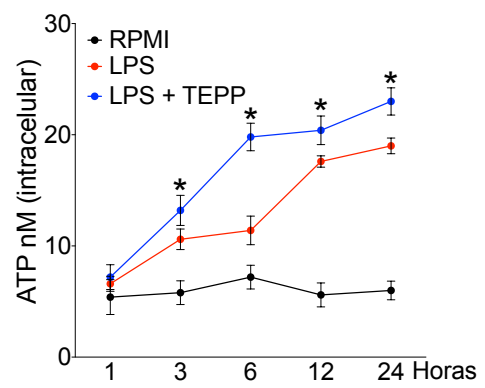

B

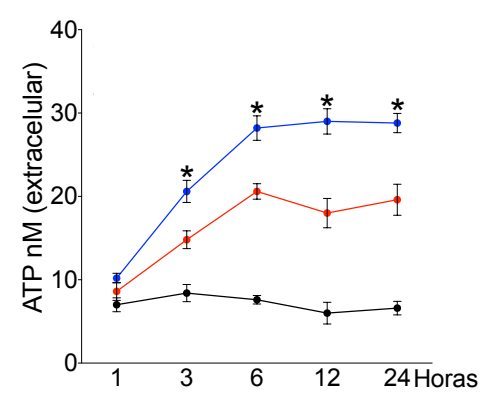

C

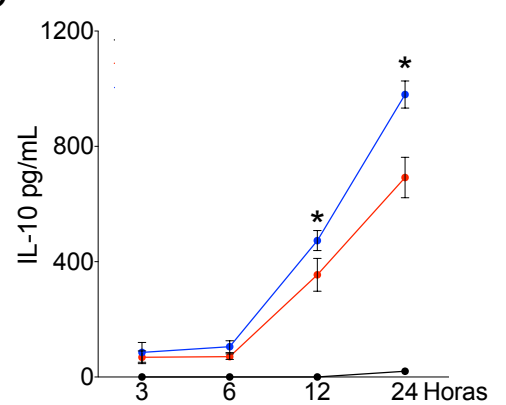

Figura 23: TEPP-46 aumenta a produção de ATP em macrófagos ativados de forma semelhante ao aumento de IL-10. BMDM foram incubados na presença de TEPP-46 $(100 \mu \mathrm{M})$ por $1 \mathrm{~h}$ e então estimulados com LPS $(100 \mathrm{ng} / \mathrm{ml})$ por até $24 \mathrm{~h}$ e então quantificado os níveis de ATP por ensaio luminescente. (A) Quantificação dos níveis de ATP no meio intracelular em BMDM tratados com

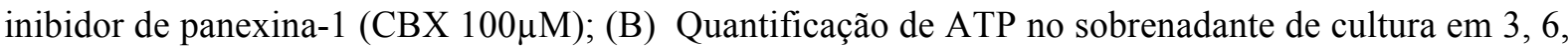

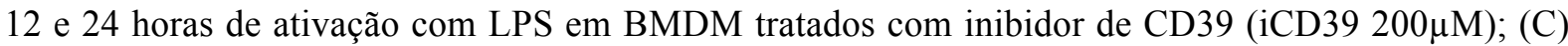
Quantificação dos níveis de IL-10 no sobrenadante de cultura celular por ensaio de ELISA. Os gráficos representam média $\pm \mathrm{SEM},{ }^{*} \mathrm{p}<0,05$ indicam valores significativamente diferentes do grupo LPS. 

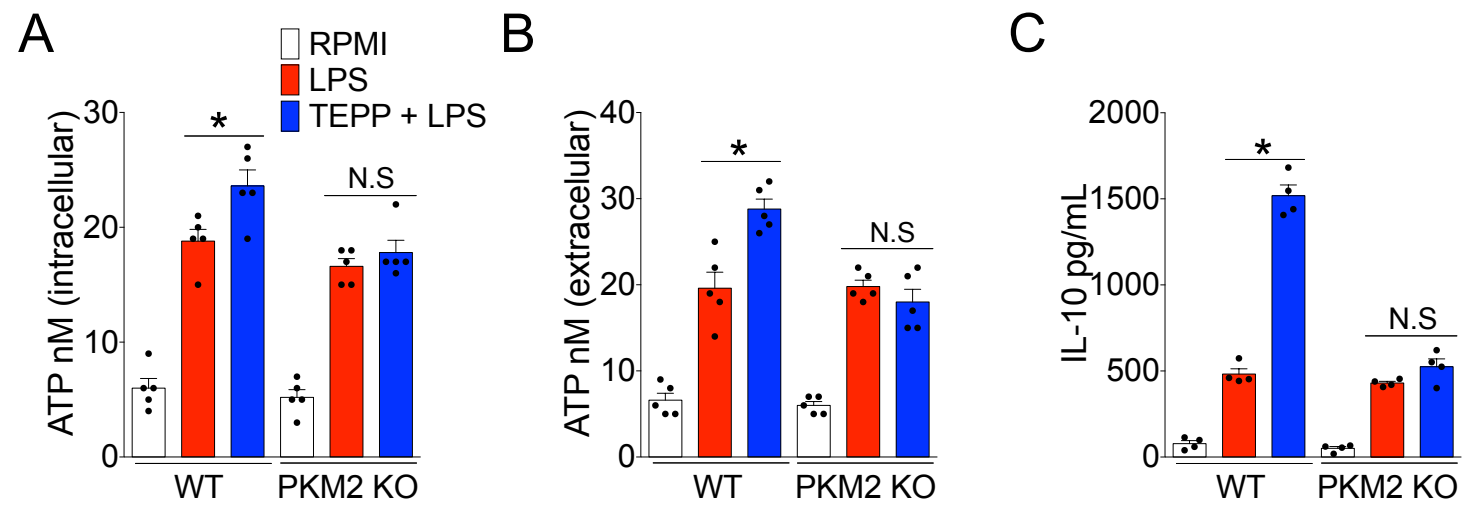

Figura 24: TEPP-46 aumenta a produção de ATP em macrófagos ativados de forma dependente da PKM2. BMDM WT ou deficientes para PKM2 (PKM2 KO) foram incubados na presença de TEPP-46 $(100 \mu \mathrm{M})$ por $1 \mathrm{~h}$ e então estimulados com LPS $(100 \mathrm{ng} / \mathrm{ml})$ por $24 \mathrm{~h}$ e então quantificado os níveis de ATP por ensaio luminescente. (A) Quantificação dos níveis de ATP no meio intracelular em

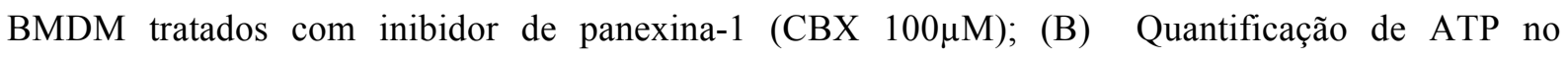

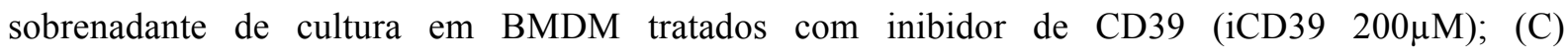
Quantificação dos níveis de IL-10 no sobrenadante de cultura celular por ensaio de ELISA. Os gráficos representam média $\pm \mathrm{SEM},{ }^{*} \mathrm{p}<0,05$ indicam valores significativamente diferentes do grupo LPS. 

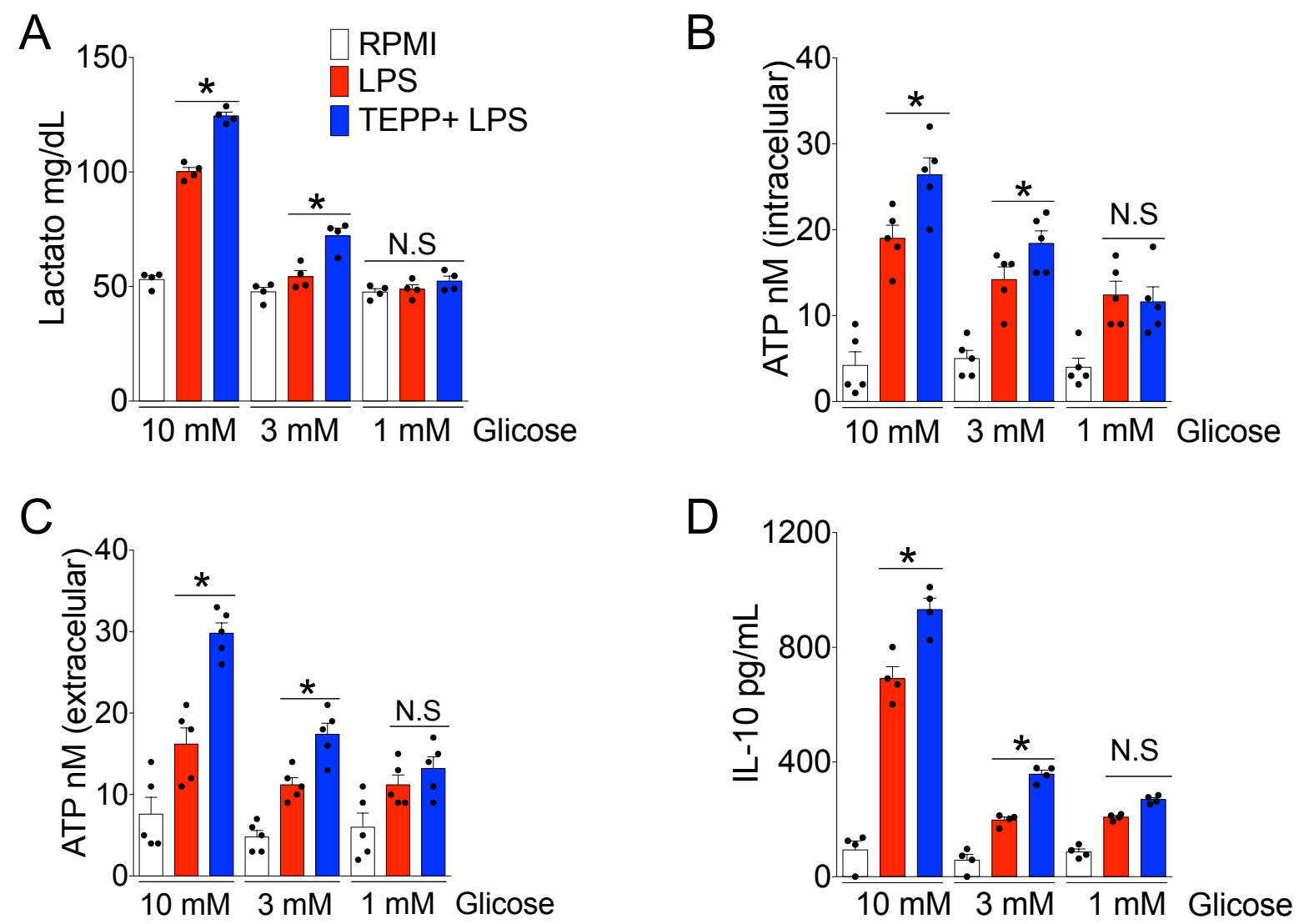

Figura 25: TEPP-46 aumenta os níveis de lactato, ATP e IL-10 dependente da disponibilidade de glicose. BMDM foram incubados com TEPP-46 $(100 \mu \mathrm{M})$ por $1 \mathrm{~h}$ e então estimulados com LPS (100ng/ml) por $24 \mathrm{~h}$ em meio RPMI com $10 \mathrm{mM}, 3 \mathrm{mM}$ ou $1 \mathrm{mM}$ de glicose. (A) Quantificação de lactato no sobrenadante de cultura por ensaio colorimétrico; (B) Quantificação de ATP intracelular na presença de CBX $(100 \mu \mathrm{M})$; (C) Quantificação de ATP extracelular na presença do inibidor de CD39 $(200 \mu \mathrm{M})$; (D) Quantificação de IL-10 em sobrenadante celular por ensaio de ELISA. Os gráficos representam média $\pm \mathrm{SEM},{ }^{*} \mathrm{p}<0,05$ indicam valores significativamente diferentes do grupo LPS. 
A

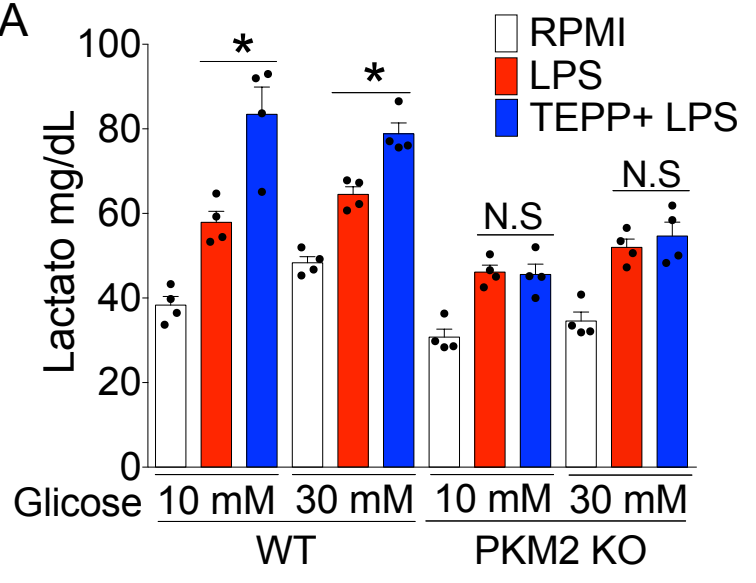

$\mathrm{B}$

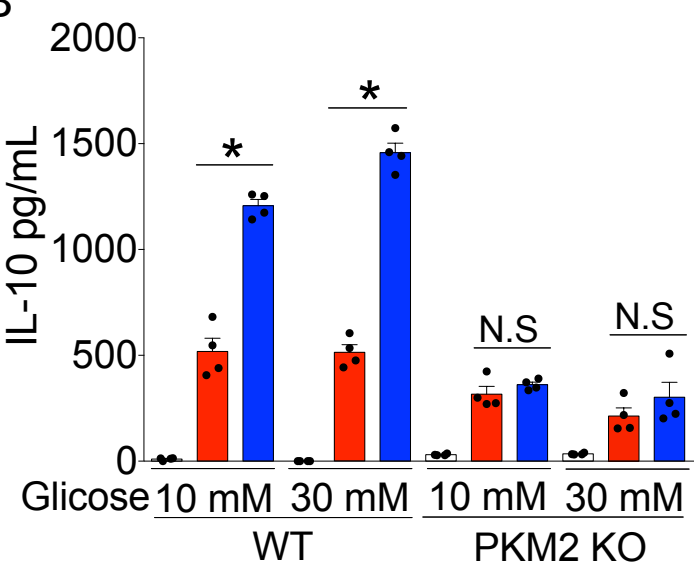

Figura 26: TEPP-46 aumenta os níveis de lactato e IL-10 dependente da PKM2. BMDM WT ou deficientes para PKM2 (PKM2 K) foram incubados com TEPP-46 $(100 \mu \mathrm{M})$ por 1h e então estimulados com LPS (100ng/ml) por $24 \mathrm{~h}$ em meio RPMI com $10 \mathrm{mM}$ ou $30 \mathrm{mM}$ de glicose. (A) Quantificação de lactato no sobrenadante de cultura por ensaio colorimétrico; (D) Quantificação de IL-10 em sobrenadante celular por ensaio de ELISA. Os gráficos representam média $\pm \mathrm{SEM},{ }^{*} \mathrm{p}<0,05$ indicam valores significativamente diferentes do grupo LPS. 
A galactose é um monossacarídeo que pode ser convertida em glicose-1-fosfato e participar da glicólise, no entanto nesse processo ocorre o consumo de duas moléculas de ATP, ou seja, a produção energética da galactose para geração de piruvato via metabolismo glicolítico não rende ATP líquido. Isso força as células a terem uma maior dependência da fosforilação oxidativa (OXPHOS) para obter energia (MICHALEK et al., 2011).

Sabendo disso, avaliamos se o aumento da produção de ATP pelo TEPP-46 ocorria pela via glicolítica ou de forma dependente da mitocôndria. Para isso, verificamos a produção de lactato, ATP e IL-10 em macrófagos ativados com LPS na presença de TEPP-46 em meio RPMI contendo $10 \mathrm{mM}$ de glicose, $10 \mathrm{mM}$ de galactose ou $10 \mathrm{mM}$ de glicose e galactose (Figura 27). Podemos observar que o tratamento com TEPP-46 aumenta a produção de lactato, ATP e IL-10 em meio RPMI contendo glicose, no entanto, em meio de cultura RPMI onde o monossacarídeo presente foi $10 \mathrm{mM}$ de galactose, o TEPP-46 não foi capaz de aumentar o metabolismo celular nem a produção da citocina IL-10 (Figura 27). Por outro lado, esse resultado não ocorreu pela presença de galactose no meio e sim pela falta de disponibilidade de glicose, pois RPMI com $10 \mathrm{mM}$ de galactose e $10 \mathrm{mM}$ de glicose o tratamento com o TEPP-46 aumentou as produções de lactato, ATP e IL-10 (Figura 27 A-C).

Nesse sentido, verificamos em macrófagos deficientes para PKM2 um resultado interessante, assim como os macrófagos WT a substituição da glicose pela galactose no meio de cultura o TEPP-46 não aumentou a produção de lactato, ATP ou IL-10, porém, na presença de $10 \mathrm{mM}$ de galactose e $10 \mathrm{mM}$ de glicose a produção desses paramentos permaneceram baixas, ao contrário do observado nos macrófagos WT (Figura 28 A-C). 
A

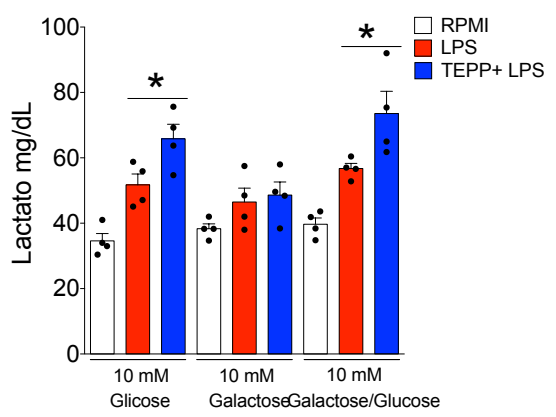

B

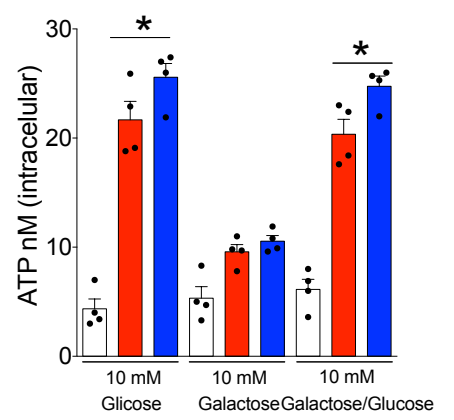

C

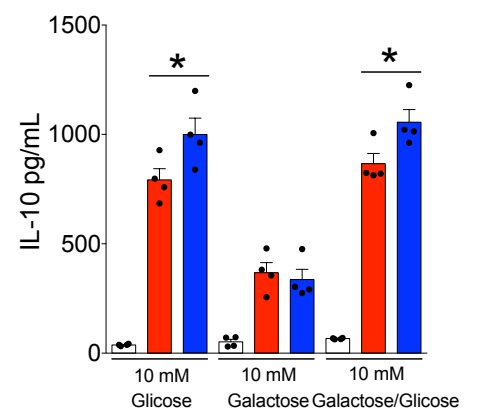

Figura 27: Aumento de IL-10 pelo TEPP-46 em macrófagos ativados é dependente do metabolismo glicolítico. BMDM foram incubados com TEPP-46 $(100 \mu \mathrm{M})$ por 1h e então estimulados com LPS (100ng/ml) por $24 \mathrm{~h}$ em meio RPMI com $10 \mathrm{mM}$ de glicose, $10 \mathrm{mM}$ de galactose os dois açúcares. (A) Quantificação de lactato no sobrenadante de cultura por ensaio colorimétrico; (B) Quantificação de ATP intracelular na presença de CBX $(50 \mu \mathrm{M})$; (C) Quantificação de IL-10 em sobrenadante celular por ensaio de ELISA. Os gráficos representam média $\pm \mathrm{SEM},{ }^{*} \mathrm{p}<0,05$ indicam valores significativamente diferentes do grupo LPS. 

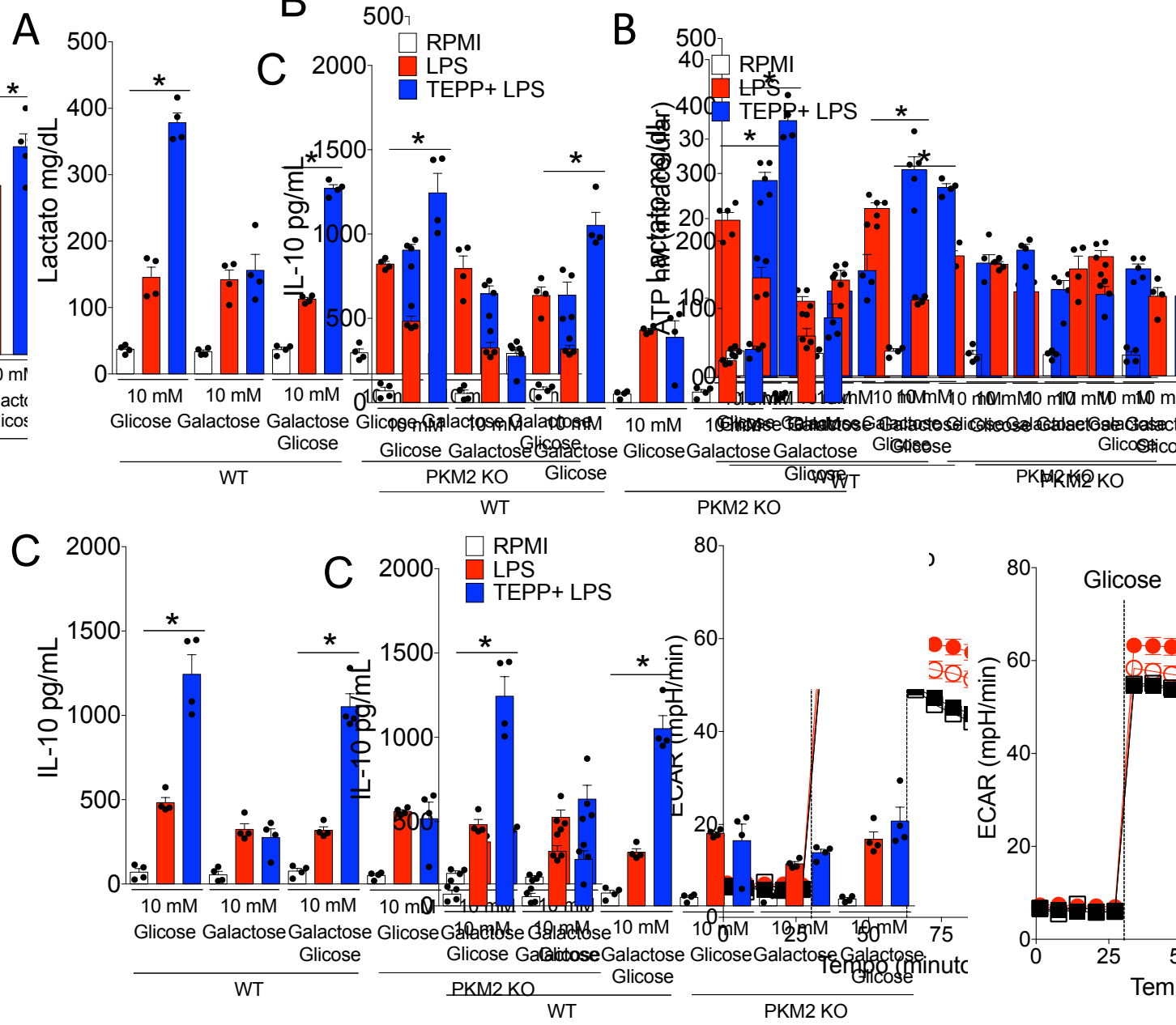

Figura 28: Aumento de IL-10 pelo TEPP-46 em macrófagos ativados é dependente do metabolismo glicolítico e da presença da PKM2. BMDM de animais WT ou deficientes para PKM2 (PKM2 KO) foram incubados com TEPP-46 $(100 \mu \mathrm{M})$ por $1 \mathrm{~h}$ e então estimulados com LPS (100ng/ml) por $24 \mathrm{~h}$ em meio RPMI com $10 \mathrm{mM}$ de glicose, $10 \mathrm{mM}$ de galactose os dois açúcares. (A) Quantificação de lactato no sobrenadante de cultura por ensaio colorimétrico; (B) Quantificação de ATP intracelular na presença de CBX $(50 \mu \mathrm{M})$; (C) Quantificação de IL-10 em sobrenadante celular por ensaio de ELISA; (D) Níveis ECAR durante a estimulação com LPS por 6h pelo ensaio de Seahorse. Os gráficos representam média $\pm \mathrm{SEM},{ }^{*} \mathrm{p}<0,05$ indicam valores significativamente diferentes do grupo LPS. 


\subsection{TEPP-46 AUMENTA A PRODUÇÃO DE IL-10 DEPENDENTE DA VIA} ADENOSINÉRGICA.

Um dos destinos mais comuns do ATP no meio extra celular é sofrer ação das ectonucleotidases, principalmente a CD39 e CD73 para geração de ADO (FENG et al., 2020). Nesse sentido, assim como nos experimentos com a FBP avaliamos os efeitos do TEPP-46 na via adenosinérgica (Figura 29A).

Observamos que o TEPP-46 aumentou a produção de ATP intra e extracelular, onde em celulas tratadas com inibidor de panexina-1 (CBX) ou deficientes para o canal de panexina-1 (PAN KO), temos um acúmulo de ATP intracelular e essa molécula não foi encontrada no meio extra celular (Figura 29B). No entanto, a inibição ou ausência desse canal não alterou a resposta do TEPP-46 em aumentar a produção de lactato (Figura 29C). Em contrapartida, o aumento na produção de IL-10 promovido pelo TEPP-46 é dependente da saída do ATP para o meio extracelular, pois na presença de CBX ou PAN KO o TEPP-46 não aumetou os níveis de IL-10 (Figura 29C). 
A

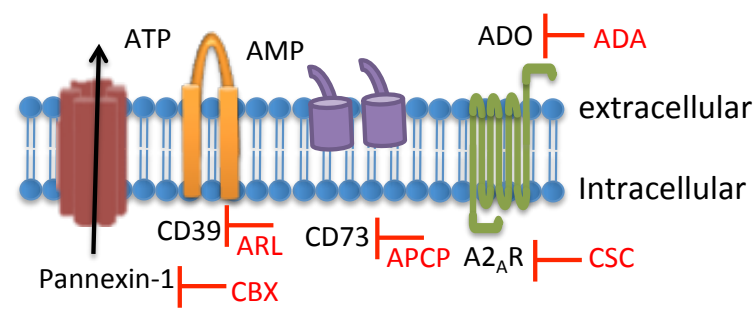

B
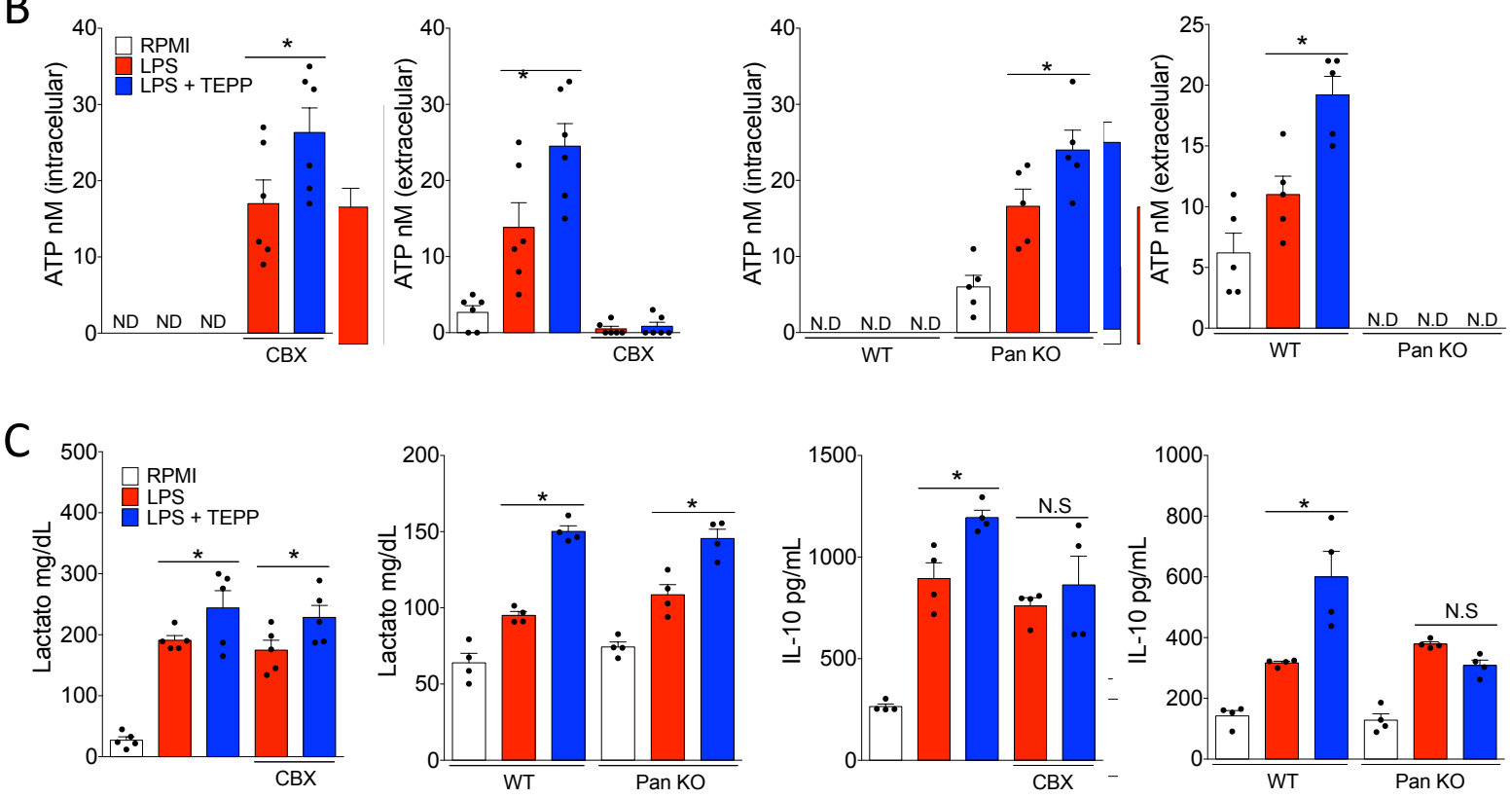

Figura 29: TEPP-46 aumenta de IL-10 em macrófagos de forma dependente da produção de ATP. BMDM foram incubados por 1 hora na presença de TEPP-46 $(100 \mu \mathrm{M})$ e então ativado com LPS (100ng/ml) durante 24h. (A) Desenho esquemático da via adenosinérgica com a estratégia de inibição. (B) Quantificação de ATP intracelular e ATP extracelular no sobrenadante celular por ensaio luminescente em BMDM tratados com inibidor do canal de panexina-1 CBX $(100 \mu \mathrm{M})$ para ATP

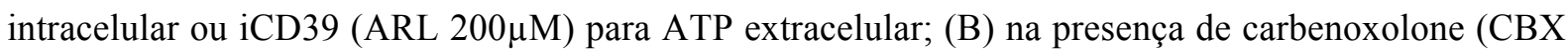
$50 \mu \mathrm{M}$ ); (D) WT v.s. Pan KO; (C) Quantificação dos níveis de lactato por ensaio colorimétrico e quantificação dos níveis de IL-10 no sobrenadante da cultura por ELISA. Os gráficos representam média $\pm \mathrm{SEM},{ }^{*} \mathrm{p}<0,05$ indicam valores significativamente do diferentes do grupo LPS. 
Assim como visto com os experimentos da FBP, verificamos os níveis de ADO em macrófagos ativados com LPS em macrófagos na presença de TEPP-46, utilizamos novamente cromatografia por (UPLC) e demonstramos que o TEPP-46 aumentou os níveis de ADO (Figura 30A). Esse aumento de ADO corroborou com os observados da FBP pois o TEP-46 aumentou os níveis de ADO maneira dependente da via adenosinérgica, visto que a inibição CD39 bloqueou a produção de ADO (Figura 30B).

Apesar da evidente importância da CD39 nos efeitos promovidos pelo TEPP-46, a ativação alostérica da PKM2 pelo TEPP-46 não alterou a expressão das ectonucelotidases CD39 ou CD73 (Figura 31A). Porém, a inibição da CD39 com ARL ou animais deficientes pra CD39 (CD39 KO) reduziu a resposta do TEPP-46 em aumentar a IL-10, resultado também observado com a inibição da CD73 (Figura 31B), indicando uma participação fundamental das ectonucleotidases em aumentar a produção de IL-10 pela ADO. 

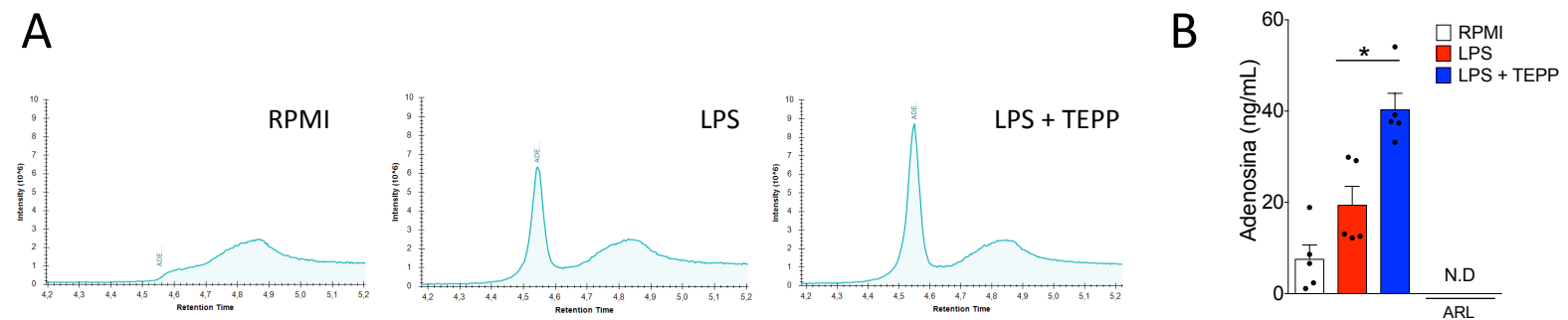

Figura 30: TEPP-46 aumenta os níveis de adenosina. BMDM foram incubados por 6 horas na presença do TEPP-46 $(100 \mu \mathrm{M})$ então ativados com LPS $(100 \mathrm{ng} / \mathrm{ml})$ por 3h. (A) Quantificação de adenosina pelo sistema UPLC-MS, Cromatograma representativo de adenosina em sobrenadante de cultura de BMDM. (B) Concentração de adenosina detectada por UPCL-MS no sobrenadante de

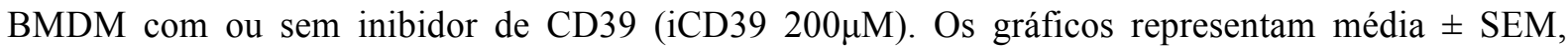
$* \mathrm{p}<0,05$ indicam valores significativamente do diferentes do grupo LPS. 
A

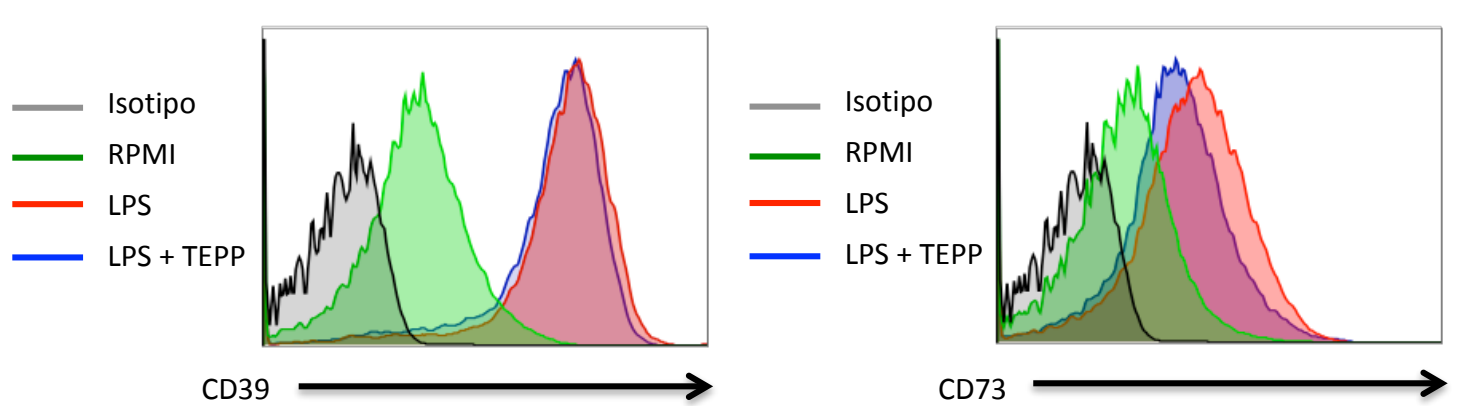

B
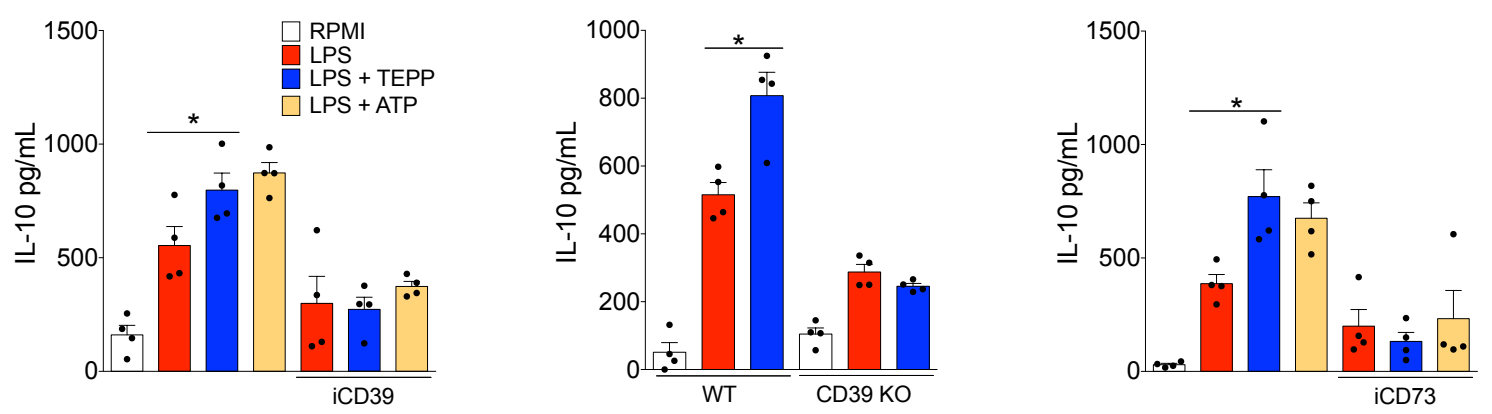

Figura 31: O aumento de IL-10 em macrófagos pelo TEPP-46 depende da ação de CD39 e CD73.

BMDM foram incubados por 1 hora na presença de TEPP-46 $(100 \mu \mathrm{M})$ e então ativados com LPS (100ng/ml) durante 24h. (A) Expressão de CD39 (esquerda) e CD73 (direita) em células não marcadas (cinzas), não ativadas (RMPI, verdes) ou ativadas com LPS (vermelhas) ou na presença de TEPP-46 (azul) por citometria de fluxo; (B) Concentração de IL-10 no sobrenadante da cultura celular

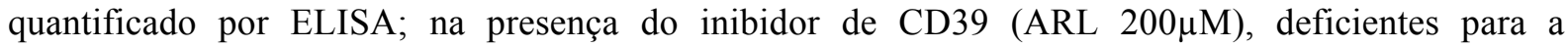

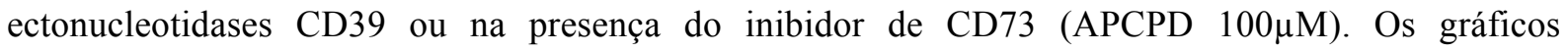
representam média $\pm \mathrm{SEM},{ }^{*} \mathrm{p}<0,05$ indicam valores significativamente do diferentes do grupo LPS. 
Avaliamos também por qual receptor a ADO estaria sinalizando para gerar o aumento de IL-10 promovido pelo tratamento com TEPP-46. A ADO pode sinalizar por distintos receptores, por isso, utilizamos diversos antagonistas para adenosina, tais como, A1R (DPCPX), A2AR (CSC), A2BR (MRS1754) e A3R (MRS1334).

Podemos notar que o aumento de IL-10 promovido pelo TEPP-46 em macrófagos ocorre de forma dependente das sinalizações de ADO nos receptores Gs (Figura 32). Os antagonistas para os receptores $\mathrm{A} 2_{\mathrm{A}}$ e $\mathrm{A} 2_{\mathrm{B}}$ reduziram a produção de IL-10 promovidas pelo TEPP-46, enquanto os antagonistas para os receptores A1 e A3 não alteram esse parâmetro (Figura 32A).

Além disso, confirmamos a importância da ADO e a sinalização dela pelo receptor $\mathrm{A} 2{ }_{\mathrm{A}}$ na produção de IL-10 induzida por TEPP-46 na figura 32B, utilizando adenosina deaminase $(\mathrm{ADA})$ e $\mathrm{BMDM}$ provenientes de animais deficientes para o receptor $\mathrm{A} 2_{\mathrm{A}}$, onde à produção de IL-10 na presença de ADO ou em BMDMs de animais deficientes para o receptor $\mathrm{A} 2_{\mathrm{A}}\left(\mathrm{A} 2_{\mathrm{A}} \mathrm{KO}\right)$ foi drasticamente reduzida quando comparada a de macrófagos sem ADA ou originados de animais WT (Figura 32B). 


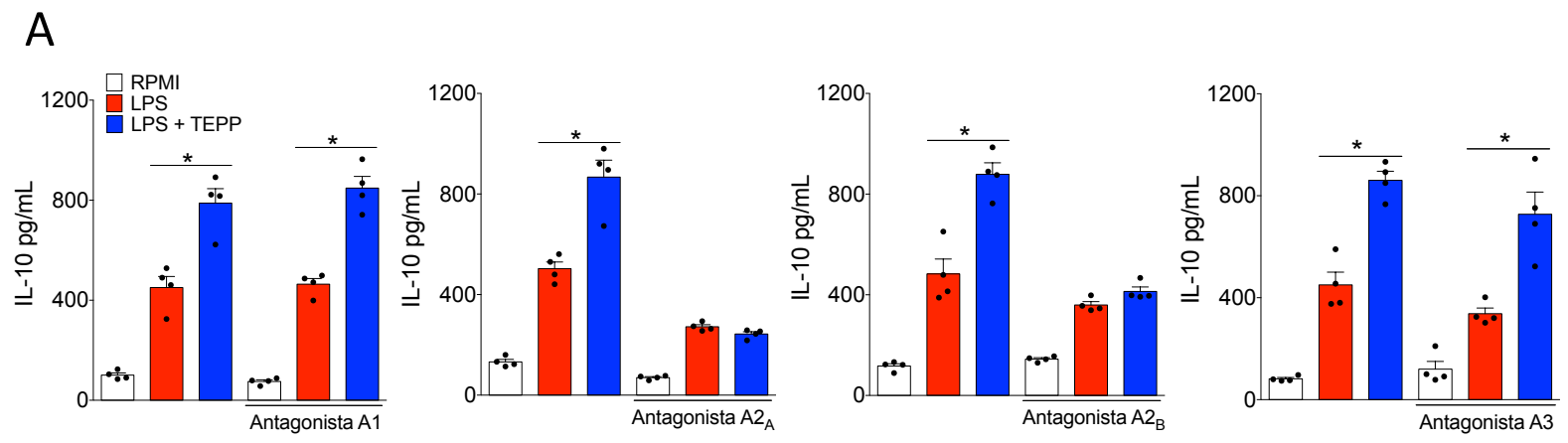

B
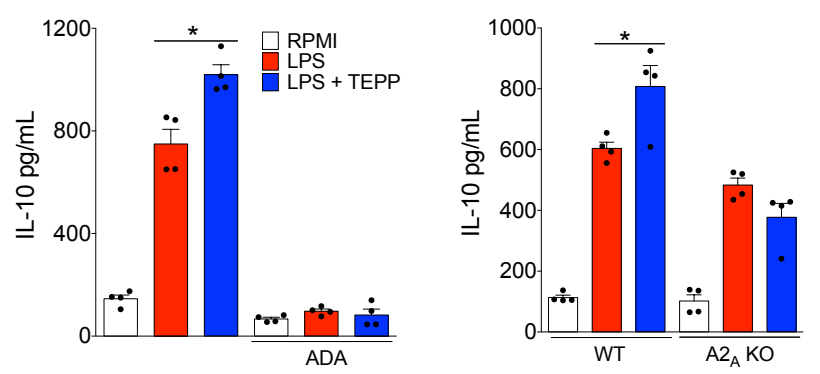

Figura 32: O aumento de IL-10 em macrófagos pelo TEPP-46 ocorre pela via adenosinérgica.

BMDM foram incubados por 1 hora na presença de TEPP-46 $(100 \mu \mathrm{M})$ e então ativados com LPS $(100 \mathrm{ng} / \mathrm{ml})$ durante $24 \mathrm{~h}$. (A e B) Concentração de IL-10 no sobrenadante da cultura celular quantificado por ELISA; (A) na presença de antagonistas dos receptores de adenosina A1 dipropilciclopentilxantina (DPCPX, $10 \mu \mathrm{M}), \mathrm{A} 2_{\mathrm{A}} 8$-(3-chlorostyryl) caffeine $(\mathrm{CSC}, 100 \mu \mathrm{M}), \mathrm{A} 2_{\mathrm{B}}$ $(\mathrm{MRS1754}, 10 \mu \mathrm{M})$ e A3 (MRS1334, 10 $\mu \mathrm{M})$ respectivamente; (B) na presença de adenosina deaminase (ADA $1 \mathrm{U} / \mathrm{ml}$ ), BMDM deficientes para o receptor de adenosina $A 2_{\mathrm{A}}\left(\mathrm{A} 2_{\mathrm{A}} \mathrm{KO}\right)$. Os gráficos representam média $\pm \mathrm{SEM},{ }^{*} \mathrm{p}<0,05$ indicam valores significativamente do diferentes do grupo LPS. 
4.12 O TRATAMENTO COM TEPP-46 AUMENTA A PRODUÇÃO DE IL-10 EM MODELO DE ENDOTOXIMIA.

Confirmamos efeito anti-inflamatório do TEPP-46, por um modelo de endotoxemia semelhante ao utilizado por (PALSSON-MCDERMOTT et al., 2015a). Para isso, utilizamos camundongos WT $\left(\mathrm{A} 22_{\mathrm{A}}^{\mathrm{f} / \mathrm{f}} \mathrm{Lysm}^{-/}\right)$ou deficientes para o receptor de $\mathrm{A} 2{ }_{\mathrm{A}}$ apenas nas células mieloides $\left(\mathrm{A} 2 \mathrm{~A}^{\mathrm{f} / \mathrm{f}}\right.$ Lysm $\left.^{\mathrm{Cre} /+}\right)$ ambos com background C57/BL6. Esses animais foram tratados previamente por via i.p com TEPP-46 (100mg/kg) 1 hora antes da injeção de LPS $(25 \mathrm{mg} / \mathrm{kg})$ na cavidade peritoneal. Após 6 horas da injeção com LPS, coletamos o soro, o pulmão e o lavado para dosagem de ADO e IL-10 e IL-6 (Figura 33A).

Observamos que camundongos tratados previamente com TEPP-46 quando submetidos à endotoxemia apresentaram um aumento dos níveis de ADO no soro avaliados por UPLC (Figura 33B), além disso, as concentrações de IL-10 estavam aumentadas enquanto a IL-6 se apresentava reduzida em animais tratados com TEPP-46 no pulmão, bem como no lavado peritoneal e soro (Figura 16C e D). De forma interessante, camundongos deficientes para o receptor de $\mathrm{A} 2{ }_{\mathrm{A}}$ apenas nas células mieloides, não apresentaram níveis de IL-10, e o tratamento com o TEPP-46 não alterou os níveis de IL-6 quando comparados com os não tratados. Esses resultados nos indicam que o tratamento com o TEPP-46 pode ter efeito antiinflamatório em uma doença aguda de forma dependente de adenosina. 
A

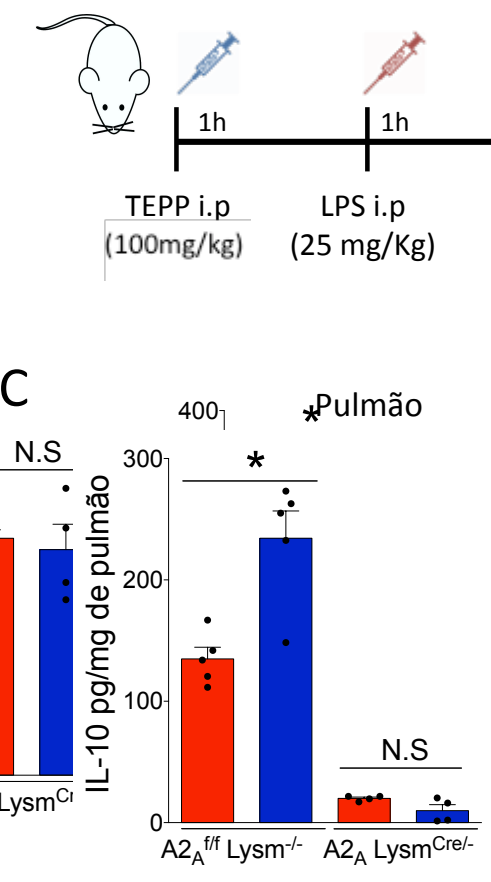

D

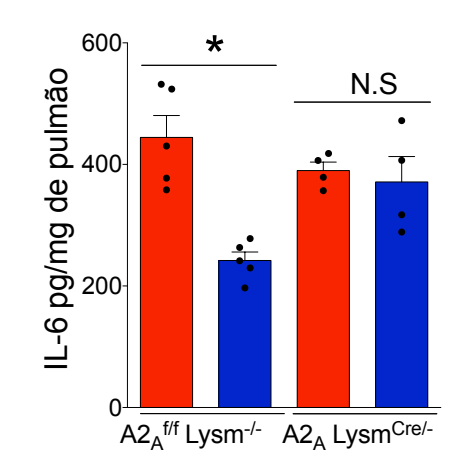

B
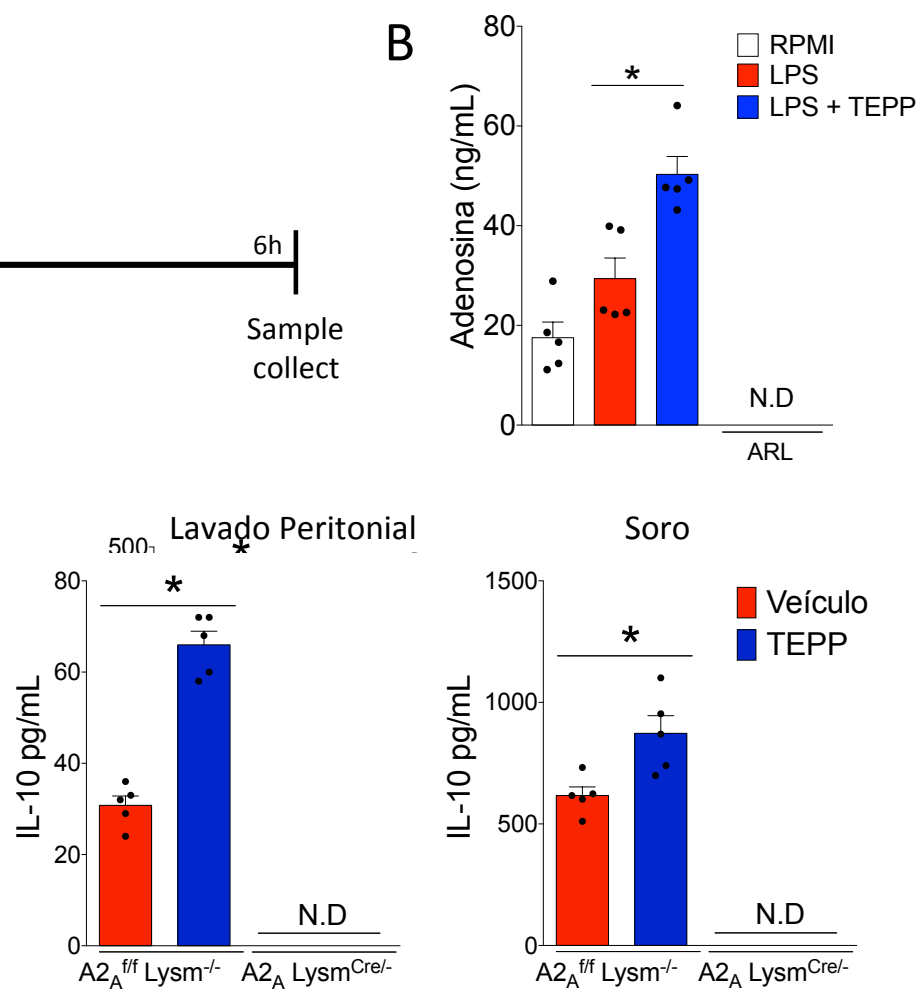

Lavado Peritonial

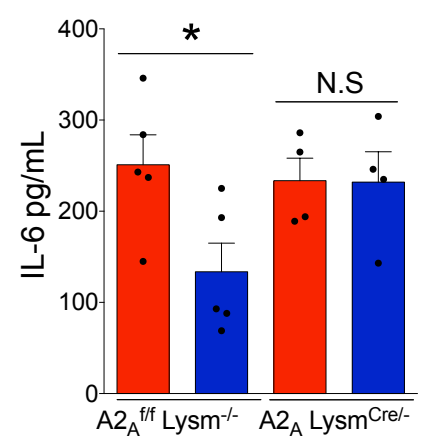

Soro

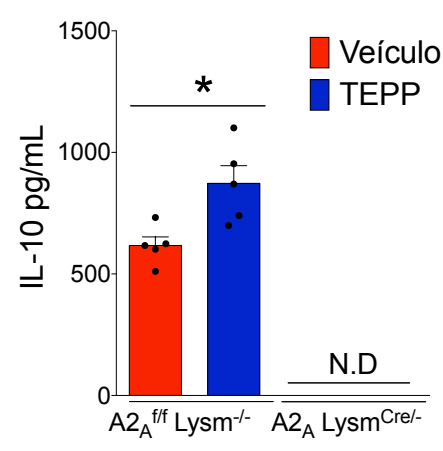

Soro

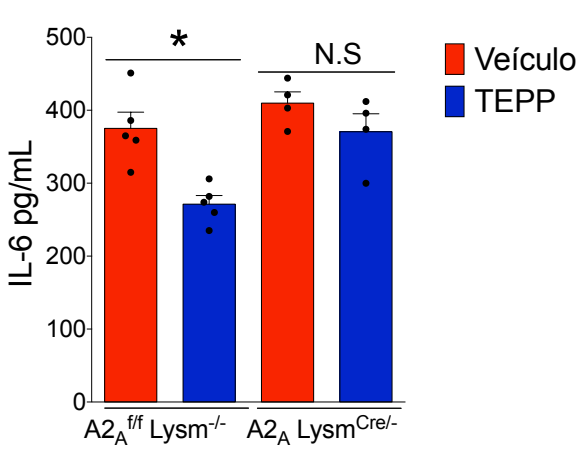

Figura 33: Tratamento com TEPP-46 aumenta os níveis de IL-10 em camundongos com peritonite. Camundongos WT $\left(\mathrm{A} 2_{\mathrm{A}} \mathrm{Lysm}^{-/-}\right)$ou deficientes para o receptor de adenosina $\mathrm{A} 2_{\mathrm{A}}$ nos macrófagos $\left(\mathrm{A} 2 \mathrm{~A}_{\mathrm{A}} \mathrm{Lysm}^{\mathrm{Cre} /}\right)$, foram tratados com TEPP-46 $(100 \mathrm{mg} / \mathrm{kg})$ após um período de $1 \mathrm{~h}$, induzimos endotoxemia por LPS (25mg/kg) i.p. por 6h. (A) Desenho experimental; (B) Quantificação dos níveis de adenosina no soro dos animais por cromatografia (UPCL-MS); (C e D) Quantificação por ELISA das citocinas (C) IL-10 e (D) IL-6 no pulmão, lavador peritoneal e soro respectivamente. Todos os dados significam \pm SEM $(p *<0,05)$. Representante de três experimentos independentes. 


\section{DISCUSSÃO}




\section{DISCUSSÃO}

A resposta inflamatória necessita de uma alta demanda energética, de forma interessante, intermediários glicolíticos como a FBP ou ativação alostérica da PKM2 pelo TEPP-46, tem se demonstrando como agentes terapêuticos promissores em doenças inflamatórias (GABER; STREHL; BUTTGEREIT, 2017). Porém os mecanismo de ação da resposta anti-inflamatória gerada pela FBP ou ativação alostérica da PKM2 pelo TEPP-46 ainda não estão esclarecidos, nosso grupo de pesquisa já demonstrou que a FBP possui atividade anti-inflamatória em modelos experimentais de artrite (VERAS et al., 2015), e um importante papel da PKM2 na diferenciação de linfócitos Th17 (DAMASCENO et al., 2020), reduzindo a severidade dessas doenças. Além disso, já foi descrito que a ativação alostérica da PKM2 é capaz de impedir a interação com HIF-1 $\alpha$ e assim gerar uma resposta antiinflamatória (PALSSON-MCDERMOTT et al., 2015a), no entanto os autores não souberam explicar como o TEPP-46 aumentava os níveis de IL-10.

Sabemos que a FBP apresenta ação anti-inflamatória como diminuição na produção de citocinas inflamatórias (CUESTA et al., 2006; PESTANA LOPES et al., 2006) e redução na proliferação de linfócitos T (DE MELLO et al., 2011) e pode aumentar o fluxo glicolítico (NUUTINEN et al., 1991), além de apresentar baixos efeitos tóxicos (MARKOV et al., 2000). Também, já foi demonstrado que o tratamento com FBP reduz a proliferação de linfócitos, no entanto os mecanismos não estão bem esclarecidos. Enquanto que, a piruvato quinase é a principal enzima responsável por regular a etapa final da glicólise, num ponto gerador de ATP onde já foi descrito que alterações na conformação da isoforma PKM2 regula a proliferação de células tumorais por vias não-glicolíticas, além dessa enzima ter um papel regulador da função efetora de macrófagos M1 (ALQURAISHI et al., 2019). 
Mecanisticamente, tanto a FBP quanto a ativação alostérica da PKM2 demonstram propriedades anti-inflamatórias, aumentando produção de IL-10 dependentes do metabolismo glicolítico pela a síntese de ATP. A liberação de ATP no meio extracelular fez com que a adenosina fosse gerada pela via de CD39/CD73 e assim sinalizando pelos receptores $A 2{ }_{A} R$ ou $\mathrm{A} 2{ }_{\mathrm{B}} \mathrm{R}$, mesmo que ambos os tratamentos não alteraram a expressão dessas ectonucleotidases, a atividades delas foi imprescindível para o aumento da produção de IL-10.

Altos os níveis de IL-10 em macrófagos promovem efeitos anti-inflamatórios, como a redução de diversos mediadores pró-inflamatórios por exemplo IL-1 $\beta$ e IL-6 (SARAIVA; O’GARRA, 2010). Sabemos que a ação da IL-10 é dependente de STAT3, quando ocorre a

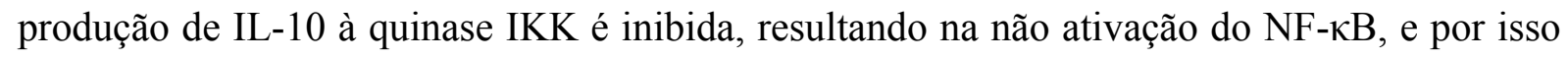
houve uma redução nos níveis de citocinas pró-inflamatórias (MURRAY et al., 2014) na presença de FBP ou TEPP-46.

Sobre a influencia metabólica que o tratamento com FBP ou TEPP-46 gerou, sabemos que, tanto a FBP quanto a PKM2 por apresentam funções glicolíticas. A FBP, por ser um intermediário glicolítico, foi capaz de aumentar a glicólise em macrófagos, o que já foi demonstrado em um estudo com células e tecidos tratados com [C13] FBP marcada, onde elas produziram [C13] lactato, o que indica que FBP quando administrado exogenamente pode participar na via glicolítica para restabelecer os níveis de ATP intracelular (HARDIN; ROBERTS, 1994). Por sua vez, a PKM2 quando tetramérica promove a produção de energia na forma de ATP, ainda favorecendo a rápida produção de intermediários metabólicos importantes para a síntese de ácidos nucleicos, aminoácidos e lipídeos (ALVES-FILHO; PÅLSSON-MCDERMOTT, 2016), e ausência de PKM2 diminui o metabolismo glicolítico assim como a produção de lactato. Quando ativada alostericamente, favorece a forma tetramérica e assim impede a translocação dessa enzima para o núcleo, sem poder ativar fator 
de transcrição HIF-1 $\alpha$ e outros vários genes relacionados ao efeito Warburg (PALSSONMCDERMOTT et al., 2015a).

Uma vez que o tratamento com FBP ou TEPP-46 aumentou o metabolismo glicolítico, avaliamos o a participação deles na síntese de ATP, porque uma das consequências da glicólise é justamente a produção de ATP (JAISWARA; KUMAR, 2017), observamos que tanto o tratamento com FBP ou a ativação alostérica da PKM2 em macrófagos ativados por LPS aumentaram os níveis intra e extracelulares de ATP, de forma dependente da via glicolítica. Isso provavelmente, aconteceu no caso da FBP, pois esse intermediário glicolítico está localizado na via em um ponto abaixo do estágio de investimento, não consumindo as duas moléculas de ATP (BOLAÑOS; ALMEIDA; MONCADA, 2010). Enquanto que a ativação alostérica da PKM2 pelo TEPP-46, agiu de forma distinta, deixando a piruvato quinase com mais afinidade pelo PEP (VANDER HEIDEN et al., 2010) e assim oxidando mais rapidamente a glicose pra piruvato, o que aumentou a produção de ATP.

Geralmente, níveis elevados de ATP estão associados a um efeito pró-inflamatório (IDZKO; FERRARI; ELTZSCHIG, 2014), relacionados com à ativação do inflamassoma (ZHA et al., 2016). O ATP extracelular em excesso pode funcionar como um DAMP ao se ligar ao receptor purinérgico P2X7, ativando o inflamassoma via NALP3 e caspase-1 (CHEN et al., 2015). No entanto, observamos o oposto quando tratamos macrófagos com FBP ou TEPP-46, os níveis de ATP foram aumentados não gerando um efeito pró-inflamatório, pelo contrário, esses tratamentos elevaram a produção de IL-10, de forma dependente do aumento da síntese de ATP e sua presença no meio extracelular, o que nos leva a sugerir que o ATP aumentando foi rapidamente convertido em ADO.

Provavelmente, não observamos essa ativação do complexo do inflamassoma pela ação das ectonucleotidases CD39 e CD73, que removem os fosfatos do ATP para formação 
de ADO, uma molécula que apresenta características anti-inflamatórias (ANTONIOLI et al., 2013; HASKÓ; CRONSTEIN, 2013; ALLARD et al., 2017). As ectonucleotidases CD39/CD73 apresentaram uma participação fundamental no aumento da produção de IL-10 em macrófagos tratados com FBP ou TEPP-46, comprovados quando utilizamos inibidores para essas moléculas, não observamos mais os efeitos promovidos pela FBP ou pela ativação alostérica da PKM2 através do TEPP-46.

Sabe-se que BMDM apresentam constitutivamente uma alta expressão de CD39 e CD73 na superfície celular (COHEN et al., 2013), No entanto, alguns fatores são capazes de aumentar a expressão dessas moléculas na superfície celular, como por exemplo, o tratamento com 8-Bromoadenosine 3',5'-cyclic monophosphate (8-Br-cAMP) para CD39 (Baek et al. 2013) e IL-2 para CD39 e CD73 (SHEVCHENKO et al., 2020), no entanto, nem a FBP ou a ativação alostérica da PKM2 alteraram a expressão das ectonucleotidases.

Observamos em experimentos com UPLC que tanto o tratamento com FBP quanto a ativação alostérica da PKM2 aumentaram os níveis de ADO, assim como os efeitos em aumentar a produção de IL-10 em macrófagos ativados com LPS foram abolidos na presença de ADA, que converte a ADO para inosina. Desde 2003, sabemos da relação entre FBP em promover uma resposta dependente de adenosina (SOLA, 2003), enquanto que, até o momento atual ainda não foi descrito nenhuma relação entre PKM2 e ADO, mesmo tanto trabalhos já demonstrarem uma forte ligação entre PKM2 e produção de ATP (ALQURAISHI et al., 2019)

Nossos resultados demonstraram que o tratamento com FBP e TEPP-46 em macrófagos aumentou os níveis IL-10 através do aumento da adenosina sinalizando pelos receptores $\mathrm{A} 2{ }_{\mathrm{A}} \mathrm{R}$ e $\mathrm{A} 2{ }_{\mathrm{B}} \mathrm{R}$. A interação da $\mathrm{ADO}$ pode ocorrer através de quatro diferentes receptores, que são o $\mathrm{A} 1 \mathrm{R}, \mathrm{A} 2{ }_{\mathrm{A}} \mathrm{R}, \mathrm{A} 2_{\mathrm{B}} \mathrm{R}$ e $\mathrm{A} 3 \mathrm{R}$, o mecanismo intracelular envolvido nos 
receptores de adenosina pode ser dividido em inibitórios ou estimulatórios, onde A1R e A3R são inibitórios, enquanto $\mathrm{A} 2{ }_{\mathrm{A}} \mathrm{R}$ e $\mathrm{A} 2{ }_{\mathrm{B}} \mathrm{R}$, através da estimulação ou inibição da adenilato ciclase, alterando os níveis de AMPc, onde o aumento da PKA e fosforilação de CREB podem inibição da via do NF-kB e consequentemente aumentar a produção de IL-10 (NÉMETH et al., 2003).

Por fim, em um modelo de inflamação aguda, o tratamento com FBP ou TEPP-46 foi capaz de aumentar os níveis de IL-10 no soro, bem como no lavado peritoneal, corroborando com os nossos achados in vitro, onde a presença desses tratamentos reduziram os parâmetros inflamatórios promovidos pelo LPS de forma dependente da ADO. Porém, como a IL-10 foi uma citocina que tem se destacou no tratamento com FBP e TEPP-46, também investigamos a participação da FBP como possível tratamento em uma doença intestinal crônica, a colite induzida por DSS, pois a deficiência de IL-10 faz com que camundongos desenvolvam essa doença de forma espontânea (GLOCKER et al., 2009; STROBER; FUSS, 2011; KOTLARZ et al., 2012). Demonstramos uma diminuição evidente do escore clínico da doença pela colonoscopia, bem como manutenção do peso corporal e redução dos parâmetros inflamatórios no cólon. Essas melhorias da doença foram associadas à via adenosinérgica e à indução da produção de IL-10 no cólon e no soro.

Todos os resultados indicam que tanto a FBP bem como a ativação alostérica da PKM2 pelo TEPP-46 produzem uma importante resposta anti-inflamatória, dependentes das vias glicolítica e adenosinérgica para aumentar os níveis de IL-10. 


\section{CONCLUSÃO}




\section{CONCLUSÃO}

Como conclusão desse conjunto de resultados observados neste trabalho, podemos inferir que o tratamento com FBP faz com que aumente a produção de IL-10 em macrófagos, através de um mecanismo dependente da liberação de ATP pela via glicolítica, no entanto, esse mecanismo de produção de ATP aparentemente é independente da ação da PKM2.

Porém a ativação alostérica da PKM2 com TEPP-46, também apresente um aumento da produção de ATP de forma dependente da via glicolítica. O ATP, produzido no interior da célula, é transportado para o meio extracelular através do canal de Panexin-1, uma vez no ambiente extracelular, o ATP sofre ação das ectonucleotidases CD39 e CD73, que retiram os fosfatos do ATP, formando ADP, AMP e por fim ADO. A adenosina formada se liga aos receptores A2 aumentando a produção de IL-10 possuindo um efeito anti-inflamatório (Figura 19).

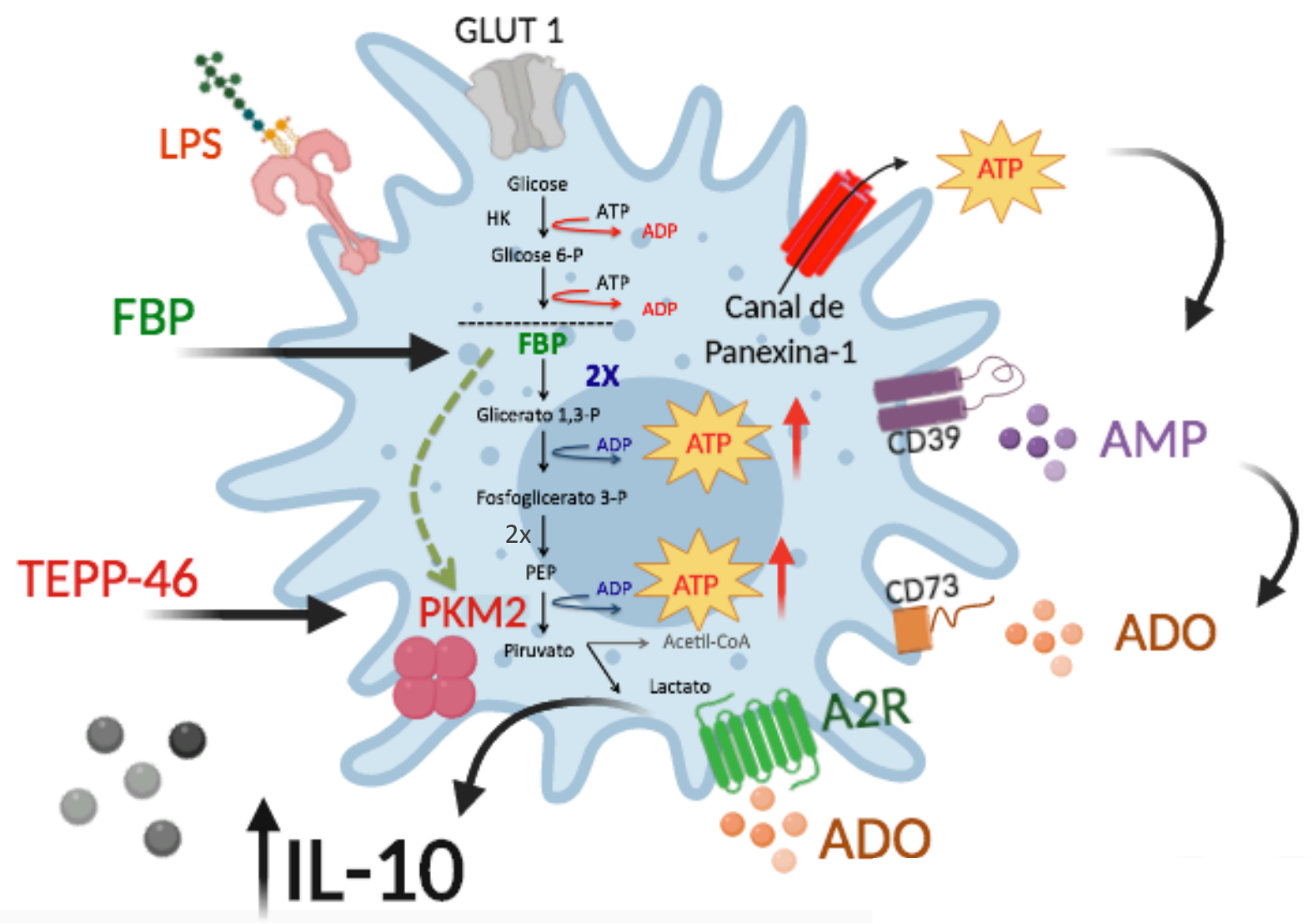

Figura 34: Mecanismo imunomodulador da FBP ou TEPP-46, através do aumento da produção de IL-10, de forma dependente da via glicolítica e adenosinérgica. 
REFERÊNCIAS BIBLIOGRÁFICAS 


\section{REFERÊNCIAS BIBLIOGRÁFICAS}

ALATAB, S. et al. The global, regional, and national burden of inflammatory bowel disease in 195 countries and territories, 1990-2017: a systematic analysis for the Global Burden of Disease Study 2017. The Lancet Gastroenterology and Hepatology, 2020.

ALLARD, B. et al. The ectonucleotidases CD39 and CD73: Novel checkpoint inhibitor targetsImmunological Reviews, 2017. .

ALQURAISHI, M. et al. Pyruvate kinase M2: A simple molecule with complex functionsFree Radical Biology and Medicine, 2019. .

ALVES-FILHO, J. C.; PÅLSSON-MCDERMOTT, E. M. Pyruvate kinase M2: A potential target for regulating inflammationFrontiers in Immunology, 2016. .

ALVES FILHO, J. C. F. et al. Anti-inflammatory effects of fructose-1,6-bisphosphate on carrageenan-induced pleurisy in rat. Pharmacological Research, 2004.

AMICI, S. A.; DONG, J.; GUERAU-DE-ARELLANO, M. Molecular mechanisms modulating the phenotype of macrophages and microgliaFrontiers in Immunology, 2017. .

ANASTASIOU, D. et al. Pyruvate kinase M2 activators promote tetramer formation and suppress tumorigenesis. Nature Chemical Biology, 2012.

ANTONIOLI, L. et al. CD39 and CD73 in immunity and inflammationTrends in Molecular Medicine, 2013. .

BESEDOVSKY, L.; LANGE, T.; HAACK, M. The sleep-immune crosstalk in health and disease. Physiological Reviews, 2019.

BetTENCOURT, I. A.; POWELL, J. D. Targeting Metabolism as a Novel Therapeutic Approach to Autoimmunity, Inflammation, and Transplantation. The Journal of Immunology, 2017.

BOLAÑOS, J. P.; ALMEIDA, A.; MONCADA, S. Glycolysis: a bioenergetic or a survival pathway?Trends in Biochemical Sciences, 2010. .

BUCK, M. D. et al. Metabolic Instruction of ImmunityCell, 2017. .

C., A. et al. Galactose enhances oxidative metabolism and reveals mitochondrial dysfunction 
in human primary muscle cells. PLoS ONE, 2011.

CHAUDHRY, R.; VARACALLO, M. Biochemistry, Glycolysis. [s.l: s.n.]

CHEN, Z. et al. Activated P2X7 receptor upregulates the expression levels of NALP3 in P388D1 murine macrophagelike cells. Molecular Medicine Reports, 2015.

CHRISTOFK, H. R. et al. The M2 splice isoform of pyruvate kinase is important for cancer metabolism and tumour growth. Nature, 2008.

COHEN, H. B. et al. TLR stimulation initiates a CD39-based autoregulatory mechanism that limits macrophage inflammatory responses. Blood, v. 122, n. 11, p. 1935-1945, 2013.

COSTRINI, R.; CANDIANI, A.; CIFRA, E. Protective action of fructose-1,6-diphosphate sodium salt towards erythrocytic fragility in patients undergoing extracorporeal circulation. IRCS Medical Science, 1980.

CRONSTEIN, B. N. et al. The adenosine/neutrophil paradox resolved: Human neutrophils possess both $\mathrm{A} 1$ and $\mathrm{A} 2$ receptors that promote chemotaxis and inhibit O-2 generation, respectively. Journal of Clinical Investigation, 1990.

CRONSTEIN, B. N.; SITKOVSKY, M. Adenosine and adenosine receptors in the pathogenesis and treatment of rheumatic diseasesNature Reviews Rheumatology, 2017. .

CSÓKA, B. et al. A2A adenosine receptors and C/EBP $\beta$ are crucially required for IL-10 production by macrophages exposed to Escherichia coli. Blood, v. 110, n. 7, p. 2685-2695, 2007.

CSÓKA, B. et al. Adenosine promotes alternative macrophage activation via A2A and A2B receptors . The FASEB Journal, 2012.

CUESTA, E. et al. Fructose 1,6-bisphosphate prevented endotoxemia, macrophage activation, and liver injury induced by D-galactosamine in rats. Critical Care Medicine, 2006.

DA ROCHA LAPA, F. et al. Anti-inflammatory effects of purine nucleosides, adenosine and inosine, in a mouse model of pleurisy: Evidence for the role of adenosine A2 receptors. Purinergic Signalling, 2012.

DAMASCENO, L. E. A. et al. PKM2 promotes Th17 cell differentiation and autoimmune inflammation by fine-tuning STAT3 activation. The Journal of experimental medicine, 2020. 
DARASHCHONAK, N. et al. Adenosine A2B receptors induce proliferation, invasion and activation of cAMP response element binding protein (CREB) in trophoblast cells. BMC Pregnancy and Childbirth, 2014.

DE MELLO, R. O. et al. Effect of N-acetylcysteine and fructose-1,6-bisphosphate in the treatment of experimental sepsis. Inflammation, 2011.

DRESCHERS, S. et al. Impaired cellular energy metabolism in cord blood macrophages contributes to abortive response toward inflammatory threats. Nature Communications, 2019.

DRURY, A. N.; SZENT-GYÖRGYI, A. The physiological activity of adenine compounds with especial reference to their action upon the mammalian heart. The Journal of Physiology, 1929.

EHRINGER, W. D. et al. Membrane permeability of fructose-1,6-diphosphate in lipid vesicles and endothelial cells. Molecular and cellular biochemistry, v. 210, n. 1-2, p. 3545, 2000.

FENG, L. L. et al. The yin and yang functions of extracellular ATP and adenosine in tumor immunityCancer Cell International, 2020. .

FIORENTINO, D. F. et al. IL-10 inhibits cytokine production by activated macrophages. Journal of immunology (Baltimore, Md. : 1950), 1991.

GABER, T.; STREHL, C.; BUTTGEREIT, F. Metabolic regulation of inflammationNature Reviews Rheumatology, 2017. .

GLOCKER, E. O. et al. Inflammatory bowel disease and mutations affecting the interleukin10 receptor. New England Journal of Medicine, 2009.

HARDIN, C. D. et al. Myocardial metabolism of exogenous FDP is consistent with transport by a dicarboxylate transporter. American Journal of Physiology - Heart and Circulatory Physiology, 2001.

HARDIN, C. D.; ROBERTS, T. M. Metabolism of exogenously applied fructose 1,6bisphosphate in hypoxic vascular smooth muscle. The American Journal of Physiology, v. 267, n. 6 Pt 2, p. H2325-32, 1994.

HASKÓ, G. et al. Adenosine inhibits IL-12 and TNF-[alpha] production via adenosine A2a 
receptor-dependent and independent mechanisms. The FASEB journal : official publication of the Federation of American Societies for Experimental Biology, v. 14, n. 13, p. 20652074, 2000.

HASKÓ, G.; CRONSTEIN, B. Regulation of inflammation by adenosine. Frontiers in Immunology, 2013.

HAUSER, A. S. et al. Pharmacogenomics of GPCR Drug Targets. Cell, 2018.

HE, Y.; HARA, H.; NÚÑEZ, G. Mechanism and Regulation of NLRP3 Inflammasome ActivationTrends in Biochemical Sciences, 2016. .

IDZKO, M.; FERRARI, D.; ELTZSCHIG, H. K. Nucleotide signalling during inflammationNature, 2014. .

IKEDA, Y.; NOGUCHI, T. Allosteric regulation of pyruvate kinase M2 isozyme involves a cysteine residue in the intersubunit contact. Journal of Biological Chemistry, 1998.

IMAMURA, K.; TANAKA, T. Multimolecular forms of pyruvate kinase from rat and other mammalian tissues: I. electrophoretic studies. Journal of Biochemistry, 1972.

JACOBSON, K. A.; GAO, Z. G. Adenosine. In: The Curated Reference Collection in Neuroscience and Biobehavioral Psychology. [s.l: s.n.]

JAISWARA, P.; KUMAR, A. Glycolysis. In: Carbohydrate Metabolism: Theory and Practical Approach. [s.l: s.n.]

KENNEDY, R. J. et al. Interleukin 10-deficient colitis: New similarities to human inflammatory bowel disease. British Journal of Surgery, 2000.

KIM, J. Regulation of immune cell functions by metabolic reprogrammingJournal of Immunology Research, 2018. .

KODANI, T. et al. Flexible colonoscopy in mice to evaluate the severity of colitis and colorectal tumors using a validated endoscopic scoring system. Journal of visualized experiments : JoVE, 2013.

KOTLARZ, D. et al. Loss of interleukin-10 signaling and infantile inflammatory bowel disease: Implications for diagnosis and therapy. Gastroenterology, 2012.

KRAUSE, G. C. et al. Fructose-1,6-bisphosphate decreases IL-8 levels and increases the 
activity of pro-apoptotic proteins in HepG2 cells. Biomedicine and Pharmacotherapy, 2017.

KUROWSKA-STOLARSKA, M. et al. IL-33 Amplifies the Polarization of Alternatively Activated Macrophages That Contribute to Airway Inflammation. The Journal of Immunology, 2009.

LATINI, S.; PEDATA, F. Adenosine in the central nervous system: Release mechanisms and extracellular concentrationsJournal of Neurochemistry, 2001. .

LIU, Y.-C. et al. Macrophage Polarization in Inflammatory Diseases. International Journal of Biological Sciences, 2014.

LIU, Y.; ZHANG, D.; LIU, X. mTOR Signaling in T Cell Immunity and Autoimmunity. International Reviews of Immunology, 2015.

LUO, W. et al. Pyruvate kinase M2 is a PHD3-stimulated coactivator for hypoxia-inducible factor 1. Cell, 2011.

MARKOV, A. K. et al. Hemodynamic, electrocardiographic, and metabolic effects of fructose diphosphate on acute myocardial ischemia. American Heart Journal, v. 100, n. 5, p. 639-646, 1980.

MARKOV, A. K. et al. Stimulating effect of fructose 1-6 diphosphate on the phagocytic function of rat RES and on human leukocyte carbohydrate metabolism. The American journal of the medical sciences, v. 290, n. 1, p. 3-10, 1985.

MARKOV, A. K. Hemodynamics and metabolic effects of fructose 1-6 diphosphate in ischemia and shock - experimental and clinical observations. Annals of Emergency Medicine, v. 15, n. 12, p. 1470-1477, 1986.

MARKOV, A. K. et al. Metabolic responses to fructose-1,6-diphosphate in healthy subjects. Metabolism: Clinical and Experimental, 2000.

MARTINEZ-OUTSCHOORN, U. E. et al. Cancer metabolism: A therapeutic perspectiveNature Reviews Clinical Oncology, 2017. .

MICHALEK, R. D. et al. Cutting Edge: Distinct Glycolytic and Lipid Oxidative Metabolic Programs Are Essential for Effector and Regulatory CD4 + T Cell Subsets . The Journal of Immunology, 2011. 
MILLS, J. H. et al. A2A Adenosine Receptor Signaling in Lymphocytes and the Central Nervous System Regulates Inflammation during Experimental Autoimmune Encephalomyelitis. The Journal of Immunology, 2012.

MOLINA-ARCAS, M.; CASADO, F.; PASTOR-ANGLADA, M. Nucleoside Transporter Proteins. Current Vascular Pharmacology, 2009.

MUNDER, M.; EICHMANN, K.; MODOLELL, M. Alternative metabolic states in murine macrophages reflected by the nitric oxide synthase/arginase balance: competitive regulation by CD4+ T cells correlates with Th1/Th2 phenotype. Journal of immunology (Baltimore, Md. : 1950), 1998.

MURRAY, P. J. et al. Macrophage Activation and Polarization: Nomenclature and Experimental GuidelinesImmunity, 2014. .

MURRAY, P. J.; WYNN, T. A. Protective and pathogenic functions of macrophage subsetsNature Reviews Immunology, 2011. .

NAGANA GOWDA, G. A.; GOWDA, Y. N.; RAFTERY, D. Expanding the limits of human blood metabolite quantitation using NMR spectroscopy. Analytical Chemistry, 2015.

NELSON, D. .; COX, M. . Glycolysis, Gluconeogenesis, and the Pentose Phosphate Pathway. In: Lehninger Principles of Biochemistry. [s.l: s.n.]

NELSON, D. L.; COX, M. M. Lehninger Principles of Biochemistry. [s.1: s.n.]

NÉMETH, Z. H. et al. Adenosine stimulates CREB activation in macrophages via a p38 MAPK-mediated mechanism. Biochemical and Biophysical Research Communications, 2003.

NEWSHOLME, P. et al. Metabolism of glucose, glutamine, long-chain fatty acids and ketone bodies by murine macrophages. The Biochemical journal, 1986.

NUNES, F. B. et al. Intravenous toxicity of fructose-1,6-bisphosphate in rats. Toxicology Letters, 2003.

NUUTINEN, E. M. et al. Effect of exogenous fructose-1,6-bisphosphate on glycolysis in the isolated perfused rat heart. American Heart Journal, 1991.

O’NEILL, L. A. J. A Metabolic Roadblock in Inflammatory MacrophagesCell Reports, 2016. . 
O’NEILL, L. A. J.; KISHTON, R. J.; RATHMELL, J. A guide to immunometabolism for immunologistsNature Reviews Immunology, 2016. .

O’NEILL, L. A. J.; PEARCE, E. J. Immunometabolism governs dendritic cell and macrophage function. The Journal of Experimental Medicine, 2016.

OHTA, A.; SITKOVSKY, M. Role of G-protein-coupled adenosine receptors in downregulation of inflammation and protection from tissue damage. Nature, 2001.

OREN, R. et al. Metabolic patterns in three types of phagocytizing cells. The Journal of cell biology, 1963.

OUYANG, W. et al. Regulation and functions of the IL-10 family of cytokines in inflammation and disease. Annual Review of Immunology, 2011.

PALMER, J. L.; ABELES, R. H. The mechanism of action of S-adenosylhomocysteinase. Journal of Biological Chemistry, 1979.

PALSSON-MCDERMOTT, E. M. et al. Pyruvate kinase M2 regulates hif- $1 \alpha$ activity and il$1 \beta$ induction and is a critical determinant of the warburg effect in LPS-activated macrophages. Cell Metabolism, v. 21, n. 1, p. 65-80, 2015a.

PALSSON-MCDERMOTT, E. M. et al. Pyruvate kinase M2 regulates hif-1 $\alpha$ activity and il$1 \beta$ induction and is a critical determinant of the warburg effect in LPS-activated macrophages. Cell Metabolism, 2015b.

PÅLSSON-MCDERMOTT, E. M.; O’NEILL, L. A. J. Targeting immunometabolism as an anti-inflammatory strategyCell Research, 2020. .

PEARCE, E.; PEARCE, E. Metabolic pathways in immune cell activation and quiescence. Immunity, 2013.

PESTANA LOPES, R. et al. The effects of fructose-1,6-bisphosphate and dexamethasone on acute inflammation and T-cell proliferation. Inflammation Research, 2006.

PLANAS, M. E. et al. Protective effect of fructose 1,6-bisphosphate against carrageenaninduced inflammation. European Journal of Pharmacology, 1993.

PRAKASAM, G. et al. Posttranslational modifications of pyruvate kinase M2: Tweaks that benefit cancerFrontiers in Oncology, 2018. . 
ROBERTS, V. S. et al. The role of adenosine receptors A $2 \mathrm{~A}$ and A $2 \mathrm{~B}$ signaling in renal fibrosisKidney International, 2014. .

RUFFELL, B.; AFFARA, N. I.; COUSSENS, L. M. Differential macrophage programming in the tumor microenvironmentTrends in Immunology, 2012. .

SANIN, D. E.; PRENDERGAST, C. T.; MOUNTFORD, A. P. IL-10 Production in Macrophages Is Regulated by a TLR-Driven CREB-Mediated Mechanism That Is Linked to Genes Involved in Cell Metabolism. The Journal of Immunology, 2015.

SARAIVA, M.; O'GARRA, A. The regulation of IL-10 production by immune cellsNature Reviews Immunology, 2010. .

SHEVCHENKO, I. et al. Enhanced expression of CD39 and CD73 on T cells in the regulation of anti-tumor immune responses. OncoImmunology, 2020.

SOLA, A. Fructose-1,6-biphosphate and nucleoside pool modifications prevent neutrophil accumulation in the reperfused intestine. Journal of Leukocyte Biology, v. 73, n. 1, p. 74 $81,2003$.

STROBER, W.; FUSS, I. J. Proinflammatory cytokines in the pathogenesis of inflammatory bowel diseases. Gastroenterology, 2011.

STROUD, R. M.; WELLS, J. A. Mechanistic diversity of cytokine receptor signaling across cell membranes.Science's STKE : signal transduction knowledge environment, 2004. .

TANNAHILL, G. M. et al. Succinate is an inflammatory signal that induces IL-1 $\beta$ through HIF-1 $\alpha$. Nature, 2013.

VAN DEN BOSSCHE, J.; O’NEILL, L. A.; MENON, D. Macrophage Immunometabolism: Where Are We (Going)?Trends in Immunology, 2017. .

VANDER HEIDEN, M. G. et al. Evidence for an alternative glycolytic pathway in rapidly proliferating cells. Science, 2010.

VERAS, F. P. et al. Fructose 1,6-bisphosphate, a high-energy intermediate of glycolysis, attenuates experimental arthritis by activating anti-inflammatory adenosinergic pathway. Scientific Reports, v. 5, p. 15171, 2015.

VIACAVA, PAULA RAMOS; ALVES FILHO, J. C. F. Frutose 1,6 bifosfato, um 
intermediário da glicólise, regula a produção de IL-10 em macrófagos de forma dependente da via adenosinérgica. 2015. Universidade de São Paulo, 2015.

WANG, J.; WU, Q.; QIU, J. Accumulation of fructose 1,6-bisphosphate protects clear cell renal cell carcinoma from oxidative stress. Laboratory Investigation, 2019.

WEICHHART, T.; HENGSTSCHLAGER, M.; LINKE, M. Regulation of innate immune cell function by mTOR. Nature reviews. Immunology, 2015.

YANG, J. et al. Adenosine increases LPS-induced nuclear factor kappa B activation in smooth muscle cells via an intracellular mechanism and modulates it via actions on adenosine receptors. Acta Physiologica, v. 210, n. 3, p. 590-599, 2014.

YANG, J. et al. Synergistic Allosteric Mechanism of Fructose-1,6-bisphosphate and Serine for Pyruvate Kinase M2 via Dynamics Fluctuation Network Analysis. Journal of Chemical Information and Modeling, 2016.

YANG, W. et al. ERK1/2-dependent phosphorylation and nuclear translocation of PKM2 promotes the Warburg effect. Nature Cell Biology, 2012.

ZHA, Q. B. et al. ATP-induced inflammasome activation and pyroptosis is regulated by AMP-activated protein kinase in macrophages. Frontiers in Immunology, 2016.

ZHAO, Q. et al. 2-Deoxy-d-glucose treatment decreases anti-inflammatory M2 macrophage polarization in mice with tumor and allergic airway inflammation. Frontiers in Immunology, 2017. 
ANEXOS 


\title{
8. ANEXOS
}

\subsection{COMITÊ DE ÉTICA EM PESQUISAS}

\author{
UNIVERSIDADE DE SÃO PAULO \\ FACULDADE DE MEDICINA DE RIBEIRĀO PRETO \\ COMISSĂO DE ÉTICA NO USO DE ANIMAIS
}

\section{CERTIFICADO}

Certificamos que o Protocolo para Uso de Animais em Experimentação $\mathrm{n}^{\circ}$ 113/2015, sobre o projeto intitulado "Frutose 1,6 biforfato, um intermediário da glicolise, participaçäo na produção de IL$10 \mathrm{em}$ macrófagos através da via adenosinérgica", sob a responsabilidade do Professor Doutor José Carlos Farias Alves Filho está de acordo com os Principios Éticos em Experimentação Animal adotado pelo Conselho Nacional de Controle de Experimentação Animal (CONCEA) e foi APROVADO em reuniåo de 02 de dezembro de 2015.

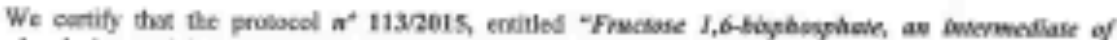

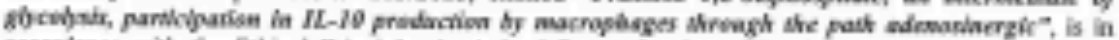
asoordines with the Ethical Principies in Animal keosarch adopted by the Narional Council for the Cooriot of Animal Experimentation (CONCEA) and was appreved by the Local Animal Edhical

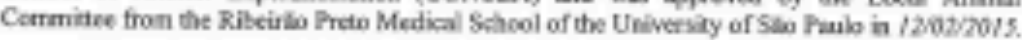

Ribeirào Preto, 02 de dezembro de 2015.

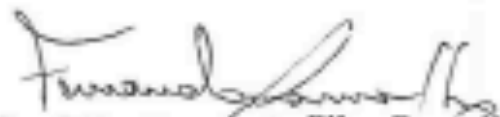

Prof. Dr. Ferplardo Silva Ramialho

Presidente da CEUA - FMRP - USP 


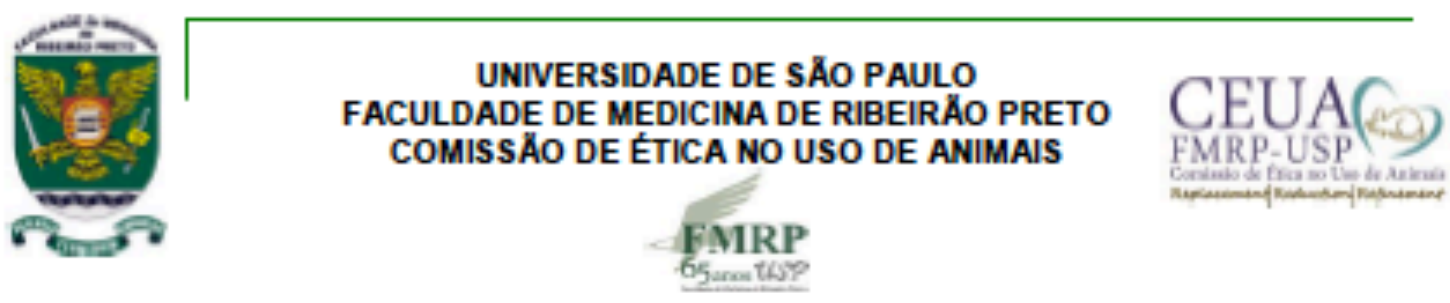

\section{CER TIFICADO}

Certificamos que o Protocolo intitulado "Papel da Ensima Giicolitica Pinvvato Kinase M2 na Produçao de II-10 am Macrofagos pela Via Adenosinergica", registrado com o mímero 145/2019, sob a responsabilidade do Prof. Dr. José Carlos Farias Akes Filho, envolvendo a produção, manutenção ou utilização de animais pertencentes ao filo Chordata, subfilo Vertebrata (exceto humanos) para fins de pesquisa cientifica, encontra-se de acordo com 05 preceitos dh Lei $\mathrm{n}^{\circ}$ 11.794 de 8 de outubro de 2008 , do Decreto $n^{\circ} 6.899$ de 15 de julho de 2009 e com as normas editadas pelo Conselho Nacional de Controle de Experimentação Animal (CONCEA), e foi APROVADO pela Comissão de Ética no Uso de Animais da Faculdade de Medicina de Ribeirão Preto da Universidade de São Paulo em reuniẫo de 26 de agosto de 2019.

Este Protocolo prevê a utilização de 72 camundongos C57Bl 6 machos pesando 20g oriundos do Serviço de Biotério da Prefeitura do Campus de Ribeirão Preto da Universidade de São Paulo; 60 camundongos LysMcre/PKM2flfil machos pesando 20g. 60 camundongos PKM2fl/l machos pesando $20 \mathrm{~g}$ e 12 camundongos Panexin-channel 1 machos pesando $20 \mathrm{~g}$ oriundos do Biotério da Cirurgia Experimental da Faculdade de Medicina de Ribeirão Preto da Universidade de São Paulo. Vigência da autorização: 26/08/2019 a 30/09/2022.

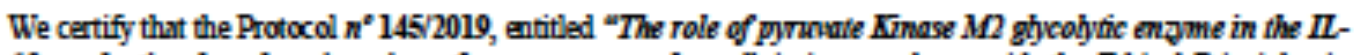
10 production by ademosinergic pathway on macrophages", is in accordance with the Ethical Principles in Animal Research adopted by the National Council far the Control of Animal Exparimentation (CONCEA) and was approved by the Local Animal Ethical Committee from Ribeirão Preto Medical School of the University of São Paulo in 08/26/2019. This protocol involves the procuction, maintenance or use of animals from phyiumChordata, subpiyhimivertobrata (except humans) far research purposes, and includes the use of $72 \mathrm{mmle}$ C57Bl/6 mice weighing $20 \mathrm{~g}$ from the Central Animal House of Ribeira Preto Medical School; 60 male LysMcre/PKMnfl/f mice weighing 20g. 60 male PKMDf/fl mice weighing $20 \mathrm{~g}$ and 12 male Panexin-channel 1 mice weighing $20 \mathrm{~g}$ from the Laboratory of Experimental Surgery, of Ribeirâo Preto Medical School, University of São Paulo. This certificate is valid until 09/30/2022. 


\subsection{CERTIFICADOS DE PRÊMIOS E MENÇÕES HONROSAS}

5

$49^{\text {th }}$ Brazilian Congress

of Pharmacology and

\section{CERTIFICATE}

We certify that Paula Ramos Viacava received Honorable Mention for the poster PT 4.012: Viacava PR, Nascimento DRB, Luiz JPM, Veras FP, Ferreira RG, Vitorino CA, Peres RS, Cunha FQ, Cunha TM, Alves-Filho JCF. "Fructose 1,6-bisphosphate, a glycolytic metabolite, tunes the metabolic reprogram of pro-inflammatory macrophages", at the 49th Brazilian Congress of Pharmacology and Experimental Therapeutics (SBFTE) held in Ribeirão Preto, São Paulo, Brazil, from October 17 to 20, 2017.

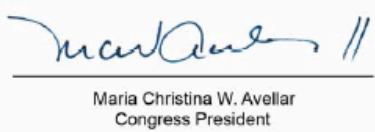



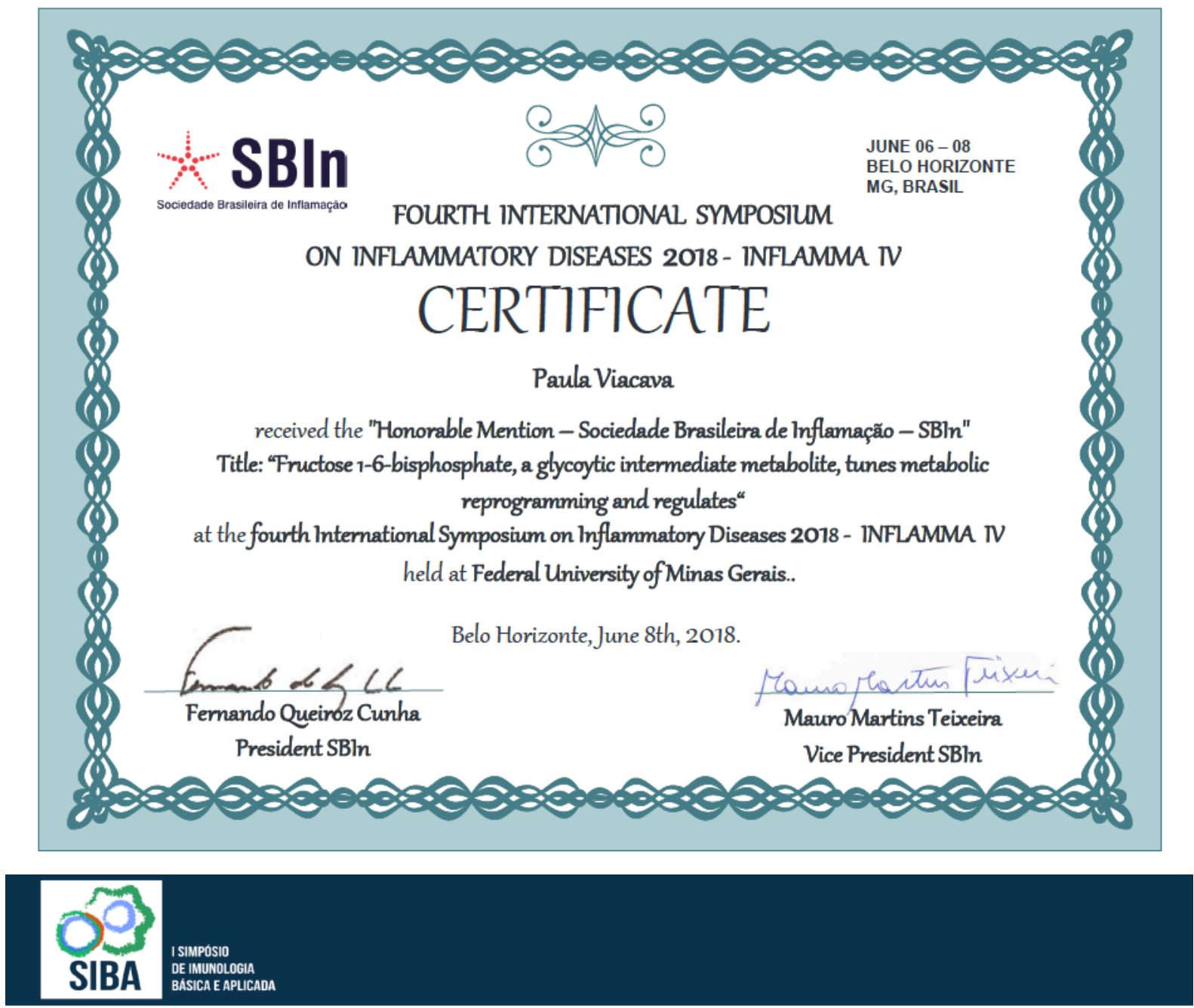

\section{CERTIFICADO}

O programa de Imunologia Básica e Aplicada da Faculdade de Medicina de Ribeirão Preto certifica que

\section{Paula R. Viacava}

Recebeu Menção Honrosa (Segundo lugar) na categoria apresentação pôster, modalidade Doutorado, com o trabalho intitulado

"Frutose 1,6-bifosfato reprograma metabolicamente macrófagos apresentando efeitos anti-inflamatórios"

I Simpósio de Imunologia Básica e Aplicada (I SIBA), 2017 Ribeirão Preto-SP, 20 a 21 de julho de 2017.

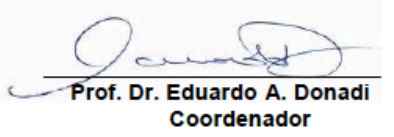




\title{
[SP Universidade de Săo Paulo
}

\section{$26^{\circ}$ SIICUSP - Simpósio Internacional de Iniciação Científica e Tecnológica da Universidade de São Paulo}

\author{
MENÇÃO HONROSA
}

\begin{abstract}
A Pro-Reitoria de Pesquisa da Universidade de Sâo Paulo atribui Mençao Honrosa a Pedro Delghingaro Forti pela apresentação do trabalho $\mathrm{A}$ enzima glicolitica Piruvato Kinase M2 regula a produçāo de IL10 em macrófago através da modulaçāo da via adenosinèrgica na area de Cièncias Biológicas na Etapa Internacional do $26^{\circ}$ Simposio Internacional de Iniciação Cientıfica e Tecnologica da USP SIICUSP, sob a orientaça de Jose Carlos Farias Alves Filho, com a colaboraçáo de Paula Ramos Viacava, e Luis Eduardo Alves Damasceno, em 2018.
\end{abstract}

Prof. Dr. Sylvio Boberto Accioly Canuto Pro Reitor de Pesquisa Universidade de Så Paulo

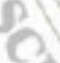

Universidade de Sac Paulo

Documento emilido às 16:11:37 horas do dia 05/12/2018 (hora e data de Brasilia) Codigo de controle: JYN4-GV33-S6Z1-YV8A

A auternticidade deste documento pode ser verificada na pagina da Universidade de São Paulo http:Muspdigital usp. br/webdoc 